Portland State University

PDXScholar

\title{
Travel Behavior, Residential Preference, and Urban Design: A Multi-Disciplinary National Analysis
}

Jessica Greene

University of Oregon

Nico Larco

University of Oregon

Yizhao Yang

University of Oregon

Marc Schlossberg

University of Oregon

Daniel Rodriguez

University of North Carolina

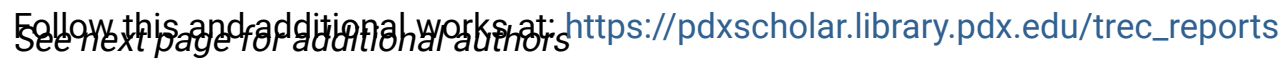

Part of the Transportation Commons, Urban Studies Commons, and the Urban Studies and Planning Commons

Let us know how access to this document benefits you.

\section{Recommended Citation}

Greene, Jessica, Nico Larco, Yizhao Yang, Marc Schlossberg, Daniel Rodriguez, Noreen McDonald, Tabitha Combs. Travel Behavior, Residential Preference, and Urban Design: A Multi-Disciplinary National Analysis. OTREC-RR-11-04. Portland, OR: Transportation Research and Education Center (TREC), 2011. https://doi.org/10.15760/trec.35

This Report is brought to you for free and open access. It has been accepted for inclusion in TREC Final Reports by an authorized administrator of PDXScholar. Please contact us if we can make this document more accessible: pdxscholar@pdx.edu. 


\section{Authors}

Jessica Greene, Nico Larco, Yizhao Yang, Marc Schlossberg, Daniel Rodriguez, Noreen McDonald, and Tabitha Combs 


\section{SOTREC}

FINAL REPORT

\section{Travel Behavior, Residential Preference, and Urban Design: A Multi-Disciplinary National Analysis}

OTREC-RR-11-04 January 2011 



\title{
Travel Behavior, Residential Preference, and Urban Design: A Multi-Disciplinary National Analysis
}

\section{OTREC-RR-11-04}

\author{
by \\ Jessica Greene \\ Nico Larco \\ Yizhao Yang \\ Marc Schlosberg \\ University of Oregon \\ Daniel Rodriguez \\ Noreen McDonald \\ Tabitha Combs \\ University of North Carolina
}

for

Oregon Transportation Research and Education Consortium (OTREC) P.O. Box 751

Portland, OR 97207

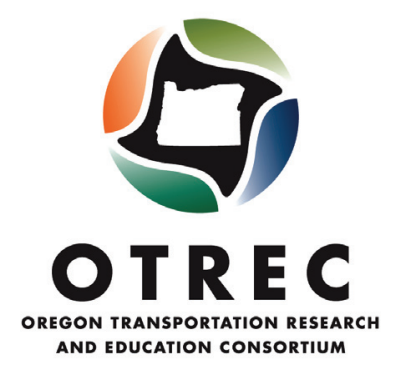

January 2011 



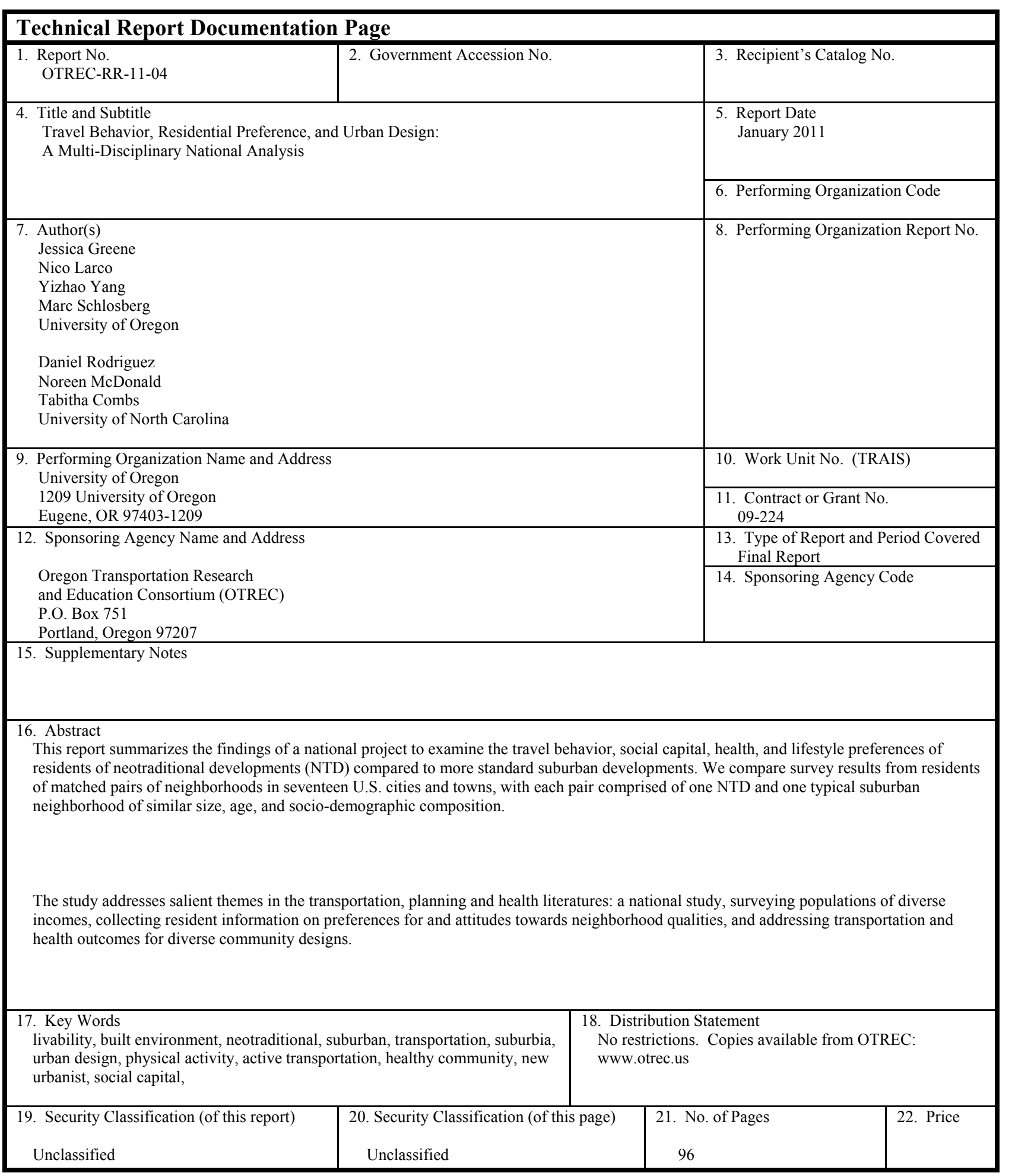




\section{ACKNOWLEDGEMENTS}

We would like to thank OTREC for the opportunity to forge a research partnership among seven researchers, across two universities on opposite sides of the country, investigating a topic of national interest. We appreciate the leadership and vision of OTREC in this regard.

\section{DISCLAIMER}

The contents of this report reflect the views of the authors, who are solely responsible for the facts and the accuracy of the material and information presented herein. This document is disseminated under the sponsorship of the U.S. Department of Transportation University Transportation Centers in the interest of information exchange. The U.S. Government assumes no liability for the contents or use thereof. The contents do not necessarily reflect the official views of the U.S. Government. This report does not constitute a standard, specification, or regulation. 


\section{CONTENTS}

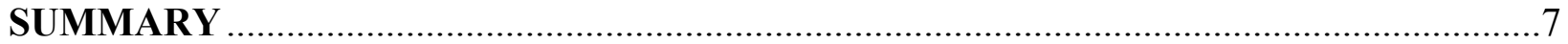

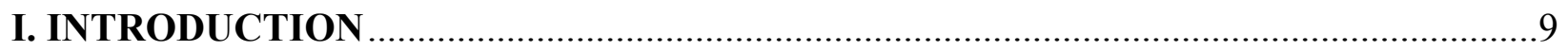

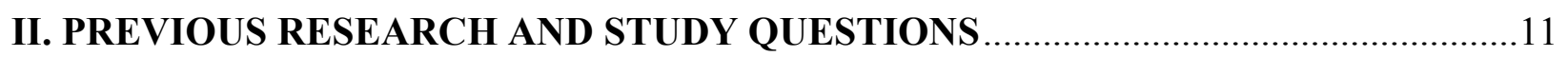

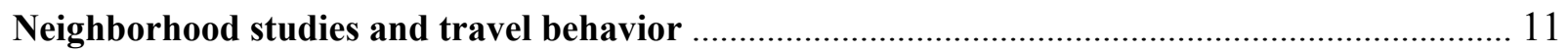

Disparities in Physical Activity \& Obesity .......................................... 13

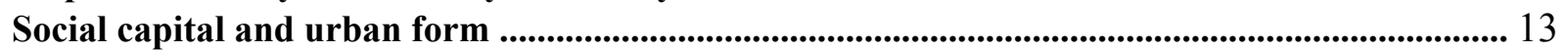

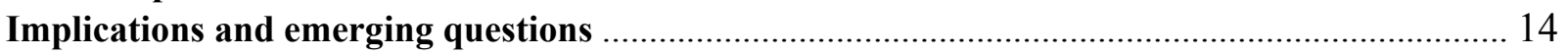

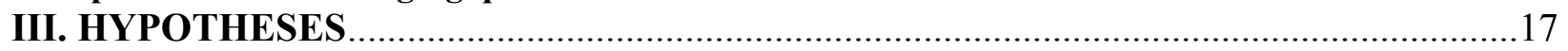

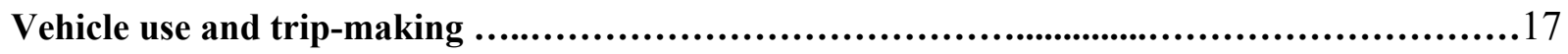

Travel attitude/preference and choice of neighborhood types......................................17

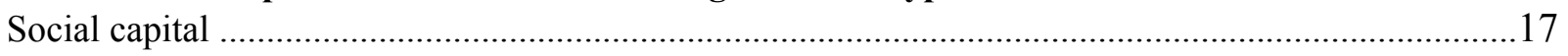

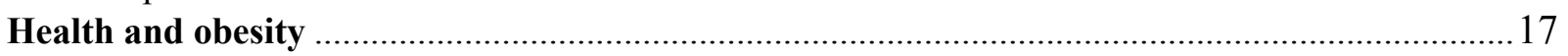

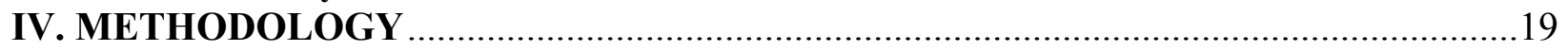

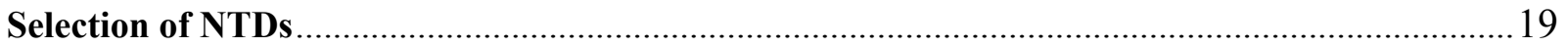

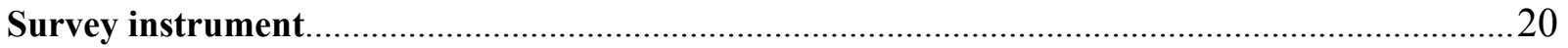

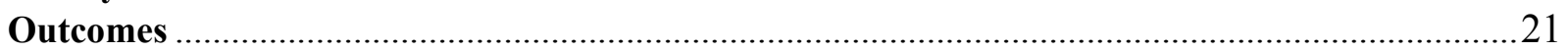

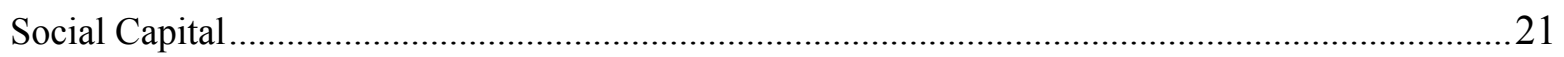

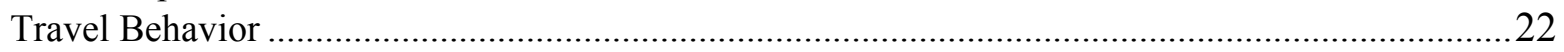

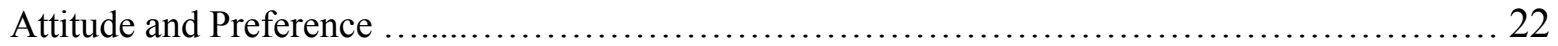

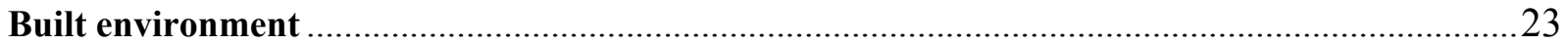

Built-Environment Derived Variables .................................................................................... 25

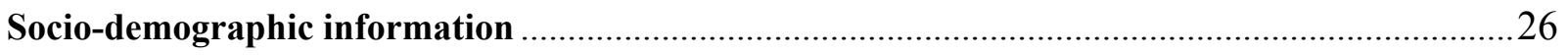

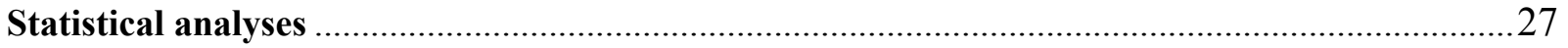

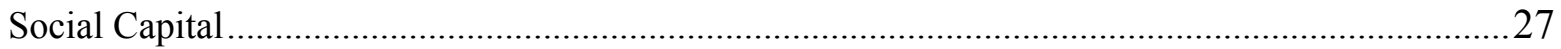

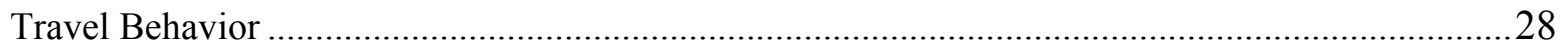

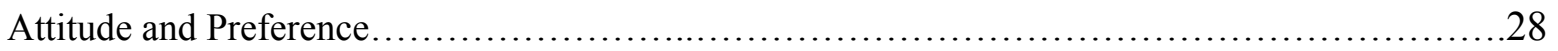

Physical Activity and Obesity ..................................................... 28

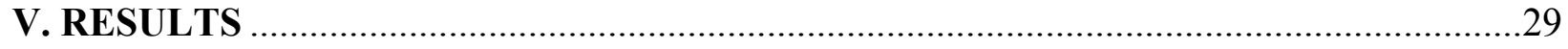

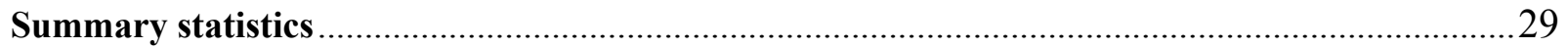

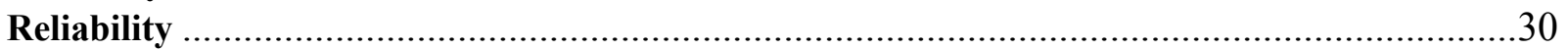

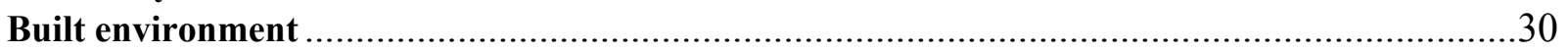

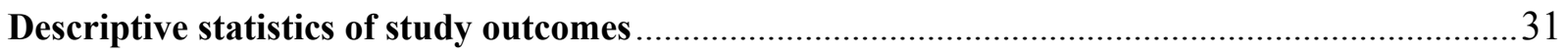

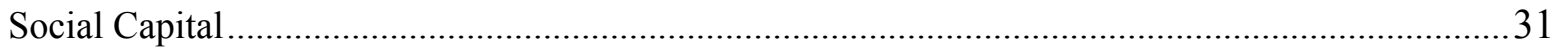

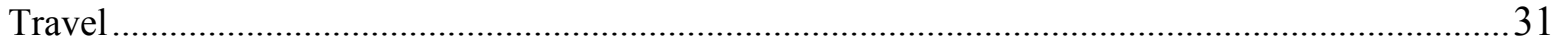

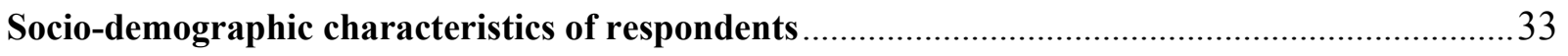

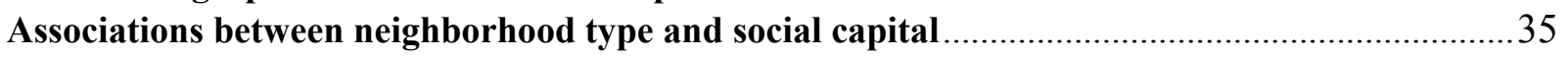

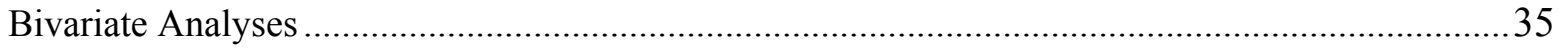

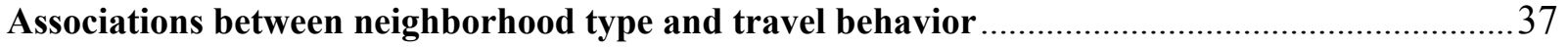

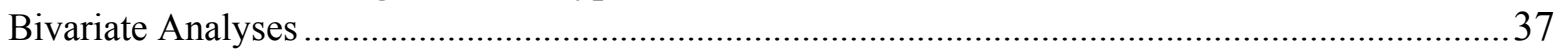

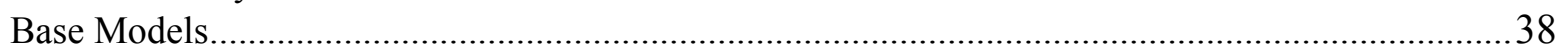

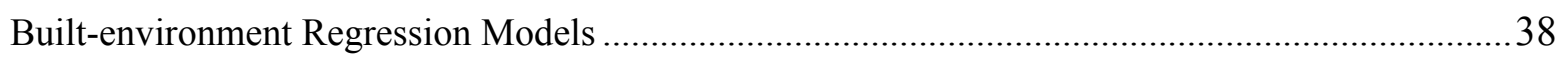

Associations between neighborhood type and environmental attitude ........................... 43

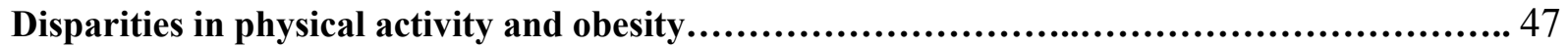


VI. DISCUSSION

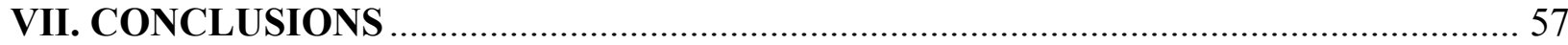

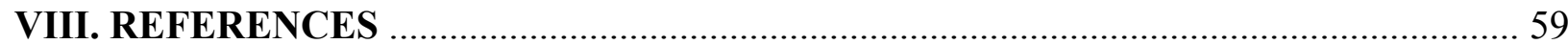

IX. APPENDICES .

65

Appendix I. Maps of study sites

Appendix II. Survey instruments

Appendix III. Mean social capital responses

Appendix IV. Reliability 


\section{SUMMARY}

The prevalence of and the support for neo-traditional developments (NTDs) in the U.S. has grown over the years, and NTD proponents have long emphasized the development paradigm's ability to alter travel behavior, reduce dependence on motorized vehicles, foster social capital and improve the health of its residents. However, little is known nationally about the actual travel behaviors and social relationships of residents in these neighborhoods, relative to residents of typical suburban neighborhoods. This report summarizes the findings of a national project to examine the travel behavior, social capital, health, and lifestyle preferences of residents of NTDs compared to more standard suburban developments. We compare survey results from residents of matched pairs of neighborhoods in 17 U.S. cities and towns, with each pair comprised of one NTD and one typical suburban neighborhood of similar size, age, and socio-demographic composition. The matched-pair design controls for differences in local policies, values, and priorities across cities.

We found that NTD residents make more trips - by car, non-motorized and within their neighborhood - than residents of typical suburban neighborhoods. We found no difference in vehicle mileage, and thereby conclude that trips taken by NTD residents tend to be shorter in length than trips taken by their suburban counterparts. Furthermore, we did not find a statistical difference between neighborhood type in the frequency of external trips. This suggests that the difference in overall trips detected is the result of greater internal trip capture by the NTDs.

Additionally, we found that there is something unique about NTDs beyond their connectivity to other roads, density, retail access, and commercial land uses that explains the additional tripmaking by their residents. It may be that parcel design guidelines (e.g., short setbacks and back alleyways), intersection and roadway design, or sidewalk connectivity contribute to the increase in trip-making in NTDs. For non-motorized trips, however, differences in density and retail access accounted for most of the differences across neighborhoods. A simulation suggested that residents of a neighborhood on the high end of the scale in terms of connectivity, residential density, and commercial activity will make almost four times more non-motorized trips than residents of neighborhoods at the low end of the scale. Developers and planners will take interest in the findings contained in this report. Further research will determine whether these relationships are causal.

We found no significant differences in residents' reports of neighborhood social capital between NTDs and typical suburban neighborhoods. We conclude that, in suburban environments, demographic differences between residents of each neighborhood type, and not the characteristics of the development, account for variation in neighborhood social capital.

Contrary to some prior studies, findings also suggest that the physical activity levels and overweight or obese status were similar regardless of whether respondents lived in a NTD or typical suburban neighborhood. This pattern was consistent for all respondents as well as for white respondents, non-white respondents, and higher income respondents. Only among lowerincome respondents was residing in a NTD related to greater physical activity. The reasons this relationship was found only among this group is something that should be explored in future research. 
For the travel attitude, NTD residents expressed stronger preference for walking and biking. However, residents living in NTDs were equally uncomfortable using public transportation as their counterparts from traditional suburban neighborhoods.

In terms of environmental attitude, NTD residents had stronger concern over land consumption, development, energy, and automobile use. They expressed greater support for government actions to redress those problems. These findings suggest a potential disconnect between expressed social goals and individual behavior by residents.

Finally, findings show that NTD residents placed much stronger emphasis on neighborhood walkability during their housing search, but it was likely for leisure walking or biking as actual overall mode choice was not significantly different between the two groups. 


\section{INTRODUCTION}

Unlike typical suburban developments, neo-traditional (NTD) or New Urbanist developments combine design features that are believed to support walking, neighborhood cohesion, and sense of community. Much has been said about the behavioral patterns of NTD residents. Among others, studies have focused on NTDs' impact on sense of community (Brown and Cropper 2001); residents' interaction (Lund 2003; Handy, Cao et al. 2006); the environment (Berke, MacDonald et al. 2003); physical activity (Rodriguez, Khattak et al. 2006); obesity (Brown, Khattak et al. 2008); vehicle ownership (Cao, Mokhtarian et al. 2007; Cao, Mokhtarian et al. 2007); and travel patterns (Boarnet and Crane 2001; Lee and Ahn 2003; Khattak and Rodriguez 2005; Handy, Cao et al. 2006; Cao, Mokhtarian et al. 2009).

The number of NTDs in the U.S. has grown over the years. Using a national average household size of 2.60 persons from the American Community Survey, Stevens (2008) estimated that approximately 743,000 people reside in NTDs that were completed or under construction, and another 713,000 will occupy projects that are in the planning stage. From 1998-2004, the number of NTD projects of 15 acres or more, completed or under construction, has increased by at least $20 \%$ per year (Steuteville 2004). Support for these neighborhoods also is growing, particularly due to the fact that they allow residents to bike and walk to destinations such as shopping, work, and public transportation (Handy, Sallis et al. 2008).

Despite the growing popularity of NTDs, most research examining their impacts is confined to a handful of neighborhoods or a single geographic area. This limits the ability to make general statements about the overall impacts of NTDs. Similarly, there are unanswered questions about whether specific characteristics of neighborhoods, such as density or street connectivity, are responsible for the behavioral differences observed between residents of neo-traditional and typical suburban neighborhoods, or whether the package of neighborhood characteristics is responsible for the differences. Finally, anecdotal evidence suggests that the siting of neighborhoods vis-à-vis existing development (for example, greenfield development versus infill) is important in explaining residents' perceptions and behavior. Preliminary LEED-ND guidelines support this view even though there is little empirical evidence to support the guidelines.

This report summarizes the findings of a national project to examine the travel behavior, social capital, health, and environmental attitudes of NTD residents relative to residents of typical suburban developments. We use a matched-pair research design of 17 cities across the U.S., thereby controlling for differences in local policies, values, and priorities across cities. This national study addresses salient themes in the transportation, planning and health literatures by surveying populations of diverse incomes, collecting resident information on preferences for and attitudes towards neighborhood qualities, and addressing transportation and health outcomes for diverse community designs. 


\section{PREVIOUS RESEARCH AND STUDY QUESTIONS}

\section{Neighborhood studies and travel behavior}

A number of studies have compared travel patterns of residents in neighborhoods that support walking and those that do not support walking, while matching the neighborhoods on other characteristics such as regional accessibility and residents' income (for a review see Ewing and Cervero 2001; Saelens, Sallis et al. 2003). To the extent that the neighborhoods embody key differences in the built environment, this research design provides whole comparisons across neighborhoods, allowing for the interaction among individual built-environment elements, although there is a broader literature relating urban form to travel (for recent reviews see Owen, Humpel et al. 2004; Wendel-Vos, Droomers et al. 2007; Saelens and Handy 2008). We focus here exclusively on neighborhood studies.

The evidence from other neighborhood-based studies focusing on travel patterns suggests that the share of trips taken by pedestrians and cyclists, and the raw number of these non-motorized trips, is higher in neighborhoods defined a priori as walkable than those that are not walkable (Friedman, Gordon et al. 1994; Cervero and Gorham 1995; Cervero and Radisch 1995; Rutherford, McCormack et al. 1996; Kitamura, Laidet et al. 1997; Handy and Clifton 2001; Dill 2004; Handy, Cao et al. 2006). However, no difference in travel for recreation or leisure was detected in the three studies that examined this (Handy 1992; Handy 1996); (Rodriguez, Khattak et al. 2006). Consistent with the findings of Saelens et al., (2003), it seems that travel for errands is the source of overall differences in non-motorized transport between neighborhoods with greater or lesser walkability.

While studies of NTDs indicate that residents of those neighborhoods actually make more total trips per day than residents of typical suburban developments, there is agreement that these trips are shorter and that many auto trips are substituted for walking trips (Rodriguez, Khattak et al. 2006; Cao 2009); Khattak \& Rodriguez, 2005; Limanond \& Niemeier, 2004). Additionally, households in NTDs make fewer external trips (Khattak \& Rodriguez, 2005; Limanond \& Niemeier, 2004), having a greater ability to stay within the neighborhood to purchase goods and services to meet the majority of their daily needs.

A prominent limitation of prior research is the reliance on cross-sectional data. This restricts the ability to make causal statements about the relationships identified. Paired-neighborhood research designs improve researchers' ability to make causal statements, but questions remain about the extent to which differences in behavior among NTD residents relative to residents of typical suburban neighborhoods are the result of a sorting process in the residential land market. In such a sorting process, households that prefer walkable environs and high local accessibility to varied land uses would be more prone to locate in specific neighborhoods that meet those preferences.

To date, most studies conclude that self-selection, as the sorting process is known, is responsible for some of the variation in behavioral differences, but that the built environment still exerts an important influence on behavior (Krizek 2003; Khattak and Rodriguez 2005; Cao, Mokhtarian et al. 2006; Handy, Cao et al. 2006; Handy, Cao et al. 2008; Cao, Mokhtarian et al. 2009).

Furthermore, after accounting for self-selection, design concepts present in NTDs, such as concentrated activities and land-use mixing, do not increase the substitution of transit for car 
trips, although they do increase the substitution of walking for car trips (Greenwald 2003; Cao, Mokhtarian et al. 2009).

More importantly, the directionality of the impact of self-selection is ambiguous. It may be that ignoring self-selection results in an underestimate, not an overestimate, of the impacts of the built environment on behavior. Ultimately, the question of whether self-selection biases the relationship between environment and behavior becomes a matter of scientific interest with limited practical relevance. Self-selection concerns should not obscure the fact that it is the way through which many of the desired effects of neighborhood design and behavior take place. Absent the NTD, and given a shortage of neighborhoods with similar characteristics (as suggested by Levine (2005) and Morrow-Jones et. al (2004)), options for those who now choose such neighborhoods would be limited to typical suburban neighborhoods.

Treating the possibility of self-selection as mainly a nuisance, researchers have experimented with increasingly sophisticated methods and instruments in the identification of the "true" relationship between the built environment and travel behavior (Bagley and Mokhtarian 2002; Bhat and Guo 2005; Greenwald and Boarnet 2001; also see a summary by Mokhtarian and Cao 2008). Much of the existing research on self-selection, though, has focused on studying the first element of this possible causal relationship; that is, how residential location influences travel behavior. What has been understudied is the latter relationship concerning how people's travel intention or preference may significantly affect residential-location choice (Choocharukul et al., 2008). A better understanding of this issue not only leads to a more accurate assessment of the real impacts environment has on travel behavior, but also improves travel research in several ways.

First, the consideration of such psychological constructs as preference and attitudes greatly expands the meaning associated with travel behavior beyond simply getting from one point to another (i.e., derived demand). A study by Schwanen and Mokhtarian (2007), for example, revealed that people opt for higher-density living in part because they are concerned about the environment and want to reduce their auto travel, whereas lower-density living is chosen in part because it is better geared to fast, flexible, and comfortable auto travel and makes it easier to display cars as status symbols.

Second, with the acknowledgment that people do actively seek certain locations to enable desired transportation options, research in this area highlights the fact that travel-mode choice is highly conditioned upon environmental factors. It also leads to the question about the degree to which the current supply of land-use configuration may have suppressed desired transportation behavior. Several studies have noted the dissonance between the type of neighborhoods people prefer and where they actually live (Schwanen and Mokhtarian, 2005) and the likely insufficiency in the supply of environments that supports non-auto travel (Levine and Inam, 2004). These findings illustrate that the benefits of modifying an environment relies not only on "inducing" more desirable travel behavior but also "enabling" existing travel preference.

Another concern with prior studies is their limited geographic scope. The majority of neighborhood studies examining travel behavior have been conducted in northern California, Texas, or the central area of North Carolina (Cervero and Radisch 1995; Handy and Clifton 2001; Handy, Cao et al. 2006; Rodriguez, Khattak et al. 2006). These studies were the first to 
uncover and examine important relationships, but given variations in how NTDs are designed, it is likely that prior results reflect the influence of local factors in addition to neighborhood design factors of more general interest.

\section{Disparities in Physical Activity \& Obesity}

For over 35 years, national studies have found that minorities and those with lower incomes have higher rates of obesity relative to whites and the more affluent (Wang and Beydoun 2007).

Recent estimates suggest that $20 \%$ of African-American and $19 \%$ of Mexican-American children are obese compared with $16 \%$ of white children (Wang and Beydoun, 2007). In adulthood the racial and ethnic disparities become substantially wider, with obesity documented in $45 \%$ of African-Americans, 37\% of Mexican-Americans and 31\% of whites. There is increasing concern that disparities in obesity may exacerbate racial and ethnic disparities in disease more broadly (Cossrow and Falkner, 2004, Committee on Prevention of Obesity in Children and Youth, 2004).

Physical activity is a key determinant of obesity, as well as an independent influence on health. White adolescents are more likely to meet physical activity recommendations than are AfricanAmerican or Hispanic adolescents, by 10 and 7 percentage points respectively (Centers for Disease Control and Prevention, 2005). White children also are less likely to be inactive than African-American and Hispanic children, and they are more likely to walk or bike to school (Centers for Disease Control and Prevention, 2005, Gordon-Larsen, et al., 2005, Andersen, et al., 1998, Richmond, et al., 2007, Pratt, et al., 1999).

Recent research has found that neighborhood characteristics, in particular the built environment, are related to physical activity and obesity (Black and Macinko 2008; Black and Macinko, et al 2007). There also is some evidence of a relationship between healthy food availability in a neighborhood and obesity rates, but this is more mixed (Black and Macinko 2008). Given the high levels of residential income and racial/ethnic segregation in the United States, some have posited that the differences in minority, majority, low-income, and high-income neighborhoods may be a contributing factor to disparities in obesity (Gordon-Larsen and Nelson 2006; Kumanyika (In Press)).

The analysis in this report examines the extent to which there are differences in physical activity and obesity by race/ethnicity and income overall in this sample, and within neighborhood types. On one hand, this analysis enables us to examine whether there are differences in physical activity and obesity by race/ethnicity and income when comparing people in similar neighborhoods, so we are in effect controlling for differences in neighborhood characteristics. And on the other hand, we are able to examine, using multivariate regression models, whether the influence of NTDs differs by demographic subgroup.

\section{Social capital and urban form}

The links between physical planning and neighborhood social relations has been the subject of research and debate since the work of the Chicago School in the 1920s and '30s (Park, et al., 1925). For example, Park's dictum stated that "social relations are spatial relations" (Massey, 2001, emphasis in original). Freeman (2001) identified two conflicting theoretical perspectives 
on the relationship between neighborhood form and social relations. The first, which he primarily identified with Jane Jacobs and more recently the New Urbanists, asserts that "mixed land uses and pedestrian-friendly streets [lead] to an enhanced sense of community in a neighborhood" (Freeman, 2001). In contrast, much work in physical planning has focused on the deleterious effects of high densities on social ties among neighbors. For example, the garden cities movement sought to house people at more moderate densities and create a stable social environment.

More recently, the debate on the relationship between space and social processes has focused on the claims of New Urbanists that the design of a neighborhood can engender a sense of community (Katz, 1994). In her description of the social goals of New Urbanism, Talen (1999) notes that, "New urbanists attempt to build a sense of community, broadly defined, via two avenues: integrating private residential space with surrounding public space; and careful design and placement of public space" (p. 1363). While none of the 27 principles in the Charter of the New Urbanism focus solely on building community, several are justified based on their contribution to community (Talen, 2002). For example, Principle 13 emphasizes the importance of diversity to create an "authentic community," and Principle 23 encourages walkable streets to "enable neighbors to know each other and protect their communities" (Talen, 2002).

Empirical investigations of this issue have used many definitions of neighborhood social relations (Lochner, et al., 1999; McNeill, et al., 2006). Most prominent have been qualitative metrics of "sense of community," counts of strong ("confidants") and weak ("acquaintances") ties within the neighborhood, and measures of interaction among neighbors. For example, Appleyard (1981) analyzed social interactions on three similar San Francisco streets that varied in the level of automobile traffic and found a negative correlation between traffic and social interactions. Other studies have focused more broadly and compared levels of social interaction in cities and suburbs. For example, Freeman (2001) found no relationship between residential population density and neighborhood social ties for residents of Atlanta, Boston, and Los Angeles.

The limited research explicitly looking at differences in social capital between neo-traditional and typical suburban communities has focused on qualitative measures of sense of community. Nasar and Julian (1995) developed a 15-item scale measuring neighborhood sense of community with questions such as, "My friends in this neighborhood are part of my everyday activities" and, "I have no friends in this neighborhood on whom I can depend." Using this scale, Nasar (2003) found no association between sense of community and whether a respondent lived in a traditional town (meant to proxy for a NTD) or typical suburb in Ohio. Brown and Cropper (2001) used a different sense of community scale and found no differences in sense of community between NTD residents and those in standard suburban subdivisions in Salt Lake City.

\section{Implications and emerging questions}

Neighborhood studies on travel behavior and neighborhood type have revealed that NTD residents walk more and make more trips overall, but travel shorter distances by car, even after attempts to control for self-selection. Similarly, there is evidence of substitution of walking trips for driving trips, a result also consistent with data from developments that mix land uses. However, small samples and restricted geographic coverage raise questions about the ability to 
make solid statements useful for planners and developers. For social capital, advocates of New Urbanism suggest that levels of social interaction and sense of community should be higher in NTDs. However, there has been no empirical investigation of differences using national samples. Therefore, the first emerging question is whether travel and social capital patterns identified in local and regional neighborhood studies are replicated in the current national study.

Surprisingly, no neighborhood studies that we know of examine whether specific design attributes are more important than others in explaining travel behavior, or whether it is the collection of attributes embodied in NTDs that explains behavioral differences compared to residents of typical suburban neighborhoods. In other words, for the travel benefits to materialize, is the entire NTD package required, or do developers have latitude in exploring different design options for some neighborhood characteristics?

The literature is replete with studies examining specific attributes of the built environment and their relationship to travel patterns. Reviews (e.g., Wendel-Vos, Droomers et al. 2007; Saelens and Handy 2008) suggest that density, mixed uses, and pedestrian supports are related to increased walking. Recent studies confirm the importance of residential density (Lee \& Moudon, 2006a; Lee \& Moudon, 2006b; Moudon et al., 2006; Ritsema van Eck et al., 2005; Rodriguez et al, In press); the presence of retail stores (Badland \& Schofield, 2005; Rodriguez et al In press, Handy et al 2006 JAPA; Lee \& Moudon, 2006a; Moudon et al., 2006); and route directness to schools, daily retail, and groceries (Lee \& Moudon, 2006a; Moudon et al., 2006) for walking behavior.

Accordingly, a second emerging question is whether the provision of key attributes together, such as high residential density with retail spaces and street connectivity, suffices to support pedestrian activity more than when the attributes are provided independently. In other words, are there synergistic and interactive effects among these attributes that benefit pedestrian activity? A third emerging question is whether these attributes (individually or collectively) suffice for pedestrian supports, or whether other attributes present in NTDs, such as building design and setbacks, also contribute to the walkability of a neighborhood.

The limited number of neighborhoods included in previous research might also help explain the paucity of research examining whether greenfield NTDs have different travel (and perhaps social) impacts than infill NTDs. Non-neighborhood studies relying on cross-sectional surveys have found that the location and regional connectivity of the neighborhood, with respect to other activity centers in the area, is critical in explaining observed travel patterns (Ewing 1995; Cervero and Kockelman 1997; Kasturi, Sun et al. 1998; Ewing and Cervero 2001). Buliung and Kanaroglou (2006) found that urban households, which might be expected to have higher levels of accessibility, have less daily travel and smaller activity spaces than suburban households. Similarly, Fan et al (In press) found that households in high-density areas with mixed uses tended to have smaller activity spaces than households in low-density areas with residential uses. Thus, a fourth emerging question is whether the impacts of NTDs on travel behavior are influenced by whether the neighborhood is infill or greenfield development.

This analysis also examines the extent to which there are differences in physical activity and obesity by race/ethnicity and income overall in this sample, and within neighborhood types (neotraditional versus typical suburban). Further, multivariate regression models are developed for 
subgroups based upon race/ethnicity and income level to examine whether neo-traditional neighborhoods have a differential impact for different subgroups. 


\section{HYPOTHESES}

Building on the literature reviewed and the emerging questions, this section summarizes the hypotheses of our study.

\section{Vehicle use and trip-making}

Hypothesis 1: Residents of NTDs drive shorter distances and make more total trips - by automobile, non-motorized and within their neighborhoods - than residents of typical suburban neighborhoods, after controlling for households' socio-demographic characteristics.

Hypothesis 2: Residents of neighborhoods with high supports for walking (measured as having greater street connectivity, larger commercial areas, higher density, and greater accessibility to retail and services), drive shorter distances and make more trips - by automobile, non-motorized and within their neighborhoods - than residents of neighborhoods with low supports for walking, after controlling for households' socio-demographic characteristics.

Hypothesis 3: Residents of NTDs make more total trips - by automobile, non-motorized and within their neighborhoods - than residents of typical suburban neighborhoods, after controlling for households' socio-demographic characteristics and for walking supports (measured has having greater street connectivity, larger commercial areas, higher density, and greater accessibility to retail and services).

\section{Travel attitude/preference and choice of neighborhood types}

The study recognizes the simultaneous influence of travel preference and residential preference on people's location choice. We hypothesize that such influences are discernible in the evaluative criteria used in people's decision-making process and their final selection of neighborhood types.

Hypothesis 1. NTD residents have stronger attitudes favoring environmental protection and stronger preference favoring alternative travel modes (walking, biking, and public transportation).

Hypothesis 2. NTD residents consciously choose their residential environments (i.e., neighborhood type) according to their travel and residential preference.

\section{Social capital}

This analysis focuses on the relationship between neighborhood design and social capital.

Hypothesis 1: NTD residents self-report higher levels of neighborhood social capital as measured by social cohesion and intergenerational closure.

\section{Health and obesity}

The primary hypothesis regarding health and obesity is that NTD residents will be less obese or overweight than their counterparts in traditional suburban neighborhoods. 


\section{METHODOLOGY}

To test the hypotheses, we used a quasi-experimental research design (Shadish, Cook et al. 2002) by matching NTDs with typical suburban neighborhoods throughout the U.S.

\section{Selection of NTDs}

The majority of the sites for this study were drawn from lists of planned or completed NTDs published by two popular Internet organizations, New Urban News

(http://www.newurbannews.com) and The Town Paper (http://www.tndtownpaper.com) in 2006. We excluded neighborhoods in cities with populations less than 1,000 or greater than 1 million (based on U.S. Census 2000 population data), leaving us with a list of 389 NTDs in some phase of development. To identify "typical suburban" neighborhoods to match our NTDs, we enlisted the help of staff in local planning and/or development offices. We explained the objectives of the study and asked the staff member to suggest a typical suburban neighborhood to match against the NTD. Staff members were given the following criteria to use in identifying typical suburban neighborhoods:

a. Fairly represent the intended neighborhood type, based on our definitions and the staff's professional judgment;

b. Were platted and approved after 1980 and within about five years of each other;

c. Contain approximately the same number of dwelling units, and have contained at least 100 occupied dwelling units as of January 2006;

d. House predominantly year-round, full-time residents, and must not be inherently exclusionary;

e. Share similar demographics and median housing prices, and if applicable, offer similar quantities of below-market-rate housing;

f. Share similar regional context and access to public transportation services, major highways, and regionally significant destinations and amenities; and

g. Are located in the same local political jurisdiction.

Finding suitable pairs of neighborhoods proved difficult, and when we exhausted our initial list we had found 12 matched pairs, short of our goal of 20. Experience suggested that rapidly growing cities and towns were most likely to be undergoing the kinds of development we were seeking. Thus, we created a secondary list comprised of the 100 fastest-growing, U.S., mid-size cities and the 100 cities with the highest relocation interest (based on real estate turnover), using data from the real estate website http://www.city-data.com for 2007. We contacted planning and development staff in each of these cities and requested NTD and typical suburban neighborhood pairs fitting the above criteria. Nine additional neighborhood pairs were identified through this method.

For all proposed matches, we verified the suggested neighborhoods by examining orthophotographic imagery, neighborhood websites, and when available, local real estate data. We asked the local planner to provide background information on both neighborhood types and to help obtain current GIS data. To confirm the matches, we conducted GIS analyses to verify that the neighborhoods in each pair were compatible and suitable for the study. In several instances, this further examination revealed information about the neighborhoods or the pairings that made them unsuitable for the study, forcing us to reject them. In the end, a total of 17 neighborhood 
pairs were suitable for the study. The cities and towns in which they are located are listed below and shown on the map in Figure 1.

Carlsbad, CA

Clackamas, OR

Cumming, GA

Fort Collins, CO

Frederick, MD

Grayslake, IL

Jupiter, FL

Mount Pleasant, SC

Pensacola, FL
Chula Vista, CA

Colorado Springs, CO

Davidson, $\mathrm{NC}$

Franklin, TN

Gaithersburg, MD

Irvine, CA

Longmont, $\mathrm{CO}$

North Richland Hills, TX

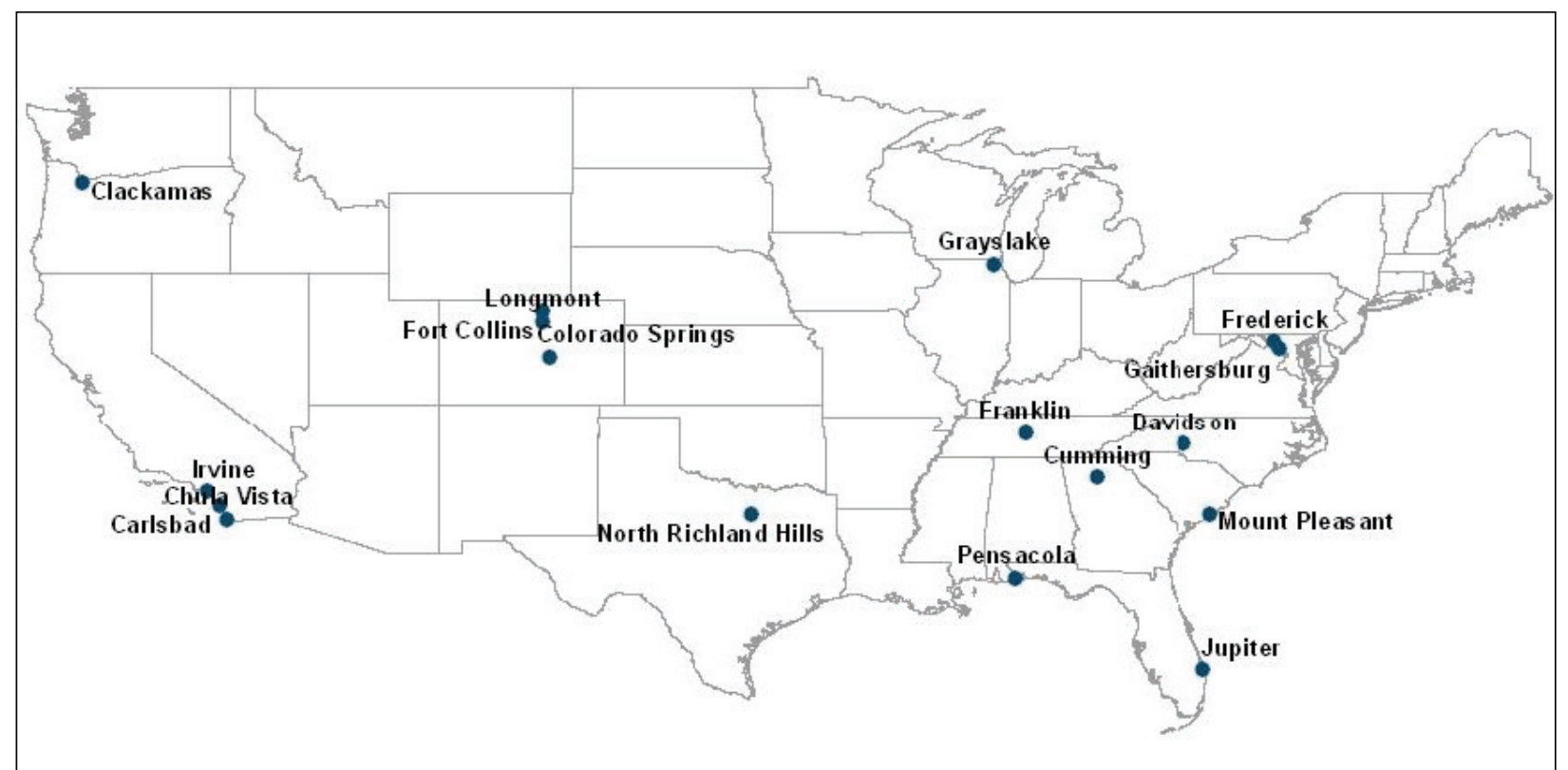

Figure 1. Location of Study Sites

For detailed site plans and descriptive characteristics of each neighborhood pair, see Appendix I.

\section{Survey instrument}

We developed and pilot-tested a survey instrument (Appendix II) that collected information on:

- Socio-demographic characteristics

- Vehicle ownership (make, model, and year) and use

- Trip-making behavior

- Physical activity

- Attitudes and preferences towards particular characteristics of neighborhoods

The survey was adapted and expanded from Khattak and Rodriguez (2005). Changes were pilottested and final paper surveys were mailed to up to 150 randomly selected, single-family 
households in each study neighborhood. ${ }^{1}$ A cover letter explained the purpose of the study and requested that the adult household member with the next birthday complete and return the survey. Respondents that returned completed surveys were entered into a drawing for one of four prizes (winner's choice of either an iPod nano or Roomba 415); this was also explained in the cover letter.

The first 100 respondents were mailed a follow-up survey, which asked the same information for vehicle ownership and use, physical activity, and selected preferences and attitudes as the first survey (Appendix II). The follow-up survey was used to determine the test-retest reliability of the instrument. In exchange for completing the follow-up survey, respondents were mailed a $\$ 10$ gift card.

\section{Outcomes}

\section{$\underline{\text { Social Capital }}$}

We adapted our measures of social capital from the work of Sampson et al $(1997 ; 1999)$. Previous research has shown these measures to be significantly associated with rates of neighborhood violence (Sampson, et al., 1997) and low birth weight (Morenoff, 2003). These indices measure an active form of social capital, specifically the likelihood of neighbors to intervene for the common good. This is a more normative approach than is often taken with measures of social interaction.

The first index, "social cohesion and trust," measured the extent of shared values among neighbors and informal social relations among neighbors. Members of a community with high levels of cohesion and trust will be more likely to respond to issues that affect the entire community, such as proposed cuts to public services in a neighborhood (Sampson et al, 1997). Five Likert-scale questions measured social cohesion: "This is a close-knit neighborhood," "People in my neighborhood can be trusted," "People in my neighborhood are willing to help their neighbors," "People in your neighborhood generally do not get along with each other" (reverse coded), and "People in your neighborhood do not share similar values" (reverse coded).

The second index, "intergenerational closure," focuses on connections between children and adults as well as adult interactions that concern children (Sampson et al, 1999, p. 635). High levels of intergenerational closure indicate a supportive environment for families. The intergenerational closure scale combined responses to the following questions: "Parents in my neighborhood know their children's friends," "You can count on adults in the neighborhood to watch out for kids and keep them safe," "Adults in the neighborhood do not know who the local children are" (reverse coded), "There are adults in the neighborhood that children can look up to," and "Parents in the neighborhood do not know each other" (reverse coded).

Each respondent's score for any index is determined by her or his mean Likert-scale response to each underlying series of questions, with 1 being the lowest response ("not at all important" or "strongly disagree") and 5 the highest ("very important" or "strongly agree"). A score for any

\footnotetext{
${ }^{1}$ Our mailing list was compiled by and purchased from CAS (www.cas-online.com). CAS randomly selected 150 single-family households from their database for each of our study areas; in neighborhoods with fewer than 150 mailing addresses available, we mailed surveys to every household.
} 
index is coded as missing if the respondent did not answer at least three of the corresponding questions.

\section{$\underline{\text { Travel Behavior }}$}

Vehicle use was measured as the sum of the self-reported previous years' mileage for the household's primary and secondary vehicles, if applicable.

To measure trip-making, we asked respondents to report the number of times in a typical fiveday week they make certain types of trips. Questions were designed to determine the trip purpose (e.g., to work or to go shopping), mode (e.g., driver, passenger in a car, foot or bicycle), and the location (i.e., within or outside the neighborhood). Respondents were instructed to indicate whether they make a particular kind of trip (purpose, mode, location) never, once or twice a week, three to five times a week, and six or more times a week. From these responses, we estimated trip frequencies for four categories: total trips, automobile trips, non-motorized trips, and trips made within the neighborhood (internal trips).

These four trip categories compose our trip-making outcomes. Because the survey requested ranges of trip frequencies, rather than the exact number of trips taken, we estimated the numbers of trips by taking the upper limit of the ranges, as follows: "never" was recoded to 0, "one to two times" was recoded to 2, "three to five times" was recoded to 5, and "six or more times" was recoded to 7 . Sensitivity analyses to the coding of the ranges are reported in the Discussion section of this report.

\section{$\underline{\text { Attitude and Preference }}$}

To assess people's environmental attitude, we asked them to report their levels of agreement with five statements. These statements include, "Too much land is consumed for new housing, stores and offices," "Environmental protection is an important issue," "Household energy consumption in the U.S. is a major contributor to global climate change," "The government should put more emphasis on encouraging places that make people less dependent on automobiles," and "As an individual, I can make a difference when it comes to conserving energy and protecting the environment." The answers are of Likert scale from 1 to 5, corresponding to a scale from "strongly disagree" to "strongly agree."

Two questions were used to assess respondents' attitude toward alternative transportation modes: walking/biking and riding the bus. Respondents were asked to indicate their level of agreement with the statements, "I enjoy walking and biking" and "I am comfortable riding the bus."

We used four questions to gauge people's residential preference for land-use mix, higher density, and housing setback. Respondents were asked to indicate their level of agreement with the statements, "Having shops and services close by is important to me," "I enjoy a house close to the sidewalk so that I can see and interact with passersby," "I prefer lots of space between my home and the street," and "I can be comfortable living in close proximity to my neighbors."

The evaluative criteria that people used in their residential decision-making process is examined using a series of questions asking the level of importance people attached to certain housing and environmental condition or quality. The items considered a range from affordability of housing 
and school quality to proximity to open space. The levels of importance respondents were given to choose from range from 1 being "not important at all" to 5 being "very important."

\section{Built environment}

For each study neighborhood, we obtained data about the built environment in GIS format, including street networks and parcel-level, land-use information. Typically, these data came directly from the local planning agency or county GIS department. The level of detail and accuracy of the land-use data varied from agency to agency, so we supplemented and verified the data using a variety of sources, described below.

We standardized the categories of land uses in the various GIS files into primary categories, several of which are further broken down into sub-categories.

- Residential - divided into multifamily residential; single-family residential; town or row houses; live/work; and mixed-use, multifamily residential.

- Institutional - divided into churches, schools, government and other unspecified institutional uses.

- Transportation - divided into rights of way for roads, alleys and greenways.

- Open/parks - divided into dedicated open space, parks, and recreational areas (e.g., ball fields, swimming pools, playgrounds).

- Commercial - any commercial land use, including parking lots connected to commercial parcels.

- Parking - any parking lot not clearly associated with a commercial parcel.

- Agriculture/farming

- Construction - any parcel under construction where intended land use is not known.

- Vacant - any undeveloped parcel clearly not classifiable as open space or parks.

- Utilities - includes utility easements and drainage areas.

- Interstitial space - un-parcelized space less than .5 acres in size, differentiated by the land use with which it is associated (e.g., SFR-interstitial is un-parcelized land intermingled with single-family development).

In the summer of 2008, we verified the land-use data for every parcel in each of our neighborhoods using Google Earth and Google Street View. In many cases, distinguishing between transportation, parking, vacant and other uses was easy. However, distinguishing among other uses (e.g., commercial and institutional) was not easy. Each parcel in our GIS data contains two land-use fields: the existing land use as provided by the local planning agency and the actual land use as determined through visual inspection of Google imagery. In our analyses, we have used the verified rather than the provided land uses.

To determine the types of commercial land uses within each neighborhood and the locations of destinations within walking distance of our survey respondents, we downloaded data from ReferenceUSA on all commercial businesses located within our sites that fall under the following NAICS codes:

- 44-45 Retail Trade

- $519 \quad$ Other Information Services 
- $52 \quad$ Finance and Insurance

- $561 \quad$ Administrative and Support Services

- 61 Educational Services

- 62 Health Care and Social Assistance

- 71 Arts, Entertainment, and Recreation

- 72 Accommodation and Food Services

- 8123 Dry-cleaning and Laundry Services

- 813 Religious, Grantmaking, Civic, Professional, and Similar Organizations

However, we found the ReferenceUSA data to be very limited and often flawed, in that it often identified commercial establishments in locations they clearly could not exist (for example, the ReferenceUSA data identified a 10,000-square-foot retail store where the Google imagery showed a modest single-family home). Among the 10 study neighborhoods for which we downloaded data from ReferenceUSA, we found commercial data to be inaccurate in eight of them.

Rather than relying on ReferenceUSA's data to determine the location of destinations, we opted to use the Walk Score, a walkability index created by www.walkscore.com. As described on Walk Score's website (www.walkscore.com/how-it-works.shtml):

Walk Score uses a patent-pending system to measure the walkability of an address. The Walk Score algorithm awards points based on the distance to the closest amenity in each category. If the closest amenity in a category is within .25 miles (or .4 km), we assign the maximum number of points. The number of points declines as the distance approaches 1 mile (or $1.6 \mathrm{~km}$ ) - no points are awarded for amenities further than 1 mile. Each category is weighted equally and the points are summed and normalized to yield a score from 0 100 .

We calculated the Walk Score for the street address of each respondent, with the exception of the respondents from our study sites in Davidson, NC. Walk Score uses the Google Maps database to determine the locations of destinations, and we discovered that Google Maps had incorrectly placed a bookstore, a library, and a shoe store in one corner of the typical suburban neighborhood in Davidson. Close inspection of the Google imagery showed nothing but singlefamily residences, and our local planning contact in Davidson confirmed that there were no commercial establishments of any kind in the area. This finding invalidated the Walk Score for both neighborhoods in the Davidson pair, as they are both within a mile of the misplaced businesses, and necessitated estimation of the Walk Score for Davidson residents by other means. Fortunately, the Davidson neighborhoods closely resembled another study neighborhood (in size and proximity to commercial establishments), so we assigned the mean Walk Score (2) from that neighborhood to the Davidson respondents.

We also calculated the land area of parcels in commercial use in each of our study areas, using the GIS parcel layers. 


\section{$\underline{\text { Built-Environment Derived Variables }}$}

In addition to the household-level Walk Score, we calculated the neighborhood-level, builtenvironment variables shown in Table 1 and summarized in Table 2 for all neighborhoods. Summary statistics for each neighborhood are shown in Appendix I.

Table 1. Neighborhood-level, Built-Environment Attributes

\begin{tabular}{lll}
\hline Attribute & Variable & Description \\
\hline Neighborhood size & total_area & Total area of tract (acres) \\
& SFDU_exist & Existing detached single-family dwelling units \\
Street network/connectivity & ext_conn & External connections per 100 existing SFDU \\
& Inr & Link-to-node ratio \\
& pct4way & Percent of intersections that are 4-way \\
streetdens & Street density, in miles per developable (non-open) acre \\
SFdens & Net single-family unit density (units per acreage in SF dwellings) \\
Density & pctopen & Open space, parks, or fully enclosed water bodies (percent of total \\
Land Use & area) \\
& pctvacant & Vacant area (percent of non-open area that is vacant) \\
& pctresid & Residential area (percent of non-open area that is residential) \\
pctSFresid & Single-family share (percent of residential area that is SFDUs) \\
& commarea & Area of commercial development in the neighborhood, in acres \\
Destinations & mean_walk & Mean Walk Score for the neighborhood \\
& greenfield & Greenfield setting (dummy variable; 1=yes) \\
Regional context & by walkscore.com; all other data provided by local sources and verified by GIS
\end{tabular}


Table 2. Comparison of Built-Environment Attributes by Neighborhood Type

\begin{tabular}{|c|c|c|c|c|c|c|c|c|}
\hline \multirow[b]{2}{*}{ Attribute } & \multicolumn{4}{|c|}{ Typical Suburban } & \multicolumn{4}{|c|}{ Neo-Traditional } \\
\hline & mean/freq & st dev & $\min$ & $\max$ & mean/freq & st dev & $\min$ & $\max$ \\
\hline total_area & 352.34 & 527.4 & 24.4 & 2334 & 290.58 & 420.51 & 23.8 & 1823.6 \\
\hline SFDU_exist & 872.18 & 1596.6 & 108 & 6951 & 599.65 & 716.12 & 42 & 2861 \\
\hline SFDU_permit & 826.64 & 597.69 & 100 & 1816 & 949.07 & 914.44 & 100 & 2968 \\
\hline mean_price & $\$ 279,397$ & 177,959 & $\$ 93,665$ & $\$ 671,468$ & $\$ 286,518$ & 169,470 & $\$ 95,483$ & $\$ 693,435$ \\
\hline \multicolumn{9}{|l|}{ year_appr } \\
\hline before 2000 & 13 & & & & 6 & & & \\
\hline $2000-2004$ & 2 & & & & 8 & & & \\
\hline 2005 or after & 2 & & & & 3 & & & \\
\hline Transit presence & 9 & & & & 9 & & & \\
\hline greenfield & 76 & & & & 76 & & & \\
\hline ext_conn & 0.86 & 0.48 & 0.1 & 1.94 & 1.95 & 2.26 & 0.11 & 10.17 \\
\hline $\ln r$ & 1.19 & 0.14 & 0.92 & 1.41 & 1.42 & 0.16 & 1.15 & 1.74 \\
\hline pct4way & $9 \%$ & 5 & $0 \%$ & $17 \%$ & $16 \%$ & 8 & $5 \%$ & $37 \%$ \\
\hline streetdens & 0.03 & 0 & 0.03 & 0.04 & 0.06 & 0.03 & 0.03 & 0.18 \\
\hline SFdens & 4.76 & 1.39 & 3.1 & 7.84 & 7.13 & 1.92 & 4.82 & 10.71 \\
\hline pctopen & $14 \%$ & 13 & $0 \%$ & $51 \%$ & $17 \%$ & 9 & $4 \%$ & $36 \%$ \\
\hline pctvacant & $6 \%$ & 10 & $0 \%$ & $31 \%$ & $6 \%$ & 11 & $0 \%$ & $34 \%$ \\
\hline pctresid & $69 \%$ & 7 & $55 \%$ & $80 \%$ & $56 \%$ & 13 & $28 \%$ & $75 \%$ \\
\hline pctSFresid & $93 \%$ & 13 & $57 \%$ & $100 \%$ & $82 \%$ & 15 & $45 \%$ & $100 \%$ \\
\hline commarea & 6.28 & 19.03 & 0 & 77.88 & 8.57 & 21.7 & 0 & 90.97 \\
\hline mean_walk & 29.92 & 21.12 & 2 & 64.42 & 40.63 & 18.25 & 2 & 76.43 \\
\hline
\end{tabular}

\section{Socio-demographic information}

Finally, we asked survey respondents to report socio-demographic information about themselves and their households. The socio-demographic variables derived from this information are shown in Table 3. We also requested the household's estimated yearly income, but ultimately dropped this variable due to a low response rate. 
Table 3. Socio-demographic Attributes

\begin{tabular}{|c|c|c|}
\hline Attribute & Variable & Description \\
\hline \multirow[t]{4}{*}{ Personal Information } & race & $\begin{array}{l}\text { Respondent's race (due to low incidence of most categories other } \\
\text { than white, the race variable was collapsed to [white/non-white]; } \\
\text { 1=white) }\end{array}$ \\
\hline & $\operatorname{sex}$ & Respondent's sex (female $=1$ ) \\
\hline & education & $\begin{array}{l}\text { Respondent's level of education (collapsed to a binary [college } \\
\text { graduate/non-college graduate] variable) }\end{array}$ \\
\hline & work_status & $\begin{array}{l}\text { Respondent's work status (categories include full or part time at } \\
\text { home, away from home, student, unemployed, and retired) }\end{array}$ \\
\hline \multirow[t]{3}{*}{ Home information } & home & $\begin{array}{l}\text { Type of structure in which respondent lives (detached single-family } \\
\text { dwelling, town house or duplex, condominium or apartment, or } \\
\text { other) }\end{array}$ \\
\hline & own & $\begin{array}{l}\text { Whether the respondent/respondent's family owns the home (as } \\
\text { opposed to renting; } 1=y e s \text { ) }\end{array}$ \\
\hline & tenure & Length of time living in the home (in years) \\
\hline \multirow{4}{*}{$\begin{array}{l}\text { Household } \\
\text { size/composition }\end{array}$} & hhld_size & Number of full-time household members \\
\hline & num_adults & Number of adults living in the household \\
\hline & num_drivers & $\begin{array}{l}\text { Number of potential drivers (household members } 17 \text { years or older) } \\
\text { living in the household }\end{array}$ \\
\hline & kids & $\begin{array}{l}\text { Whether there are children under the age of } 18 \text { living in the } \\
\text { household (1=yes) }\end{array}$ \\
\hline
\end{tabular}

\section{Statistical analyses}

In all of our analyses, statistical significance was determined with a 95\% level of confidence. All analyses were conducted in Stata (College Station, TX, versions 9.2 and 10.1). For all regression analyses, we use robust standard errors with clustering to account for potential correlations among participants within neighborhood pairs.

\section{$\underline{\text { Social Capital }}$}

We used three statistical methods to examine differences in social capital and cohesion between neo-traditional and typical suburban neighborhoods. First, t-tests were applied to assess the strength of the relationship between neighborhood type and social capital without controlling for other factors and to identify conforming or contrasting patterns within neighborhood pairs. Next, we developed multivariate models to adjust for demographic variation in the populations. We used Tobit models due to the right-censoring of social capital scores and employed binary logistic regression to determine whether neighborhood type predicts high social capital scores (in this case, a score of at least 4). In each regression analysis, covariates were each respondent's sex, race (white or non-white), age, length of time in the neighborhood, and presence of children under 18 in the home with clustering by neighborhood pair.

Finally, we used matching techniques to compare social capital scores for individuals living in NTDs to what their scores would have been if they lived in a typical suburban development (Oakes and Johnson, 2006). This counterfactual, which is by definition unobservable, is estimated by matching individuals that are demographically similar but live in different types of neighborhoods. Direct matching, as opposed to propensity score matching (Oakes and Johnson, 2006), is used because this method does not rely on appropriate parameterization of the 
propensity score and is therefore more robust than propensity score methods (Abadie and Imbens, 2007). The nnmatch function in Stata 9.2 was used to conduct the analysis assuming heteroscedastic errors and correcting for bias introduced through non-exact matches (Abadie and Imbens, 2006; Abadie, et al., 2004).

\section{$\underline{\text { Travel Behavior }}$}

\section{Vehicle Mileage}

We use ordinary least squares regression to examine the effects of neighborhood type and built environment on vehicle mileage. Because yearly mileage (self-reported mileage in the previous year of households' primary and secondary motor vehicles) was heavily skewed to the right, we applied a square root transformation to normalize the variable.

\section{Trips}

For the four trip-related outcomes, we used count regression models to avoid the inefficient and biased estimates that may result from applying ordinary least-squares regression. Unlike Poisson regression, negative binomial models do not assume equivalence of the dependent variable's mean and variance.

\section{$\underline{\text { Attitude and Preference }}$}

We tested the reliability of the attitude items in capturing the concept using mean scores to represent a respondent's overall environmental attitude. T-tests were used to compare the mean values of residential preference variables between respondents from two types of neighborhoods, and comparisons were made to understand the importance for environmental conditions considered in respondents' decision-making process on residential location.

\section{$\underline{\text { Physical Activity and Obesity }}$}

Multivariate regression models are developed for subgroups based upon race/ethnicity and income level, to examine whether NTDs have a differential impact for different subgroups. 


\section{RESULTS}

\section{Summary statistics}

We mailed 4,837 surveys and received 588 valid responses back, for an overall response rate of $12.2 \%$. As shown in Table 4, the response rate was somewhat higher among neo-traditional neighborhoods $(13.8 \%)$ than non-NTD neighborhoods $(10.5 \%)$. The response rate was highest in the South (sites in NC, SC, and GA; 16.8\%) and lowest on the West Coast (sites in CA and OR; 9.6\%) and Midwest (site in IL; 9\%).

Table 4. Survey Response Rate

\begin{tabular}{lrrr}
\hline & Sent & Received & Rate \\
\hline Neighborhood Type & & & \\
$\quad$ Typical suburban & 2,426 & 255 & $10.5 \%$ \\
$\quad$ Neo-traditional & 2,411 & 333 & $13.8 \%$ \\
Region & & & \\
$\quad$ Mid-Atlantic & 545 & 62 & $11.4 \%$ \\
South & 900 & 151 & $16.8 \%$ \\
Florida & 519 & 59 & $11.4 \%$ \\
Tennessee/Texas & 600 & 82 & $13.7 \%$ \\
Rockies & 872 & 101 & $11.6 \%$ \\
$\quad$ West Coast & 1,200 & 115 & $9.6 \%$ \\
$\quad$ Midwest & 201 & 18 & $9.0 \%$ \\
\hline Total & 4,837 & 588 & $12.2 \%$ \\
\hline
\end{tabular}

Given the low response rate, we compared three demographic attributes from our surveys with census block-level data from the 2000 Census to determine whether potential bias existed. Only three of our demographic attributes - household size, percent of households that are owneroccupied, and race - were available at the block level. Table 5 shows how our sample populations compare with the Census data for the three variables. Our study sites have a higher proportion of white residents, higher rates of home ownership, and larger household sizes. This is not entirely surprising given that our single-family dwellings dominate our sample. With single-family units and ownership come larger household sizes.

Since many of our study sites are in rapidly growing areas that have likely changed substantially since the 2000 Census, we also compare a sub-sample of older, more established neighborhoods and newer neighborhoods in established areas with Census data, with similar results. More recent demographic data (e.g., the 2008 American Community Survey) has data available only at the county level, which cannot be directly compared. 
Table 5. Comparison of sample demographics with Census data

\begin{tabular}{|c|c|c|}
\hline \multicolumn{3}{|c|}{$\begin{array}{c}\text { Restricted Sample } \\
\text { (Neighborhoods completed mostly before 2000; } n=8 \text { ) }\end{array}$} \\
\hline & area mean & nhood mean \\
\hline household size & 1.986 & 2.656 \\
\hline pct_owner & 70.978 & 92.065 \\
\hline pct_non-white & 20.474 & 16.256 \\
\hline \multicolumn{3}{|c|}{$\begin{array}{l}\text { Less-restricted Sample } \\
\text { (Restricted sample plus neighborhoods in areas with }>500 \text { pop in } 2000 ; n=16 \text { ) }\end{array}$} \\
\hline & area mean & nhood mean \\
\hline household size & 2.108 & 2.616 \\
\hline pct_owner & 76.279 & 95.017 \\
\hline pct_non-white & 16.471 & 11.234 \\
\hline
\end{tabular}

\begin{tabular}{|c|c|c|}
\hline \multicolumn{3}{|c|}{$\begin{array}{l}\text { All neighborhoods } \\
(n=34)\end{array}$} \\
\hline & area mean & nhood mean \\
\hline household size & 1.976 & 2.646 \\
\hline pct_owner & 71.083 & 96.167 \\
\hline pct_non-white & 12.547 & 10.215 \\
\hline \multicolumn{3}{|c|}{$\begin{array}{l}\text { area mean }=\text { average of Census blocks containing study households, } \\
\text { weighted by the proportion of study households in that Census block }\end{array}$} \\
\hline
\end{tabular}

The follow-up survey duplicated questions from several sections of the initial survey. The sections included are: vehicles owned, physical activity and health, trip-making, neighborhood preferences, and attitudes. We received 52 of the 100 follow-up surveys. Responses on the follow-up survey were compared with the respondent's answers to the initial survey. Agreement was determined via kappa statistic (for categorical and variables) and concordance statistic (for continuous variables), which correct for chance agreement (Appendix IV). Concordance and kappa statistics close to 1 indicate perfect agreement, while statistics close to 0 indicate no agreement beyond what can be achieved by chance. Average kappa/concordance statistics ranged from 0.51 to 0.74 , indicating moderate to substantial agreement using Landis \& Koch's (1977) classification of scores. Survey questions in the "vehicles owned" section had the highest testretest reliability agreement (mean kappa/concordance $=0.736$ ), while questions about tripmaking behavior had the lowest test-retest reliability (mean kappa/concordance $=0.51$ ).

\section{Built environment}

The study neighborhoods ranged in size from 23.8 acres (the NTD in Pensacola, FL) to 2,334 acres (the typical suburban neighborhood in Irvine, CA). They also varied considerably on all of the built-environment attributes we measured, as shown in Table 2. Because of high correlations among the internal connectivity measures (link-node ratio, street density, and percent of fourway intersections), we opted to keep only the link-node ratio in our analyses. 
On average, our NTDs had greater internal and external connectivity, greater residential densities, more non-residential land uses, and higher average Walk Scores than the typical suburban neighborhoods. There was little difference in the two neighborhood types in terms of vacant area and, surprisingly, commercial area. As neighborhoods were matched in part on their regional context, there was an equal number of greenfield developments in each neighborhood type (13 of 17 neighborhoods of each type were greenfields).

\section{Descriptive statistics of study outcomes}

\section{$\underline{\text { Social Capital }}$}

After elimination of respondents with missing values, the final sample size for the social capital analyses was 561. Internal validity of our social capital measures was high, with Cronbach's alphas of 0.8 for social cohesion and intergenerational closure (see Appendix III-A). The correlation between the two indices was 0.65 .

$\underline{\text { Travel }}$

The travel behavior analyses were limited to observations that had no missing responses in the trip-making section of the survey, reducing the sample size from 588 to 357 . The vehicle-miles analysis was further restricted to exclude respondents who had not lived in their current homes for at least one year, as the mileage variable pertains to the entire previous year's mileage. Table 6 below shows summary statistics for the un-transformed vehicle mileage and the four trip categories.

Table 6. Descriptive Statistics - Travel Behavior

\begin{tabular}{lrrrrr}
\hline Variable & $\mathrm{N}$ & Mean & St. dev. & Min & Max \\
\hline Vehicle-miles in previous year & 310 & $22,446.21$ & 13219 & 0 & 92,000 \\
Total trips & 357 & 14.45 & 6.07 & 2 & 38 \\
Automobile trips & 357 & 9.09 & 4.34 & 0 & 28 \\
Non-motorized trips & 357 & 1.51 & 2.36 & 0 & 14 \\
Internal trips & 357 & 5.14 & 4.37 & 0 & 25 \\
\hline
\end{tabular}

Reported differences in trip-making and mode choice are summarized in Figure 2. NTD residents make more internal trips, and of those a high percentage are by non-motorized travel modes. Consistent with prior research, a considerable percentage $(33.6 \%)$ of internal trips in NTDs is by car. For typical suburban neighborhoods, there was a higher-than-expected number of internal trips, and a high percentage of those internal trips were taken by car $(83 \%)$. 


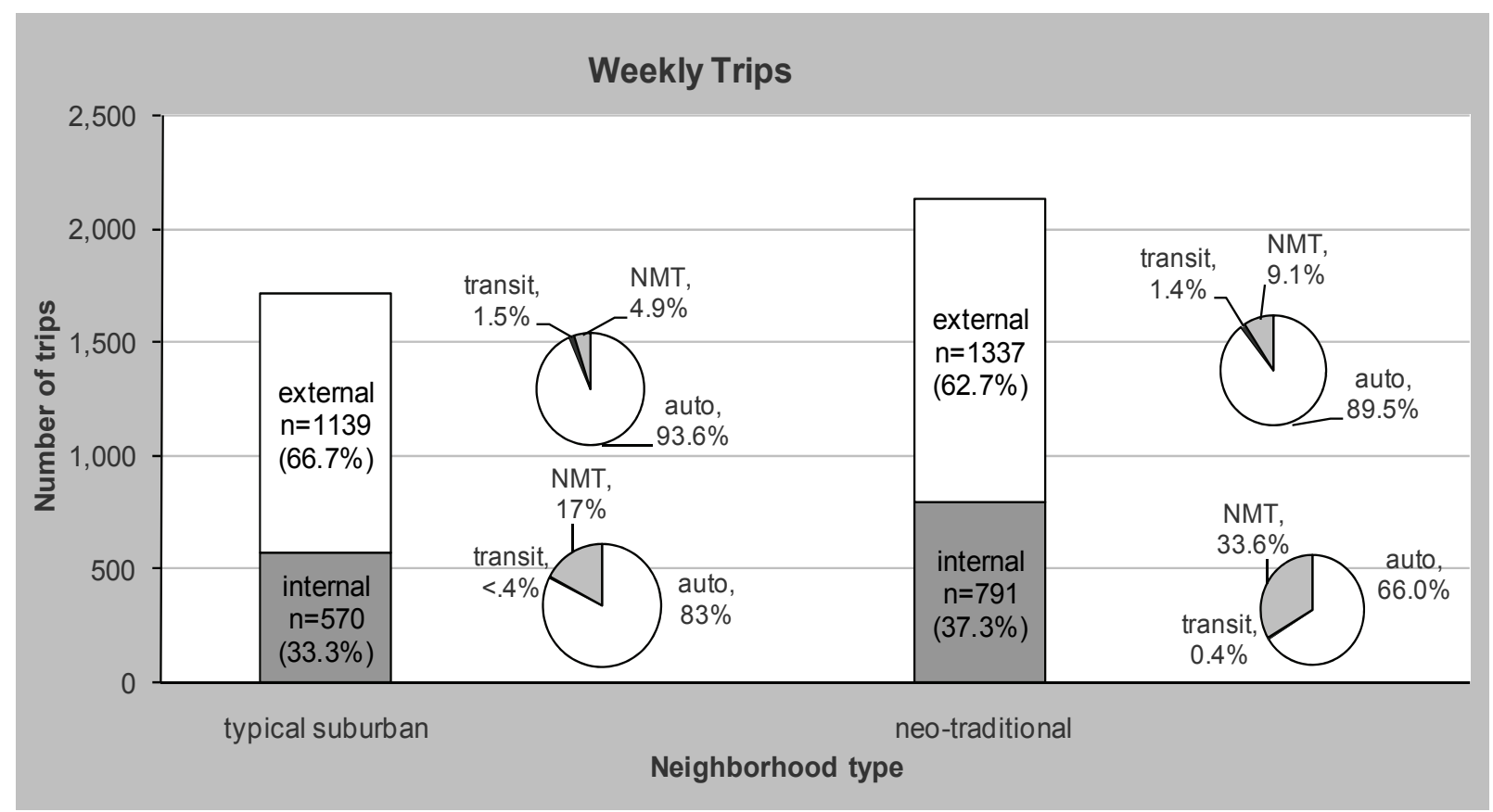

Figure 2. Weekly internal and external trips by mode and neighborhood type

Part of the difference in non-motorized trip-making is the result of variations in each pair. In most cases, NTD residents made substantially more non-motorized trips than residents of the typical suburban match. But there are several exceptions in which the opposite occurred, as shown in Figure 3.

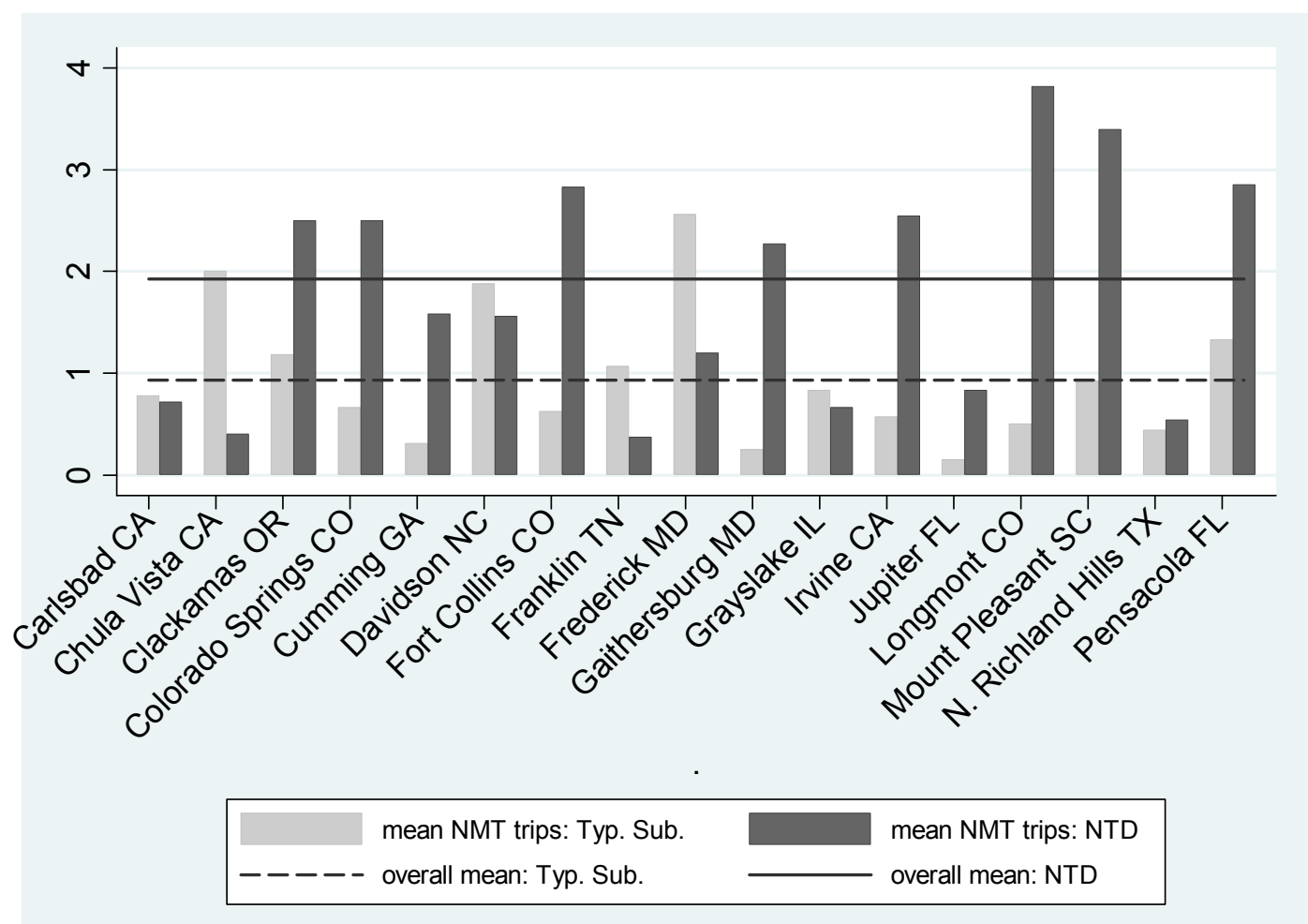

Figure 3. Average weekly non-motorized trips by neighborhood pair 


\section{Socio-demographic characteristics of respondents}

While we strove to control for socio-demographic factors when selecting study neighborhoods, socio-demographic differences at the individual level remained, even within pairings. To determine which factors were therefore necessary to control for statistically, we conducted bivariate tests of significant difference between neighborhood types. The following variables were significantly different and therefore likely to confound our subsequent modeling efforts: sex, household size, presence of children, home type (detached single-family/town home vs. multifamily apartment/condo), and tenure in the home. While race (white/non-white) was not significantly different between neighborhood types, in the absence of income race becomes an important covariate to include. Table 7 shows descriptive statistics and differences in sociodemographics by neighborhood type for all respondents. 


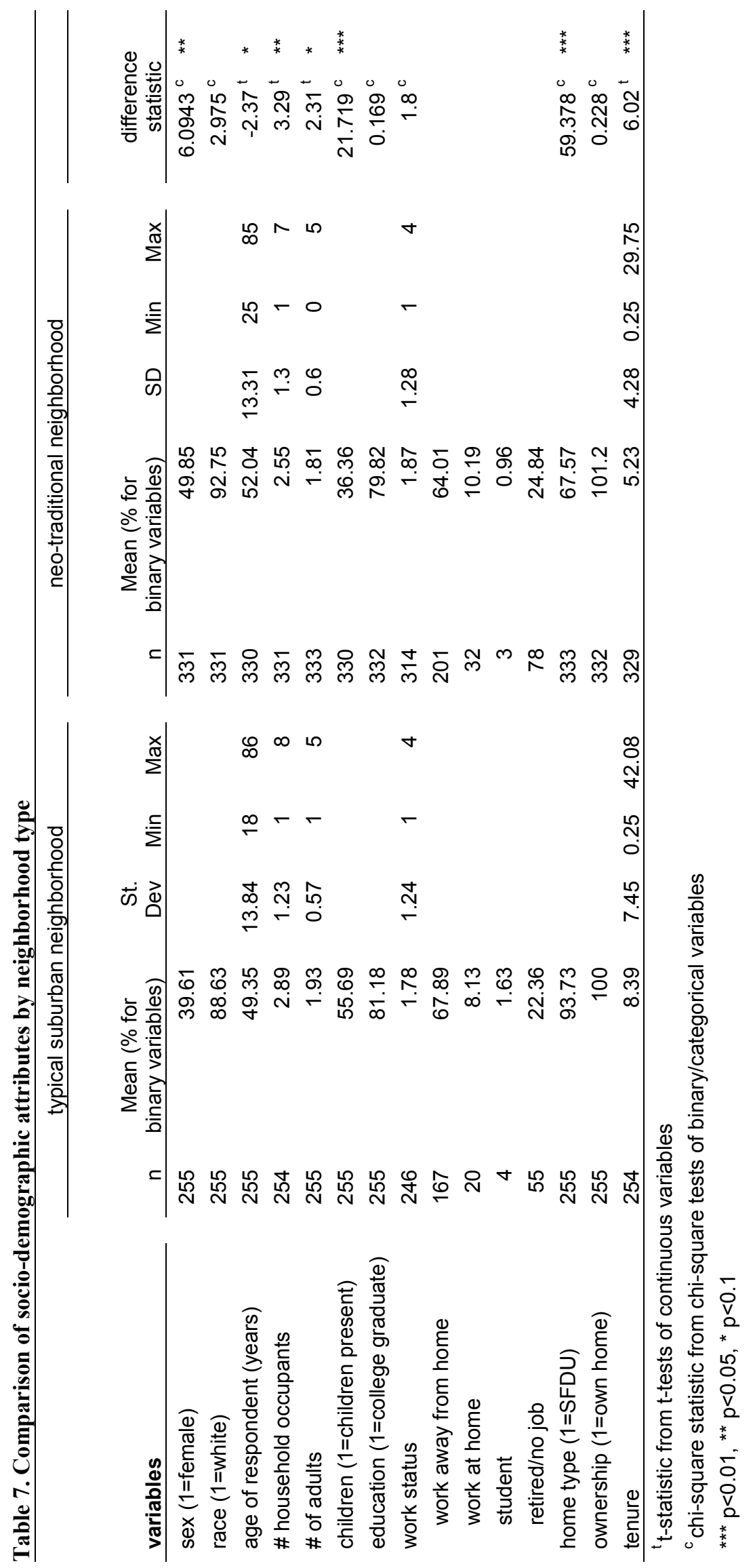




\section{Associations between neighborhood type and social capital}

\section{$\underline{\text { Bivariate Analyses }}$}

\section{Unadjusted Differences in Social Capital by Neighborhood Type}

The t-test results indicate that social capital and cohesion vary significantly between typical suburban and neo-traditional neighborhoods (Table 8). For the social cohesion and trust index, NTD residents had scores that were $4 \%$ higher on average then residents of typical suburban neighborhoods $(\mathrm{p}=0.008)$. NTD residents also reported higher levels of intergenerational closure. However, the difference between the groups was small and at the edge of statistical significance $(p=0.057)$. Overall, NTD residents have slightly higher mean social capital scores than residents of typical suburban neighborhoods.

\section{Adjusted Differences in Social Capital by Neighborhood Type}

Controlling for the demographic characteristics of respondents eliminated differences in levels of social capital between typical suburban and neo-traditional neighborhoods. This finding was robust to the method of adjusting for demographic differences. For example, Tobit and logit models, as well as matching methods, all showed no statistically significant difference between the two groups in reported levels of social capital.

In each regression approach, race and age are the most consistently significant covariates. Mean scores in each index are higher for whites and older individuals but lower for one-adult households. Other findings of interest include the lack of a significant relationship between the presence of children in the household and reciprocated exchange scores and the negative relationship between tenure in the neighborhood and social capital scores. 


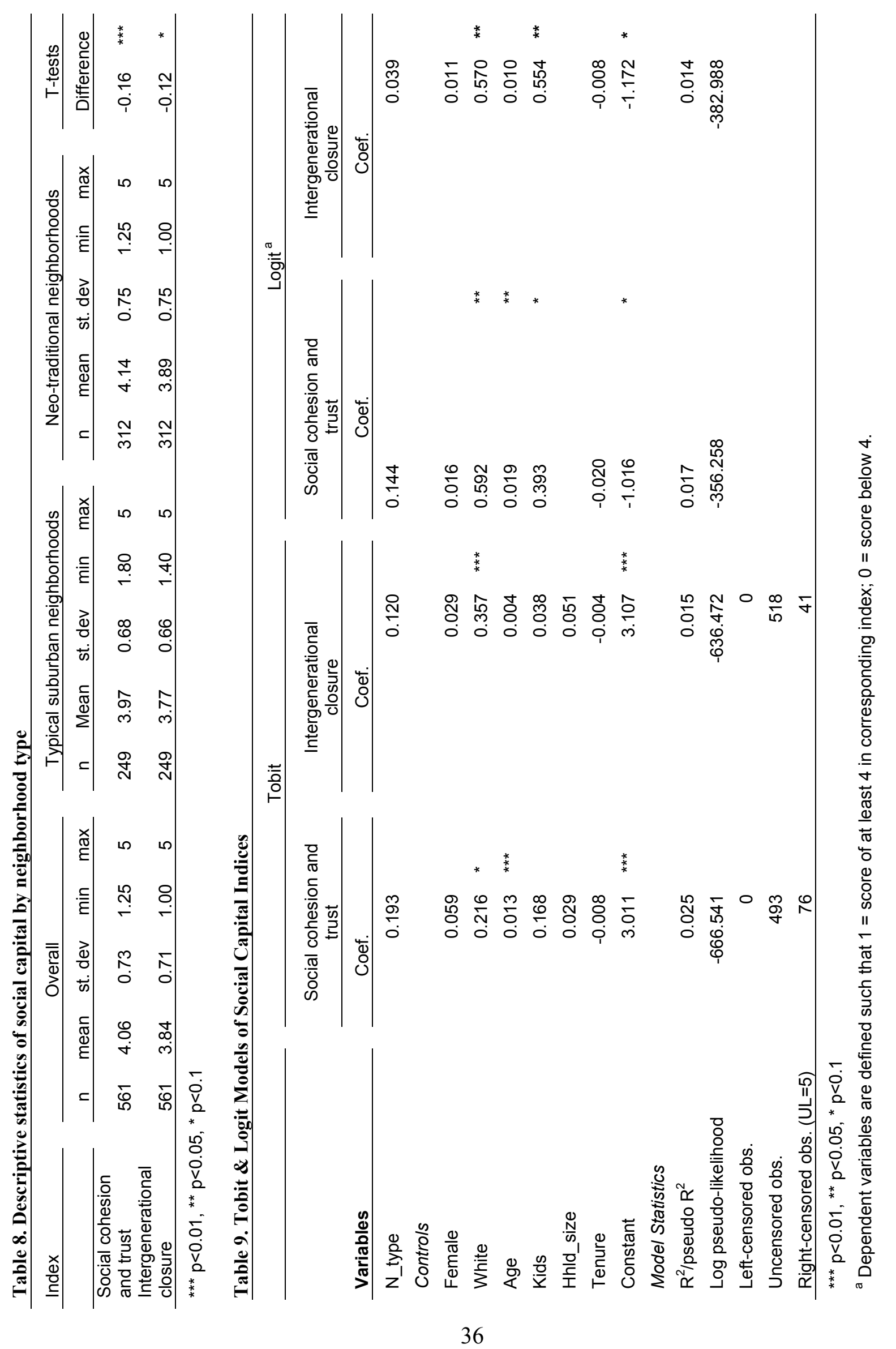


Table 10. Average Differences in Social Capital by Neighborhood Type: Matching Methods

Social cohesion and trust Intergenerational closure

\begin{tabular}{lll} 
Adjusted Average Difference & 0.102 & 0.107 \\
p-value & 0.169 & 0.200 \\
\hline
\end{tabular}

Models control for age, tenure, sex, race, and presence of children in the household

\section{Associations between neighborhood type and travel behavior}

$\underline{\text { Bivariate Analyses }}$

Vehicle use

Though residents of typical suburban neighborhoods drove more, on average, than NTD residents, t-tests shows no significant difference in previous year's mileage between the two neighborhood types, as shown in Table 11.

Table 11. Vehicle-use descriptive statistics by neighborhood type

\begin{tabular}{|c|c|c|c|c|c|c|c|c|c|c|}
\hline \multirow[b]{2}{*}{ Variables } & \multicolumn{4}{|c|}{ typical suburban $(n=145)$} & \multicolumn{4}{|c|}{ neo-traditional $(n=165)$} & & \\
\hline & Mean & SD & Min & Max & Mean & SD & Min & Max & t-statistic & \\
\hline Mileage (thousands) & 23.78 & 13.09 & 0.012 & 82 & 21.27 & 13.26 & 0 & 92 & 1.674 & $*$ \\
\hline $\begin{array}{l}\text { Transformed } \\
\text { mileage (sq. root) }\end{array}$ & 148.43 & 42.01 & 3.46 & 286.36 & 139.28 & 43.42 & 0 & 303.32 & 1.884 & $*$ \\
\hline
\end{tabular}

${ }^{* * *} p<0.01,{ }^{* *} p<0.05,{ }^{*} p<0.1$

Trip-making

In all four trip categories examined - total trips, auto trips, non-motorized trips, and internal trips - NTD residents made more trips than their counterparts in typical suburban neighborhoods. However, the difference in trip frequencies is only significant for non-motorized and internal trips, with NTD residents making approximately $15 \%$ and $20 \%$ more trips, respectively, than residents of typical suburban neighborhoods. Table 12 shows summary statistics for each trip category by neighborhood type and a t-test to identify difference (without adjusting for clustering at neighborhood-pair level). 
Table 12. Trip-making descriptive statistics by neighborhood type

\begin{tabular}{|c|c|c|c|c|c|c|c|c|c|c|}
\hline \multirow[b]{2}{*}{ Variables } & \multicolumn{4}{|c|}{ typical suburban $(n=165)$} & \multicolumn{4}{|c|}{ neo-traditional $(n=192)$} & & \\
\hline & Mean & SD & Min & Max & Mean & SD & Min & Max & \multicolumn{2}{|c|}{ t-statistic } \\
\hline total trips & 13.818 & 5.61 & 2 & 38 & 14.97 & 6.41 & 3 & 37 & -1.825 & * \\
\hline auto trips & 9.309 & 4.35 & 0 & 28 & 8.917 & 4.34 & 2 & 24 & 0.850 & \\
\hline non-motorized trips & 0.933 & 1.63 & 0 & 8 & 1.979 & 2.72 & 0 & 14 & -4.474 & $* * *$ \\
\hline internal trips & 4.606 & 4.08 & 0 & 18 & 5.614 & 4.57 & 0 & 25 & -2.168 & ** \\
\hline
\end{tabular}

${ }^{* * *} p<0.01,{ }^{* *} p<0.05,{ }^{*} p<0.1$

\section{$\underline{\text { Base Models }}$}

The first set of multivariate regression models we present are base models, with neighborhood type (N_type) as the primary explanatory variable. In these and all subsequent models, we control for socio-demographic factors race (white), sex (female), and the presence of children in the household (kids). ${ }^{2}$ Results for these models are presented in the columns labeled "Base Model" of Tables 12 - 16.

\section{Vehicle use}

As in the bivariate model, the difference in vehicle mileage between neighborhood types remains insignificant at the 0.05 level when socio-demographic controls are added to the model (see base model column, Table 12).

\section{Trip-making}

The relationships between neighborhood type and total, non-motorized, and internal trip frequency are strengthened once socio-demographic factors are included. NTD residents make approximately $13 \%$ more trips overall, $27 \%$ more internal trips, and over twice as many nonmotorized trips as residents of typical suburban neighborhoods. As in the bivariate model, there is no statistically significant difference in automobile trip frequency between the two neighborhood types (see base model columns in Table 14 - Table 17).

\section{$\underline{\text { Built-environment Regression Models }}$}

We present two expanded regression models for each of our travel behavior outcome measures. In the first, we replace the N_type variable with seven variables representing different aspects of the built environment; in the second, we include the N_type variable along with the builtenvironment variables. The purpose of these two models is to determine whether any apparent relationships between neighborhood type and travel behavior can be explained by differences in the built environment, or if neighborhood type itself has an intrinsic relationship with travel behavior. The built-environment variables we examine are external connection density (ext_conn), link-to-node ratio (lnr; multiplied by 10 to improve interpretability), net singlefamily residential density (SFdens), percent of the neighborhood's developable area that is

\footnotetext{
${ }^{2}$ The other socio-demographic factors that differed significantly between neighborhood types were household size, home type, and tenure in the home. However, these variables were insignificant in all of our travel behavior models, and Wald tests indicated that they did not add sufficient explanatory power to the models to justify their inclusion. In the interest of parsimony, we leave them out of the travel behavior models presented here.
} 
vacant (pctvacant; divided by 10 to improve interpretability), acres of commercial area in the neighborhood (commarea; divided by 10), and regional setting (greenfield), all measured at the neighborhood level. We also include our one household-level, built-environment variable, the Walk Score.

\section{Vehicle use}

Only one built environment variable - Walk Score - is a significant predictor of vehicle use, and its effect is very weak. Far and away the best predictor of vehicle use is the presence of children in the household (households with children drove approximately 500 more miles in the previous year than households without children), followed by the respondent's sex (women reported about 60 fewer miles than men). The neighborhood-type variable is not significant (Table 12, model 1 column).

Table 13. OLS regression models of vehicle mileage

\begin{tabular}{|c|c|c|c|c|c|c|}
\hline Variables & \multicolumn{2}{|c|}{ Base Model } & \multicolumn{2}{|c|}{ Model 1} & \multicolumn{2}{|c|}{ Model 2} \\
\hline N_type & -3.498 & & & & 8.339 & \\
\hline \multicolumn{7}{|l|}{ Controls } \\
\hline White & 3.114 & & -4.928 & & -6.585 & \\
\hline Female & -7.363 & $* *$ & -7.678 & $* *$ & -7.708 & $* *$ \\
\hline Kids & 23.48 & $* * *$ & 22.76 & $* * *$ & 23.54 & $* * *$ \\
\hline \multicolumn{7}{|c|}{ Built-Environment Attributes } \\
\hline ext_conn & & & -0.582 & & -0.839 & \\
\hline Lnr & & & -14.74 & & -26.77 & \\
\hline SFdens & & & 1.222 & & 0.275 & \\
\hline pctvacant & & & 0.243 & & 0.250 & \\
\hline commarea & & & -0.214 & * & -0.262 & $* * *$ \\
\hline Walk Score & & & -0.333 & $* * *$ & -0.312 & $* * *$ \\
\hline greenfield & & & 5.233 & & 5.559 & \\
\hline Constant & 134 & $* * *$ & 160.7 & $* * *$ & 178.6 & $* * *$ \\
\hline \multicolumn{7}{|c|}{ Model Statistics } \\
\hline Observations & 310 & & 310 & & 310 & \\
\hline R-squared & 0.095 & & 0.150 & & 0.154 & \\
\hline
\end{tabular}

${ }^{* * *} p<0.01,{ }^{* *} p<0.05,{ }^{*} p<0.1$

\section{Trip-making}

\section{Total trips}

In the models with built-environment factors only (neighborhood type not included as an explanatory variable), three features of the built environment are significant predictors of total trips, though their effects are small: external connection density, commercial area, and Walk Score. The direction of the relationships between total trips and external connectivity and total trips and commercial area is negative, opposite of what we hypothesized.

Adding the neighborhood-type variable back into the model does not substantially affect the coefficients on the built-environment variables, though neighborhood type is itself significant: 
holding built-environment and socio-demographic factors constant, NTD residents still make approximately $24 \%$ more total trips than residents of typical suburban neighborhoods.

Table 14. Count regression models of Total Trips

\begin{tabular}{|c|c|c|c|c|c|c|c|c|c|}
\hline \multirow[b]{2}{*}{ Variables } & \multicolumn{3}{|c|}{ Base Model } & \multicolumn{3}{|c|}{ Model 1} & \multicolumn{3}{|c|}{ Model 2} \\
\hline & \multicolumn{2}{|l|}{ Coef. } & IRR & \multicolumn{2}{|l|}{ Coef. } & \multirow[t]{2}{*}{ IRR } & \multicolumn{2}{|l|}{ Coef. } & \multirow{2}{*}{$\begin{array}{l}\text { IRR } \\
1.242\end{array}$} \\
\hline N_type & 0.122 & $* * *$ & 1.130 & & & & 0.217 & $* \star *$ & \\
\hline \multicolumn{10}{|l|}{ Controls } \\
\hline White & -0.299 & $* * *$ & 0.742 & -0.281 & ** & 0.755 & -0.299 & $* * *$ & 0.742 \\
\hline Female & 0.087 & *** & 1.090 & 0.101 & $* * *$ & 1.106 & 0.099 & $* * *$ & 1.104 \\
\hline Kids & 0.156 & $* * *$ & 1.169 & 0.147 & $* * *$ & 1.158 & 0.162 & $* * *$ & 1.176 \\
\hline \multicolumn{10}{|c|}{ Built-Environment Attributes } \\
\hline ext_conn & & & & -0.044 & $* * *$ & 0.957 & -0.049 & $* * *$ & 0.953 \\
\hline Lnr & & & & 0.009 & & 1.009 & -0.021 & & 0.979 \\
\hline SFdens & & & & 0.011 & & 1.011 & -0.015 & & 0.985 \\
\hline pctvacant & & & & 0.002 & & 1.002 & 0.002 & & 1.002 \\
\hline commarea & & & & -0.014 & $* * *$ & 0.986 & 0.026 & $* * *$ & 1.026 \\
\hline Walk Score & & & & 0.030 & $* *$ & 1.030 & 0.035 & $* * *$ & 1.036 \\
\hline greenfield & & & & -0.003 & & 0.997 & 0.007 & & 1.007 \\
\hline Constant & 2.753 & *** & & 2.577 & *** & & 3.007 & $* * *$ & \\
\hline \multicolumn{10}{|l|}{ Model Statistics } \\
\hline Observations & 357 & & & 357 & & & 357 & & \\
\hline Log pseudo-likelihood & 1105.146 & & & 1103.366 & & & 1098.505 & & \\
\hline$P($ alpha $) \sim=0$ & 0.000 & & & 0.000 & & & 0.000 & & \\
\hline
\end{tabular}

${ }^{* * *} p<0.01,{ }^{* *} p<0.05,{ }^{*} p<0.1$

\section{Auto trips}

Like in the total trips models, external connection density, commercial area, and Walk Score are significant, though relatively weak, predictors of auto trip frequency. Again, the signs on external connection density and commercial area are negative, opposite of what we hypothesized. In addition, the coefficient on percent of the neighborhood that is vacant (not including open space or parks) is also significant and positive, but small.

When we include the neighborhood-type variable along with the built-environment features, the coefficient on neighborhood becomes significant, but in the opposite direction of what we found in the bivariate analyses. Controlling for built-environment variables and socio-demographics, NTD residents make $17 \%$ more auto trips than residents of typical suburban neighborhoods.

Interestingly, when neighborhood type is included in the auto trip-frequency model, an additional built-environment variable becomes significant (single-family residential density), though the effects of all the built-environment factors remain relatively weak compared to the effect of neighborhood type. 
Table 15. Count regression models of Automobile Trips

\begin{tabular}{|c|c|c|c|c|c|c|c|c|c|}
\hline \multirow[b]{2}{*}{ Variables } & \multicolumn{3}{|c|}{ Base Model } & \multicolumn{3}{|c|}{ Model 1} & \multicolumn{3}{|c|}{ Model 2} \\
\hline & \multicolumn{2}{|l|}{ Coef. } & \multirow{2}{*}{$\begin{array}{l}\text { IRR } \\
1.009\end{array}$} & \multicolumn{2}{|l|}{ Coef. } & \multirow[t]{2}{*}{ IRR } & \multicolumn{2}{|l|}{ Coef. } & \multirow{2}{*}{$\begin{array}{l}\text { IRR } \\
1.172\end{array}$} \\
\hline N_type & 0.009 & & & & & & 0.159 & ** & \\
\hline \multicolumn{10}{|l|}{ Controls } \\
\hline White & -0.319 & $* *$ & 0.727 & -0.315 & $* * *$ & 0.730 & -0.326 & $* * *$ & 0.722 \\
\hline Female & 0.113 & $* * *$ & 1.120 & 0.135 & $* * *$ & 1.145 & 0.133 & $* * *$ & 1.142 \\
\hline Kids & 0.224 & $* * *$ & 1.251 & 0.217 & $* * *$ & 1.242 & 0.229 & $* * *$ & 1.257 \\
\hline \multicolumn{10}{|c|}{ Built-Environment Attributes } \\
\hline ext_conn & & & & -0.068 & $* * *$ & 0.934 & -0.071 & $* * *$ & 0.932 \\
\hline Lnr & & & & -0.001 & & 0.999 & -0.023 & & 0.977 \\
\hline SFdens & & & & -0.006 & & 0.994 & -0.025 & ** & 0.975 \\
\hline pctvacant & & & & 0.004 & ** & 1.004 & 0.004 & $* *$ & 1.004 \\
\hline commarea & & & & -0.031 & $* * *$ & 1.031 & -0.039 & $* * *$ & 0.962 \\
\hline Walk Score & & & & 0.033 & $* * *$ & 0.968 & 0.037 & $* * *$ & 1.038 \\
\hline greenfield & & & & -0.056 & * & 0.946 & -0.048 & & 0.953 \\
\hline Constant & 2.320 & $* * *$ & & 2.385 & $* * *$ & & 2.700 & $* * *$ & \\
\hline \multicolumn{10}{|l|}{ Model Statistics } \\
\hline Observations & 357 & & & 357 & & & 357 & & \\
\hline Log pseudo-likelihood & -980.549 & & & -973.389 & & & -971.298 & & \\
\hline $\mathrm{P}($ alpha $) \sim=0$ & 0.000 & & & 0.000 & & & 0.000 & & \\
\hline
\end{tabular}

${ }^{* * *} p<0.01,{ }^{* *} p<0.05,{ }^{*} p<0.1$

\section{Non-motorized trips}

Five of our built environment factors are significant predictors of non-motorized trips: external connection density, internal connectivity (link-node ratio), percent vacant area, commercial area, and whether or not the neighborhood is in a greenfield setting. The effects of the first four are substantial, and the directions are consistent with our hypotheses. The effect of being in a greenfield is positive; holding all other built-environment factors and socio-demographic factors constant, greenfield residents make over two and a half times more non-motorized trips than residents of infill neighborhoods, perhaps due to the limited presence of destinations outside the neighborhood that can be accessed by walking or bicycling. Interestingly, the coefficient on Walk Score, a measure intended to capture access to destinations within walking distance, is not significant in this model.

When the neighborhood type variable is added into the model, it is not significant when controlling for built-environment factors, in contrast to what we hypothesized. With the exception of internal connectivity (which becomes insignificant with the addition of the neighborhood-type variable), the coefficients on the built-environment variables are unchanged. 
Table 16. Count regression models of Non-motorized Trips

\begin{tabular}{|c|c|c|c|c|c|c|c|c|c|}
\hline \multirow[b]{2}{*}{ Variables } & \multicolumn{3}{|c|}{ Base Model } & \multicolumn{3}{|c|}{ Model 1} & \multicolumn{3}{|c|}{ Model 2} \\
\hline & \multicolumn{2}{|l|}{ Coef. } & IRR & \multicolumn{2}{|c|}{ Coef. } & \multirow[t]{2}{*}{ IRR } & \multicolumn{2}{|c|}{ Coef. } & \multirow{2}{*}{$\begin{array}{l}\text { IRR } \\
1.278\end{array}$} \\
\hline N_type & 0.785 & $* * *$ & 2.192 & & & & 0.245 & & \\
\hline \multicolumn{10}{|l|}{ Controls } \\
\hline White & -0.220 & & 0.803 & -0.082 & & 0.921 & -0.125 & & 0.882 \\
\hline Female & 0.065 & & 1.067 & 0.0185 & & 1.019 & 0.019 & & 1.019 \\
\hline Kids & 0.082 & & 1.085 & -0.003 & & 0.997 & 0.018 & & 1.018 \\
\hline \multicolumn{10}{|c|}{ Built-Environment Attributes } \\
\hline ext_conn & & & & 0.205 & $* * *$ & 1.228 & 0.200 & $* * *$ & 1.221 \\
\hline Lnr & & & & 0.139 & $* * *$ & 1.149 & 0.108 & & 1.114 \\
\hline SFdens & & & & 0.000 & & 1.000 & -0.026 & & 0.974 \\
\hline pctvacant & & & & -0.021 & $* * *$ & 0.979 & -0.021 & $* * *$ & 0.979 \\
\hline commarea & & & & 0.162 & $* * *$ & 1.176 & 0.143 & $* * *$ & 1.154 \\
\hline Walk Score & & & & 0.065 & & 1.067 & 0.065 & & 1.067 \\
\hline greenfield & & & & 0.956 & $* * *$ & 2.601 & 0.957 & $* * *$ & 2.604 \\
\hline Constant & 0.0397 & & & -2.791 & $* * *$ & & -2.303 & ** & \\
\hline \multicolumn{10}{|l|}{ Model Statistics } \\
\hline Observations & 357 & & & 357 & & & 357 & & \\
\hline Log pseudo-likelihood & -566.804 & & & -558.608 & & & -558.318 & & \\
\hline$P($ alpha $) \sim=0$ & 0.000 & & & 0.000 & & & 0.000 & & \\
\hline
\end{tabular}

${ }^{* * *} p<0.01,{ }^{* *} p<0.05,{ }^{*} p<0.1$

\section{Internal trips}

For internal trips, we expect to find that larger commercial areas are strongly associated with greater internal trip-capture. Unexpectedly, none of the built-environment factors is significant unless neighborhood type is included as a covariate. Furthermore, the built-environment variables that we expected to find significant - external connectivity and commercial area - are not significant. Only internal connectivity and Walk Score are significant: an increase of 0.1 on the link-to-node ratio yields a 9\% decrease in internal trips and a 10-point increase in the Walk Score yields a 10\% increase in internal trips. Meanwhile, the effect of neighborhood type on internal trips, controlling for the built environment and socio-demographics, is quite large: NTD residents make nearly $80 \%$ more internal trips than residents of typical suburban neighborhoods. 
Table 17. Count regression models of Internal Trips

\begin{tabular}{|c|c|c|c|c|c|c|c|c|c|}
\hline \multirow[b]{2}{*}{ Variables } & \multicolumn{3}{|c|}{ Base Model } & \multicolumn{3}{|c|}{ Model 1} & \multicolumn{3}{|c|}{ Model 2} \\
\hline & \multicolumn{2}{|l|}{ Coef. } & \multirow{2}{*}{$\begin{array}{l}\text { IRR } \\
1.278\end{array}$} & \multicolumn{2}{|l|}{ Coef. } & \multirow[t]{2}{*}{ IRR } & \multicolumn{2}{|l|}{ Coef. } & \multirow{2}{*}{$\begin{array}{l}\text { IRR } \\
1.777\end{array}$} \\
\hline N_type & 0.245 & $* * *$ & & & & & 0.575 & $* * *$ & \\
\hline \multicolumn{10}{|l|}{ Controls } \\
\hline White & -0.579 & $* * *$ & 0.560 & -0.543 & ** & 0.581 & -0.579 & $* * *$ & 0.560 \\
\hline Female & 0.127 & & 1.135 & 0.170 & & 1.185 & 0.163 & & 1.177 \\
\hline Kids & 0.132 & & 1.141 & 0.058 & & 1.060 & 0.075 & & 1.078 \\
\hline \multicolumn{10}{|c|}{ Built-Environment Attributes } \\
\hline ext_conn & & & & -0.070 & & 0.932 & -0.0764 & & 0.926 \\
\hline Lnr & & & & -0.011 & & 0.989 & -0.092 & $* * *$ & 0.912 \\
\hline SFdens & & & & 0.009 & & 1.009 & -0.064 & & 0.938 \\
\hline pctvacant & & & & 0.000 & & 1.000 & -0.001 & & 0.999 \\
\hline commarea & & & & 0.022 & & 1.022 & -0.013 & & 0.987 \\
\hline Walk Score & & & & 0.085 & * & 1.089 & 0.101 & ** & 1.106 \\
\hline greenfield & & & & 0.038 & & 1.039 & 0.073 & & 1.076 \\
\hline Constant & 1.885 & $* * *$ & & 1.910 & $* * *$ & & 3.075 & $* * *$ & \\
\hline \multicolumn{10}{|l|}{ Model Statistics } \\
\hline Observations & 357 & & & 357 & & & 357 & & \\
\hline Log pseudo-likelihood & -961.646 & & & -983.506 & & & -979.238 & & \\
\hline$P($ alpha $) \sim=0$ & 0.000 & & & 0.000 & & & 0.000 & & \\
\hline
\end{tabular}

\section{Associations between neighborhood type and environmental attitude}

The number of cases with complete data for all attitude and preference questions is 603 . The five items measuring environmental attitudes appear to work well at capturing the latent factor. The cronbach's alpha based on standardized items is 0.79 , indicating a good internal consistency.

The t-test shows that respondents from neo-traditional neighborhoods reported higher scores for overall environmental attitude, measured as the average scores of the five items considered. Among the five component items, statistically significant mean differences exist for three items. Compared to their counterparts in the traditional suburban neighborhoods, NTD residents reported higher levels of agreement with the statements concerning land consumption, automobile-induced energy consumption, and government actions.

For travel modes, NTD residents had a slightly higher preference for walking or bicycling. The average scores for both groups were above four and the variations in the answers were small. These findings indicate consistency in people's preference for walking or bicycling. Both groups reported uneasiness in riding buses. Both average scores were below three for both groups, meaning people on average did not agree with the statement, "I am comfortable riding the bus." And they were not statistically different. For residential preference, the neo-traditional group reported distinctively greater preference or tolerance for higher density and land-use mix.

The order of importance that people assigned to 14 elements in their location evaluative criteria showed similarity and difference for respondents between the two neighborhood types. The 
similarity was that all respondents gave lowest priority to access to public transportation. Quality of house was ranked the second most important for respondents from the two neighborhood types.

The striking difference was the importance of having environmental conditions that support walking. For NTD residents, "Ease of walking" in the neighborhood was the sixth most important factor, compared to 13th for the traditional suburban residents. Neighborhood design was the most important factor for the NTD residents, and the fourth most important for those living in typical suburban neighborhoods.

Not surprisingly, NTD residents, who on average reported greater toleration toward higher density, placed lower levels of importance on lot size. They placed higher importance on being close to shops and services, consistent with their preference for better accessibility. Interestingly, both groups appeared to downplay importance of having good proximity to schools or jobs. The neo-traditional group ranked this factor the 13th most important, only more important than having good access to public transportation. 


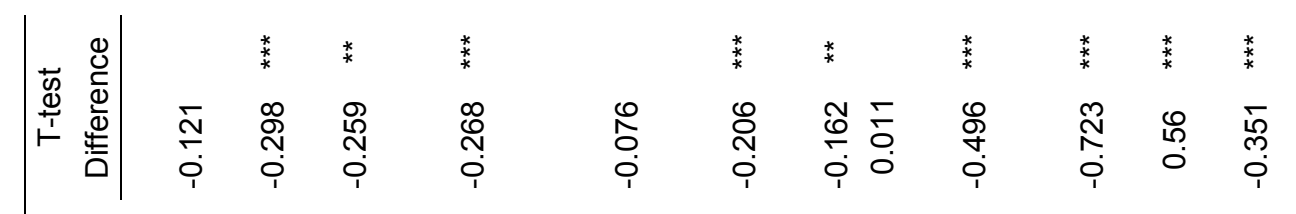

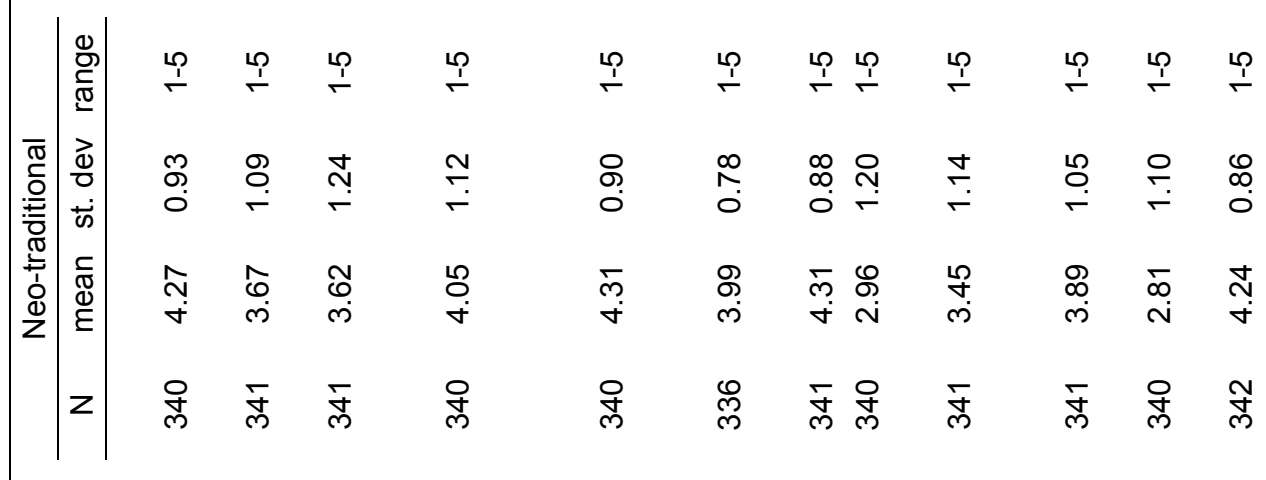

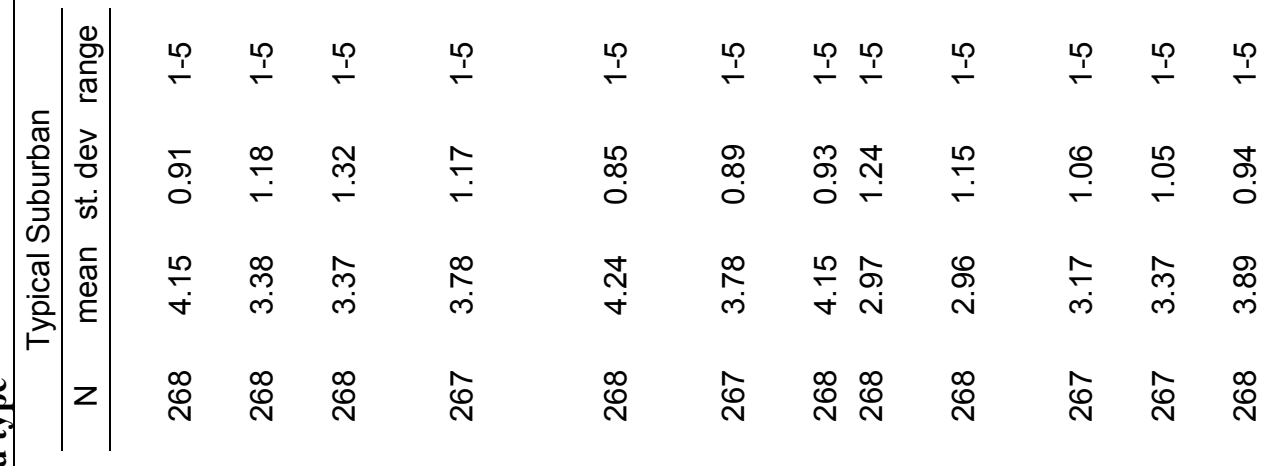

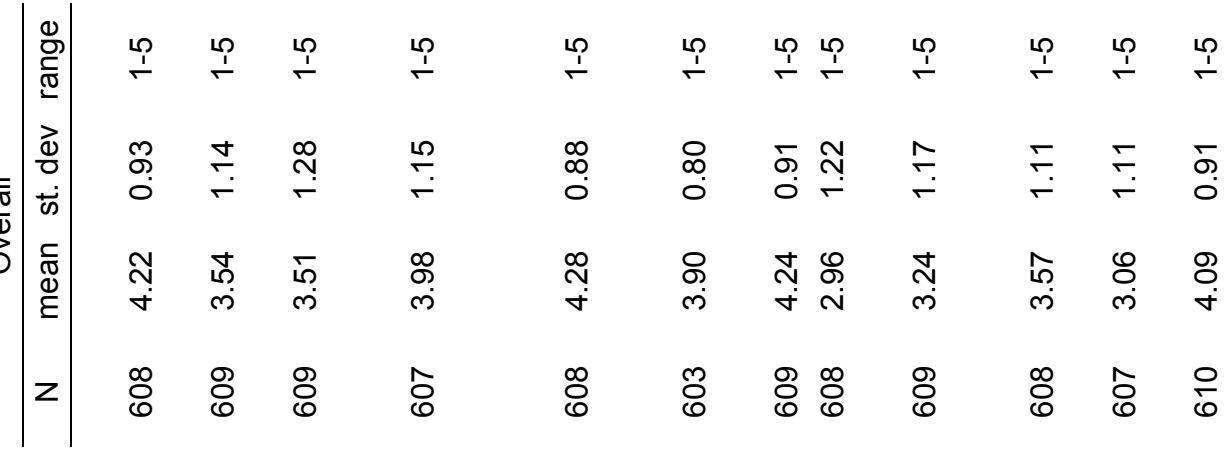

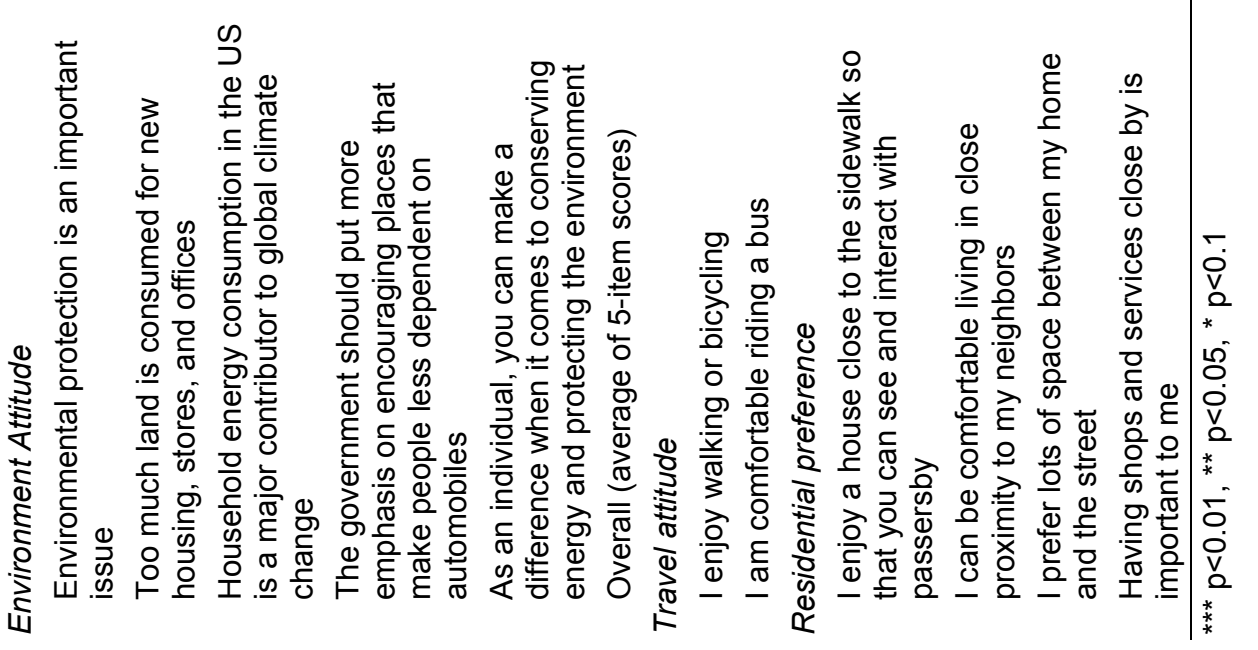




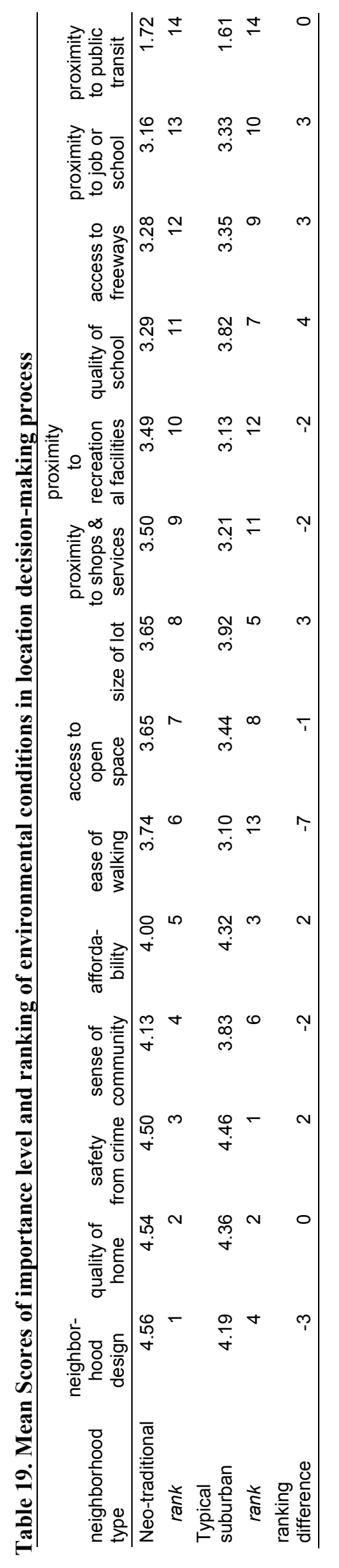




\section{Disparities in physical activity and obesity}

NTD respondents differed in their demographics from the typical suburban respondents (Table 20). The NTD respondents were more likely to have higher incomes than their typical suburban counterparts (30\% versus 19\%, respectively, had incomes over $\$ 150,000)$, though they had comparable educational levels. NTD respondents were also more likely to be older and white than respondents in typical suburban neighborhoods.

Overall, the majority of the sample did not meet recommended physical activity levels, and over half $(55 \%)$ were categorized as overweight or obese (Table 21$)$. One quarter $(24 \%)$ met recommended moderate physical activity levels (150 minutes of moderate or vigorous activity per week), while only $16 \%$ met the requirements for vigorous physical activity ( 75 minutes of vigorous activity per week).

There were no significant differences in physical activity or weight status based upon race/ethnicity or income level in the sample (Table 20). Furthermore, with one exception, neighborhood type was not related to how much physical activity respondents had or to whether or not they were overweight or obese. The relationship between neighborhood type and the outcome variables was examined for all respondents, for white and non-white respondents separately, and for higher- and lower-income respondents separately. Among lower-income respondents, those residing in neo-traditional neighborhoods were significantly more likely to meet the recommendations for vigorous physical activity ( $26 \%$ compared to $12 \%$ of typical suburban respondents). The same pattern was observed for moderate physical activity, but it did not reach levels of statistical significance.

In multivariate logistic regression models, neither neighborhood type, race/ethnicity nor income was predictive of the physical activity and weight outcomes (Table 22). Interestingly, gender was related to the outcomes, but inconsistently. While women were less likely to meet the physical activity recommendations then men, they were substantially less likely to be overweight or obese $(\mathrm{OR}=.25)$. Older age was also associated with less physical activity and higher weight.

Multivariate logistic regression models were developed for subsets of the respondents. They examined the relationship between residing in neo-traditional neighborhoods relative to typical suburbs separately for whites, non-whites, lower-income and higher-income residents. Consistent with the bivariate findings presented in Table 21, lower-income respondents residing in a neotraditional neighborhood were significantly more likely to meet the vigorous physical activity recommendations than were those in typical suburbs (Table 23). Neighborhood type had no relationship to the physical activity and weight outcomes in analyses that focused separately on higher-income white and non-white respondents.

Table 20. Demographic Characteristics by Neighborhood Type

\begin{tabular}{|lccc|}
\hline & $\begin{array}{c}\text { All } \\
\text { Respondents } \\
\text { Percent } \\
(\mathrm{n}=621)\end{array}$ & $\begin{array}{c}\text { Neo-traditional } \\
\text { Residents } \\
\text { Percent } \\
(\mathrm{n}=346)\end{array}$ & $\begin{array}{c}\text { Typical suburban } \\
\text { Residents } \\
\text { Percent } \\
(\mathrm{n}=275)\end{array}$ \\
\hline Race/Ethnicity & & & \\
White & 89.2 & 91.6 & $86.2^{*}$ \\
Non-white & 10.8 & 8.4 & 13.8 \\
\hline
\end{tabular}




\begin{tabular}{llll} 
Income & & & \\
$\$ 80,000$ or less & 28.7 & 27.3 & $30.3^{* *}$ \\
$\$ 80,001-\$ 150,000$ & 46.3 & 42.3 & 51.1 \\
More than $\$ 150,000$ & 25.0 & 30.3 & 18.6 \\
Age & & & \\
40 or younger & 28.2 & 24.9 & $32.4^{* *}$ \\
$41-50$ & 22.2 & 19.6 & 25.5 \\
$51-60$ & 24.6 & 29.5 & 18.5 \\
61 and older & 25.0 & 26.0 & 23.6 \\
& & & \\
Education & & 20.3 & 20.4 \\
High school degree or less & 20.4 & 45.9 & 44.0 \\
College degree & 45.1 & 33.7 & 35.6 \\
Graduate or professional & 34.6 & & \\
degree & & & \\
& & 49.6 & $39.6^{*}$ \\
Gender & & 50.4 & 60.4 \\
Female & & & \\
Male & 45.1 & & \\
\hline
\end{tabular}

${ }^{*} \mathrm{p}<.05 * * \mathrm{p}<.01$ 
Table 21. Physical Activity and Obesity Levels by Socio-demographic Group and Neighborhood Type

\begin{tabular}{|c|c|c|c|}
\hline \multirow[t]{2}{*}{ Physical Activity and Obesity } & \multicolumn{2}{|c|}{ Neighborhood Type } & \multirow[b]{2}{*}{$\begin{array}{c}\text { All } \\
\text { Respondents }\end{array}$} \\
\hline & Neo-Traditional & $\begin{array}{l}\text { Typical } \\
\text { Suburban }\end{array}$ & \\
\hline \multicolumn{4}{|l|}{ Physical Activity } \\
\hline \multirow{2}{*}{\multicolumn{4}{|c|}{$\begin{array}{l}\text { Recommended Moderate Physical } \\
\text { Activity }(\%)\end{array}$}} \\
\hline & & & \\
\hline All & 23.2 & 24.1 & 23.6 \\
\hline White & 23.9 & 23.4 & 23.7 \\
\hline Non-white & 16.0 & 28.6 & 23.3 \\
\hline Lower Income & 32.8 & 22.6 & 27.9 \\
\hline Higher Income & 18.3 & 22.1 & 20.0 \\
\hline \multirow{2}{*}{\multicolumn{4}{|c|}{$\begin{array}{l}\text { Recommended Vigorous Physical } \\
\text { Activity (\%) }\end{array}$}} \\
\hline & & & \\
\hline All & 17.3 & 15.0 & 16.3 \\
\hline White & 17.5 & 14.8 & 16.4 \\
\hline Non-white & 14.8 & 16.2 & 15.6 \\
\hline Lower Income & 25.7 & $12.3 *$ & 19.3 \\
\hline Higher Income & 13.9 & 16.0 & 14.8 \\
\hline \multicolumn{4}{|l|}{ Weight (\%) } \\
\hline \multicolumn{4}{|l|}{ Overweight or Obese } \\
\hline All & 52.8 & 57.4 & 54.9 \\
\hline White & 52.7 & 57.5 & 54.8 \\
\hline Non-white & 54.2 & 57.1 & 55.9 \\
\hline Lower Income & 46.4 & 54.8 & 50.4 \\
\hline Higher Income & 56.4 & 60.3 & 58.1 \\
\hline
\end{tabular}

${ }^{*} \mathrm{p}<.05$ for difference between neo-traditional and typical suburban.

Note: Recommended moderate physical activity is getting at least 150 minutes of either moderate or vigorous activity per week. Recommended vigorous physical activity is getting at least 75 minutes of vigorous activity, as outlined by the Department of Health and Human Services. Households making $\$ 80,000$ or less per year were considered lower income. 
Table 22. Odds Ratios from Logistic Regression Models for Physical Activity \& Obesity

\begin{tabular}{|c|c|c|c|}
\hline & $\begin{array}{l}\text { Moderate Physical } \\
\text { Activity }\end{array}$ & $\begin{array}{c}\text { Vigorous } \\
\text { Physical Activity }\end{array}$ & $\begin{array}{c}\text { Overweight or } \\
\text { Obese }\end{array}$ \\
\hline \multicolumn{4}{|l|}{ Neighborhood Type } \\
\hline Neo-traditional & 1.00 & 1.28 & 0.83 \\
\hline Typical Suburban & $(1.00)$ & $(1.00)$ & $(1.00)$ \\
\hline \multicolumn{4}{|l|}{ Race/Ethnicity } \\
\hline White & 0.93 & 0.80 & 0.90 \\
\hline Non-white & $(1.00)$ & $(1.00)$ & $(1.00)$ \\
\hline \multicolumn{4}{|l|}{ Income } \\
\hline$\$ 80,000$ or less & $(1.00)$ & $(1.00)$ & $(1.00)$ \\
\hline$\$ 80,001-\$ 150,000$ & 0.69 & 0.76 & 1.20 \\
\hline More than $\$ 150,000$ & 0.58 & 0.62 & 1.36 \\
\hline \multicolumn{4}{|l|}{ Age } \\
\hline 40 or younger & $(1.00)$ & $(1.00)$ & $(1.00)$ \\
\hline $41-50$ & $0.51^{*}$ & 0.77 & $1.75^{*}$ \\
\hline $51-60$ & 1.00 & 1.00 & $1.97 *$ \\
\hline 61 and older & 0.80 & 0.85 & 1.79 \\
\hline \multicolumn{4}{|l|}{ Education } \\
\hline $\begin{array}{l}\text { High school degree or } \\
\text { less }\end{array}$ & $(1.00)$ & $(1.00)$ & $(1.00)$ \\
\hline College degree & 0.75 & 0.79 & 0.86 \\
\hline $\begin{array}{l}\text { Graduate or } \\
\text { professional degree }\end{array}$ & 0.90 & 0.90 & 0.65 \\
\hline \multicolumn{4}{|l|}{ Gender } \\
\hline Female & $0.59 *$ & $0.41 * *$ & $0.25 * * *$ \\
\hline Male & $(1.00)$ & $(1.00)$ & $(1.00)$ \\
\hline
\end{tabular}

$* \mathrm{p}<.05 * * \mathrm{p}<.01$ 
Table 23. Odds Ratios for Neo-traditional Neighborhood from Logistic Regression Models of Demographic Subgroups (Whites, Non-Whites, Lower Income, and Higher Income)

\begin{tabular}{|lccc|}
\hline \multicolumn{2}{c|}{$\begin{array}{c}\text { Odds Ratios for Neo-traditional Neighborhood } \\
\text { Moderate Physical } \\
\text { Activity }\end{array}$} & $\begin{array}{c}\text { Vigorous Physical } \\
\text { Activity }\end{array}$ & $\begin{array}{c}\text { Overweight or } \\
\text { Obese }\end{array}$ \\
\hline Race/Ethnicity & 1.00 & & \\
White & 0.54 & 1.16 & 0.79 \\
Non-white & & 1.31 & 1.00 \\
Income & 1.62 & & \\
Lower Income & 0.75 & $2.58^{\$}$ & 0.80 \\
Higher Income & 0.88 & 0.85 \\
\hline
\end{tabular}

Models control for education, gender, and age.

${ }^{*} \mathrm{p}<.05^{\$}<.10$ 


\section{DISCUSSION}

This study has examined the social capital, travel behavior, obesity, and environmental attitude aspects of living in neo-traditional developments. Using a matched-pair, quasi-experimental research design, we surveyed residents of 17 pairs of neighborhoods throughout the U.S. We found no difference in social capital for residents of NTDs relative to residents of typical suburban neighborhoods after controlling for demographics. This finding contradicts our original hypothesis and the rhetoric of advocates of New Urbanism. However, it does match the results of the single existing study that looked at this question using a neo-traditional and suburban neighborhood in Salt Lake City (Brown \& Cropper, 2001).

This finding should not suggest that NTDs are unsuccessful at creating social bonds among neighbors. Rather, this is evidence that typical suburban developments are equally successful. Why might this be the case? Talen (1999) identified a large body of research from urban sociology that emphasizes the importance of individual demographic characteristics such as social class in the formation of relationships within the neighborhoods. This literature suggests that as neighborhood homogeneity increases, social connections within the neighborhood will also increase. In this study, both the neo-traditionalist and typical suburban neighborhoods were relatively homogenous, at least along racial lines.

For hypothesis 1 regarding travel behavior, we found that NTD residents make more total trips by auto and non-motorized - than their typical suburban counterparts. However, there were no significant differences in overall miles driven, suggesting NTD dwellers make more, but shorter, auto trips. In other models (not shown), we tested other explanations of the apparent increased trip-making among NTD residents - controlling for other socio-demographic characteristics, vehicle ownership, and so on - but the relationship between neighborhood type and total tripmaking held. This finding is consistent with hypothesized relationships by others (Crane and Crepeau 1998; Boarnet and Crane 2001), who suggest that by bringing origins and destinations closer together trip costs are reduced and, therefore, total trip consumption may increase, not decrease.

Internal trips hold the key to understanding the travel behavior differences uncovered by our results. After controlling for confounders, NTD residents made more internal trips than residents of typical suburban neighborhoods in our sample. Yet there is no statistical difference between NTD and typical suburban residents in the number of external trips made after adjusting for other covariates (models not shown). Thus, the greater overall trip-making by NTD residents is explained at least in part by increased internal trip-making. This explanation also applies to car trips: overall car trips are higher for NTD dwellers, in part because they make more internal car trips (external car trips are similar for residents of both types of neighborhoods). This is consistent with the results of Khattak and Rodriguez (2005) in North Carolina. They found that a higher number of internal trips in neo-traditional neighborhoods were made by private cars relative to conventional suburban neighborhoods.

For hypothesis 2, regarding the role of the built-environment features of NTDs in predicting travel behavior, we found mixed results. On one hand, the built-environment features examined do not appear to be very good predictors of total trip-making. The single most consistent predictor of total trip-making was neighborhood type, even when controlling for the built 
environment. On the other hand, built-environment features were significant predictors of car and non-motorized trips. As walking and cycling becomes easier (through greater internal and external connectivity) and the size of the commercial area in the neighborhood increases, nonmotorized trip-making increases substantially.

The NTD dummy variable was not significant for non-motorized trips when the builtenvironment variables were included in the model (hypothesis 3 ). Thus, while the base models indicated that NTD residents make considerably more non-motorized trips than residents of typical suburban neighborhoods, this appears to be explained in large part by the more supportive walking and bicycling environments found in our sample of NTDs than in any intrinsic "neo-traditional" quality. We might have expected otherwise - that neighborhood type indeed has a strong effect on non-motorized trip-making after controlling for the builtenvironment attributes in the study - given that our models neglected to measure the pedestrianfriendly design features commonly associated with New Urbanism, such as shorter setbacks, more interesting building facades, and better sidewalk connectivity. Based on our models, it appears that, regardless of neighborhood type, walking and cycling trips might be promoted through improved street connectivity and increased commercial activity.

By contrast, the NTD variable was significant along with the built-environment variables for internal trips, total trips, and car trips. In these models, a subset of the seven built-environment variables (ranging from two to five variables) was significant. This suggests that some of the intrinsic qualities of neo-traditional design that we did not measure appear to have an impact on these trips, beyond the features measured by our built-environment variables. Recall from Figure 2 that the difference in internal trips appears to explain much of the difference in total and auto trip-making between the two neighborhood types. Therefore, the effect of the unmeasured intrinsic characteristics of neo-traditional design seem to carry over to overall trips and auto trips through their relationship with internal trips.

Figures 4 and 5 reflect simulations performed with the estimated results for non-motorized trips and for auto travel. They show the predicted number of trips for residents in NTDs and typical suburban neighborhoods, while at the same time varying the built-environment variables from values of the bottom $10^{\text {th }}$ percentile of the data to the top $10^{\text {th }}$ percentile (in terms of the extent to which the built-environment features reflect the characteristics of neo-traditional neighborhood design). In Figure 3, the small offset between the black (NTD) and grey (typical suburban) neighborhood reflects the statistically insignificant difference identified in our models. No matter the neighborhood type, however, a resident of a neighborhood with built-environment features in the $90^{\text {th }}$ percentile are expected to make three to four times as many non-motorized trips as a resident of a neighborhood with built-environment features in the $10^{\text {th }}$ percentile. In Figure 4 , the difference between the two lines is statistically significant, and suggests that at all levels of the built environment NTD residents are expected to make more auto trips than residents of typical neighborhoods. However, as the values of the built-environment variables become closer to what is expected in neo-traditional design, predicted auto trips decrease for both neighborhood types. 


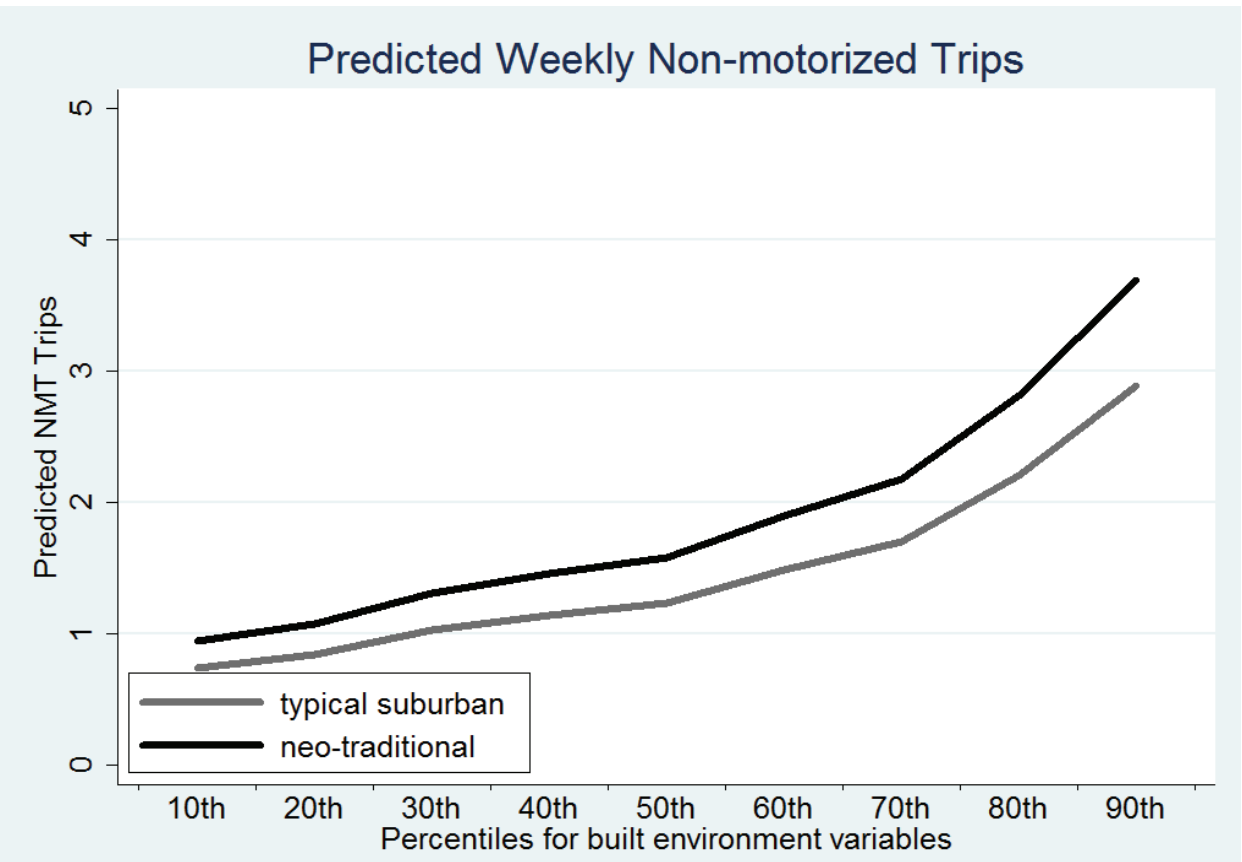

Figure 4. Predicted weekly non-motorized trips by built-environment variables' percentile in the data

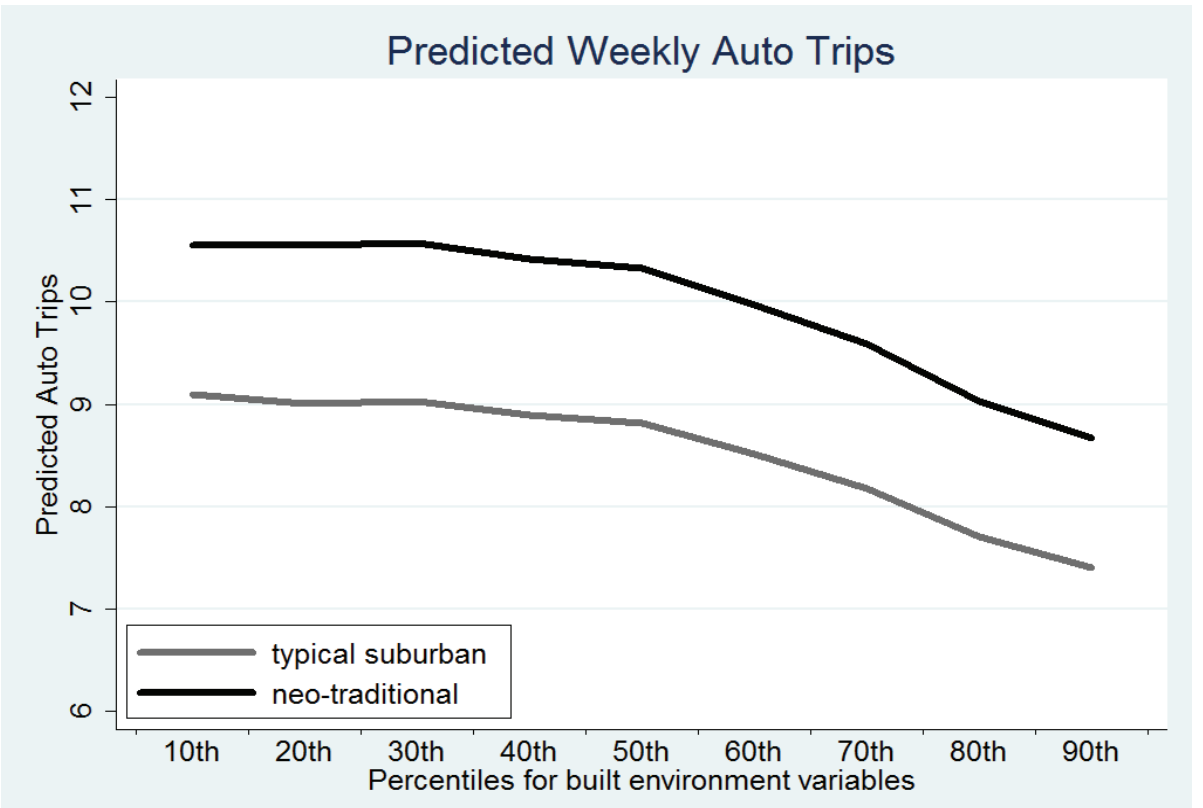

Figure 5. Predicted weekly car trips by built-environment variables' percentile in the data

A lesson for developers and planners is the importance of accounting for increased auto use for internal trips in NTDs. When the potential for higher auto use within the neighborhood raises concerns about air quality or local safety, developers should consider ways of minimizing the impacts, for example by limiting parking or by using traffic calming measures that detract from using cars for internal trips.

The role of context (greenfield vs. infill neighborhoods) was relevant only for non-motorized travel. Greenfield neighborhood residents made more non-motorized trips, regardless of the 
neighborhood type, connectivity, and commercial activity. It could be that the greenfield location "traps" trips, whereas in an infill location trips (regardless of mode) may be attracted to neighboring areas. Alternatively, it may be that the results are measuring recreational tripmaking (e.g., walking/jogging for exercise/socializing), which may be more prevalent in greenfields than infill settings. The survey did not establish a priori the definition of trip.

In our look at obesity, physical activity and neighborhood type, contrary to some prior studies, these analyses suggest that physical activity levels and overweight or obese status were similar regardless of whether respondents lived in a neo-traditional or typical suburban neighborhood. This pattern was consistent for all respondents as well as for white respondents, non-white respondents and higher-income respondents. Only among lower-income respondents was residing in a neo-traditional neighborhood related to greater physical activity. The reasons that this relationship was only found among this group is something that should be explored in future research.

Our findings also provide some support for our hypotheses on environmental attitudes. NTD residents had stronger concern over land consumption due to development and energy consumption due to automobile use. They also expressed greater support for government actions to redress those problems. For attitude about travel, however, NTD residents were equally uncomfortable using public transportation as their counterparts from traditional suburban neighborhoods. NTD residents expressed stronger preference for walking and biking, which, as mentioned earlier, can be seen in increased neighborhood trips as opposed to use of these modes for work trips. As the respondents in this study were of relatively higher income groups, our findings indicate the continuing challenge of inducing those with transportation choices to choose public transportation for more of their journeys.

Since non-car travel modes were generally not preferred by respondents from either neighborhood type, environmental attributes (e.g., closeness to public transit, neighborhood walkability, proximity to jobs) did not emerge as important in residents' location decisionmaking process. Our findings show that NTD residents placed much stronger emphasis on neighborhood walkability during their housing search. This amenity of their desired neighborhood likely emerged for leisure-oriented walking and biking trips, which again was shown in the data on the increased number of mainly local walking and biking trips in the neotraditional neighborhoods.

Our study is not without limitations. The response rate is very low, and we have indication of some response bias - homeowners and white residents are overrepresented in our sample although more up-to-date Census data would be required to assess the degree of bias. Another limitation is that the survey had value ranges for respondents to report trip patterns. We relied on the upper end of the range. To ensure that this recoding was not introducing bias, we examined alternative ways of coding the reported ranges (results not shown), but the findings were very similar to what was presented above. 


\section{CONCLUSIONS}

The study extends the growing literature on the built environment-behavior relationship by focusing on residents of NTDs using a nationwide sample of matched pairs, and relying on original, reliable data to measure micro-scale features of the built environment. Our findings for social capital suggest that typical suburban and neo-traditional developments have similar levels of social cohesion and intergenerational closure. The limited differences observed between the two design types were removed after controlling for demographic differences. It is also interesting to note that residents of both types of communities self-reported very high levels of social capital. Contrary to the assertions of many New Urbanists, typical suburbs do not appear to induce feelings of alienation among their residents.

For travel behavior, we found that NTD residents make more trips - by car, non-motorized and within their neighborhood - than residents of typical suburban neighborhoods. Because we did not find a difference in vehicle use, we conclude that trips taken by NTD residents tend to be shorter in length than trips taken by their suburban counterparts. Furthermore, the NTD variable remained significant for all outcomes except non-motorized travel after accounting explicitly for built-environment characteristics such as connectivity, density, vacant land, access to commercial areas, Walk Score, and whether the neighborhood was a greenfield or infill development. A simulation of predicted counts suggests that an area with built-environment characteristics taking on values at the $90^{\text {th }}$ percentile of the data collected will have almost four times the non-motorized trips than areas with built-environment characteristics taking on values at the $10^{\text {th }}$ percentile of the data collected. Further research will determine whether these relationships are causal.

Limited differences in health and obesity were observed, as well as limited differences in social cohesion and public transportation usage. It may be that the population of the study areas was somewhat homogenous and, despite the differences in neighborhood form, the social demographic characteristics led to similar behaviors, if not attitudes.

However, it may also be that the geographic boundaries of neighborhood types and the number of nearby destinations may not have been fully accounted for in the matched-site pairs. As seen in aerial photographs as well as the Walk Score measures, a number of study sites were not located within walking (or sometimes biking distance) to commercial destinations. This limited the active travel in these areas to recreational travel instead of utilitarian travel as well.

Further study of matched sites with similar Walk Scores and access to destinations may reveal larger differences in resident travel behavior. That is, analyzing the connectivity and accessibility of certain types of neighborhoods must fully account both for its internal characteristics and amenities as well as external, but proximate, destinations as well.

And, while the overall study did account for much of both of these scales, there seems to be an opportunity for a more focused and expanded analysis possible on a subset of sites that have similar adjacent destination profiles. In such situations, then, does connectivity and neighborhood have a greater impact on travel modes and trip types? This question will be further explored in a separate, subsequent and independent research report. 


\section{REFERENCES}

Appleyard, D. (1981). Livable streets. Berkeley: University of California Press.

Bagley, Michael N. and Patricia L. Mokhtarian. 2002. The impact of residential neighborhood type on travel behavior: A structural equations modeling approach. The Annals of Regional Science 36: 279-297.

Berke, P., MacDonald, J., White, N., Holmes, M., Line, D., Oury, K., et al., 2003. Greening Development to Protect Watersheds: Does New Urbanism Make a Difference? Journal of the American Planning Association, 69(4), 397-413.

Bhat, Chandra R. and Jessica Y. Guo. 2007. A comprehensive analysis of built environment characteristics on household residential choice and auto ownership levels. Transportation Research: Part B 41: 506-526.

Black JL, Macinko J. 2008. Neighborhoods and obesity. Nutrition Reviews. 66(1):2-20.

Boarnet, M., \& Crane, R., 2001. Travel by Design: The Influence of Urban Form on Travel, Oxford University Press, New York.

Brown, A. L., Khattak, A. J., \& Rodriguez, D. A., 2008. Neighborhood Types, Travel and Body Mass: A Study of New Urbanist and Suburban Neighborhoods. Urban Studies, 45(8).

Brown, B. B., \& Cropper, V. L., 2001. New urban and standard suburban subdivisions: Evaluating psychological and social goals. Journal of the American Planning Association, 67(4), 402-419.

Cao, X. Y., 2009. Disentangling the influence of neighborhood type and self-selection on driving behavior: an application of sample selection model. Transportation, 36(2), 207-222.

Cao, X. Y., Mokhtarian, P. L., \& Handy, S. L., 2006. Neighborhood design and vehicle type choice: Evidence from Northern California. Transportation Research Part D-Transport and Environment, 11(2), 133-145.

Cao, X. Y., Mokhtarian, P. L., \& Handy, S. L., 2007a. Do changes in neighborhood characteristics lead to changes in travel behavior? A structural equations modeling approach. Transportation, 34(5), 535-556.

Cao, X. Y., Mokhtarian, P. L., \& Handy, S. L., 2007b. Cross-sectional and quasi-panel explorations of the connection between the built environment and auto ownership. Environment and Planning A, 39(4), 830-847.

Cao, X. Y., Mokhtarian, P. L., \& Handy, S. L., 2009. The relationship between the built environment and nonwork travel: A case study of Northern California. Transportation Research Part a-Policy and Practice, 43(5), 548-559. 
Cao, X. Y., Handy, S.L. and Patricia L. Mokhtarian. 2006. The influences of the built environment and residential self-selection on pedestrian behavior: Evidence from Austin, TX. Transportation 33: 1-20.

Cervero, R., \& Gorham, R., 1995. Commuting in transit versus automobile neighborhoods. Journal of the American Planning Association, 61(2), 210-225.

Cervero, R., \& Kockelman, K., 1997. Travel demand and the 3Ds: Density, diversity and design. Transportation Research D, 2(3), 199-219.

Cervero, R., \& Radisch, C., 1995. Travel choices in pedestrian versus automobile-oriented neighborhoods. Transport Policy, 3(3), 127-141.

Choocharukul, Kasem, Hong Tan Van, and Satoshi Fujii. 2008. Psychological effects of travel behavior on preference of residential location choice. Transportation research. Part A, Policy and practice 42: 116-124.

Crane, R., \& Crepeau, R., 1998. Does neighborhood design influence travel? A behavioral analysis of travel dairy and GIS data. Transportation Research D, 3(4), 225-238.

Dill, J., 2004. Travel Behavior and Attitudes: New Urbanist Versus Traditional Suburban Neighborhoods. 83d Transportation Research Board Annual Meeting, Washington, D.C.

Ewing, R., \& Cervero, R., 2001. Travel and the built environment. Transportation Research Record, $1780,87-114$.

Ewing, R., 1995. Beyond density, mode choice, and single-purpose trips. Transportation Quarterly, 49, 15-24.

Freeman, L. (2001). The effects of sprawl on neighborhood social ties. Journal of the American Planning Association, 67(1), 69-77.

Friedman, B., Gordon, S. P., \& Peers, J. B., 1994. Effect of neotraditional neighborhood design on travel characteristics. Transportation Research Record, 1466, 63-70.

Gordon-Larsen P, Nelson MC, Page P, Popkin BM. 2006. Inequality in the built environment underlies key health disparities in physical activity and obesity. Pediatrics. 117(2):417-424.

Greenwald, M. J., 2003. The road less traveled - New urbanist inducements to travel mode substitution for nonwork trips. Journal of Planning Education and Research, 23(1), 39-57.

Handy, S. L., Cao, X. Y., \& Mokhtarian, P. L., 2008. The causal influence of neighborhood design on physical activity within the neighborhood: Evidence from Northern California. American Journal of Health Promotion, 22(5), 350-358.

Handy, S., \& Clifton, K. J., 2001. Local shopping as a strategy for reducing automobile travel. Transportation, 28, 317-346. 
Handy, S., 1992. Regional versus local accessibility: Neo-traditional development and its implications for non-work travel. Built environment, 18, 253-267.

Handy, S., 1996. Methodologies for exploring the link between urban form and travel behavior. Transportation Research D, 1(2), 151-165.

Handy, S., Cao, X. Y., \& Mokhtarian, P. L., 2006. Self-selection in the relationship between the built environment and walking - Empirical evidence from northern California. Journal of the American Planning Association, 72(1), 55-74.

Handy, S., Sallis, J. F., Weber, D., Maibach, E., \& Hollander, M., 2008. Is Support for Traditionally Designed Communities Growing? Evidence From Two National Surveys. Journal of the American Planning Association, 74(2), 209-221.

Kasturi, T., Sun, X., \& Wilmot, C. G., 1998. Household travel, household characteristics, and land use: an empirical study from the 1994 Portland activity-based travel survey. Transportation Research Record, 1617, 10-17.

Katz, P. (1994). The new urbanism: Toward an architecture of community. New York: McGrawHill Professional.

Khattak, A., \& Rodriguez, D., 2005. Travel behavior in neo-traditional developments: A case study from the U.S.A. Transportation Research A, 39(6), 481-500.

Kitamura, R., Laidet, L., \& Mokhtarian, P., 1997. A micro-analysis of land use and travel in five neighborhoods in the San Francisco Bay Area. Transportation, 24, 125-158.

Krizek, K., 2003. Residential Relocation and Changes in Urban Travel: Does NeighborhoodScale Urban Form Matter? Journal of the American Planning Association, 69(3), 265281.

Krizek, Kevin J. 2000. Residential relocation and changes in urban travel: Does neighborhoodscale urban form matter? Journal of the American Planning Association 69: 265-281.

Kumanyika S. In Press. Environmental influences on childhood obesity: Ethnic and cultural influences in context. Physiology \& Behavior.

Landis, J. R., \& Koch, G. G., 1977. The measurements of observer agreement for categorical data. Biometrics, 33, 159-174.

Lee, C.-M., \& Ahn, K.-H., 2003. Is Kentlands better than Radburn? The American Garden City and the new urbanist paradigms. Journal of the American Planning Association, 69(1), $50-71$.

Levine, J. and L. Frank 2007. "Transportation and land-use preferences and residents' neighborhood choices: the sufficiency of compact development in the Atlanta region." Transportation 34(2): 255-274. 
Levine, J. C., 2005. Zoned Out: Regulations, Markets, and Choices in Transportation and Metropolitan Land Use, Resources for the Future Press, Washington, DC.

Lochner, K., Kawachi, I., \& Kennedy, B. P. (1999). Social capital: A guide to its measurement. Health and Place, 5(4), 259-270.

Lund, H., 2003. Testing the claims of New Urbanism. Journal of the American Planning Association, 69(4), 414-429.

Massey, D. S. (2001). The prodigal paradigm returns: Ecology comes back to sociology. In A. Booth, \& A. C. Crouter (Eds.), Does it take a village?: Community effects on children, adolescents, and families. Mahwah, NJ: Lawrence Erlbaum Associates, Inc.

McNeill, L. H., Kreuter, M. W., \& Subramanian, S. (2006). Social environment and physical activity: A review of concepts and evidence. Social Science and Medicine, 63(4), 1011 1022.

Michael J. Greenwald, Michael J. and Marlon G. Boarnet. 2001. Built environment as determinant of walking behavior: Analyzing nonwork pedestrian travel in Portland, Oregon Transportation. Research Record: Journal of the Transportation Research Board 1780: 3341.

Mokhtarian, Patricia L. and Xinyu Cao. 2008. Examining the impacts of residential self-selection on travel behavior: A focus on methodologies. Transportation Research Part BMethodological 43: 204-228.

Morenoff, J. (2003). Neighborhood mechanisms and the spatial dynamics of birth weight. American Journal of Sociology, 108(5), 976-1017.

Morrow-Jones, H. A., Irwin, E. G., \& Roe, B., 2004. Consumer preference for neotraditional neighborhood characteristics. Housing Policy Debate, 15(1), 171-202.

Nasar, J. L. (2003). Does neotraditional development build community? Journal of Planning Education and Research, 23(1), 58-68.

Nasar, J. L., \& Julian, D. A. (1995). The psychological sense of community in the neighborhood. Journal of the American Planning Association, 61(2), 178-184.

Owen, N., Humpel, N., Leslie, E., Bauman, A., \& Sallis, J. F., 2004. Understanding environmental influences on walking; Review and research agenda. American Journal of Preventive Medicine, 27(1), 67-76.

Papas MA, Alberg AJ, Ewing R, Helzlsouer KJ, Gary TL, Klassen AC. 2007. The built environment and obesity. Epidemiologic reviews. 29(1):129-143.

Park, R. E., Burgess, E. W., McKenzie, R. D., \& Wirth, L. (1925). The City. Chicago, Ill.,: The University of Chicago Press. 
Rodriguez, D. A., Khattak, A. J., \& Evenson, K. R., 2006. Can new urbanism encourage physical activity? Comparing a new urbanist neighborhood with conventional suburbs. Journal of the American Planning Association, 72(1), 43-54.

Rutherford, S. G., McCormack, E., \& Wilkinson, M., 1996. Travel Impacts of Urban Form: Implications From an Analysis of Two Seattle Area Travel Diaries. TMIP Conference on Urban Design, Telecommuting, and Travel Behavior, Washington, D.C.

Saelens, B. E., Sallis, J. F., \& Frank, L. D., 2003. Environmental correlates of walking and cycling: findings from the transportation, urban design, and planning literatures. Annals of Behavioral Medicine, 25(2), 80-91.

Saelens, B. E., Sallis, J. F., Black, J. B., \& Chen, D., 2003. Neighborhood-based differences in physical activity: an environment scale evaluation. American Journal of Public Health, 93(9), 1552-1558.

Saelens, B., \& Handy, S., 2008. Built Environment Correlates of Walking: A Review. Medicine \& Science in Sports \& Exercise, 40, S550-566.

Sampson, R., Raudenbush, S., \& Earls, F. (1997). Neighborhoods and violent crime: A multilevel study of collective efficacy. Science, 277, 918-924.

Shadish, W. R., Cook, T. D., \& Campbell, D. T., 2002. Experimental and quasi-experimental designs for generalized causal inference, Houghton Mifflin, Boston.

Stevens, M., 2008. Can individual planners make communities safer? A study of the use of discretion in managing urban development. PhD Thesis, University of North Carolina, Chapel Hill, Chapel Hill.

Talen, E. (1999). Sense of community and neighbourhood form: An assessment of the social doctrine of new urbanism. Urban Studies, 36(8), 1361-1379.

Talen, E. (2002). The social goals of new urbanism. Housing Policy Debate, 13(1), 165-188.

Wang Y, Beydoun MA. 2007. The obesity epidemic in the united states--gender, age, socioeconomic, racial/ethnic, and geographic characteristics: A systematic review and metaregression analysis. Epidemiologic reviews. 29:6-28.

Wendel-Vos, W., Droomers, M., Kremers, S., Brug, J., \& van Lenthe, F., 2007. Potential environmental determinants of physical activity in adults: a systematic review. Obesity Reviews, 8(5), 425-440. 


\section{APPENDICES}

\section{Appendix I. Maps of study sites}

\section{Carlsbad, CA}

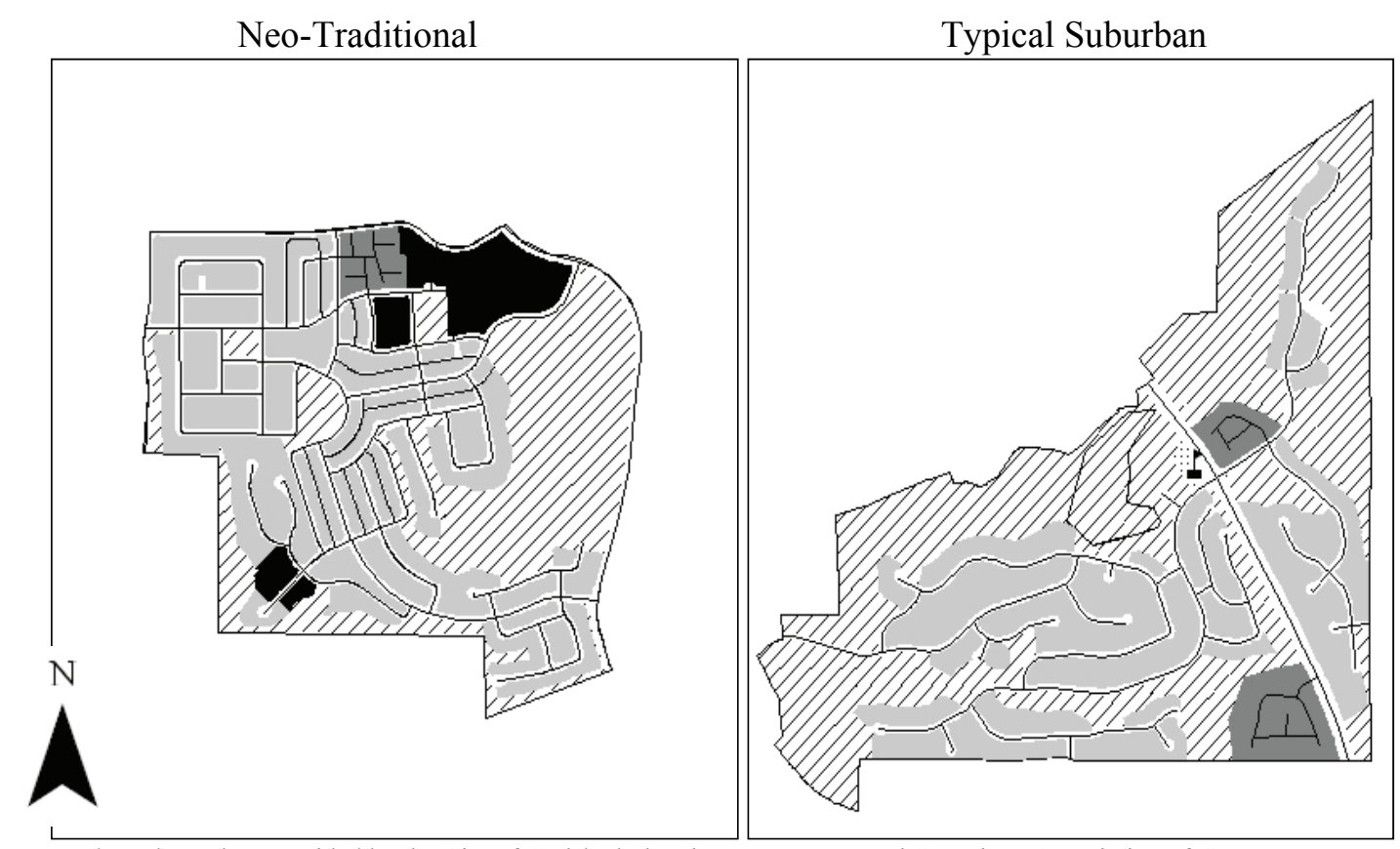

*Land-use data provided by the City of Carlsbad Planning Department and San Diego Association of Governments.

\section{Legend}

Streets
Single Family Residential
Vacant
Multi-Family Residential

Y///, Parks and Open Space

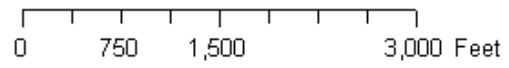

1 School

Public Institution

ROW

\begin{tabular}{lcc} 
& $\begin{array}{c}\text { Neo-Traditional } \\
\text { (Carrillo Ranch) }\end{array}$ & $\begin{array}{c}\text { Typical Suburban } \\
\text { (Bressi Ranch) }\end{array}$ \\
\hline Total area of tract (acres) & 267.00 & 349.40 \\
Existing dwelling units & 534 & 383 \\
Permitted dwelling units & 623 & 1816 \\
Mean single-family home price & $\$ 693,000$ & $\$ 671,00$ \\
Year approved & 2002 & 1998 \\
Year completed & 2006 & 2002 \\
Public Transit Access & No & No \\
Greenfield & Yes & Yes \\
Vacant area (pct of total area) & $8 \%$ & $0 \%$ \\
Parks/open space (pct of total area) & $29 \%$ & $51 \%$ \\
Residential area (pct of total built area) & $52 \%$ & $73 \%$ \\
Commercial area (acres) & 0 & 0 \\
Net single-family density (units per acre) & 5.56 & 3.61 \\
Street density (miles per 100 acres) & 5.58 & 3.67 \\
Link-node ratio & 1.47 & 1.10 \\
External connections & 5 & 3 \\
Mean Walk Score & 37 & 16.75 \\
\hline
\end{tabular}




\section{Chula Vista, CA}

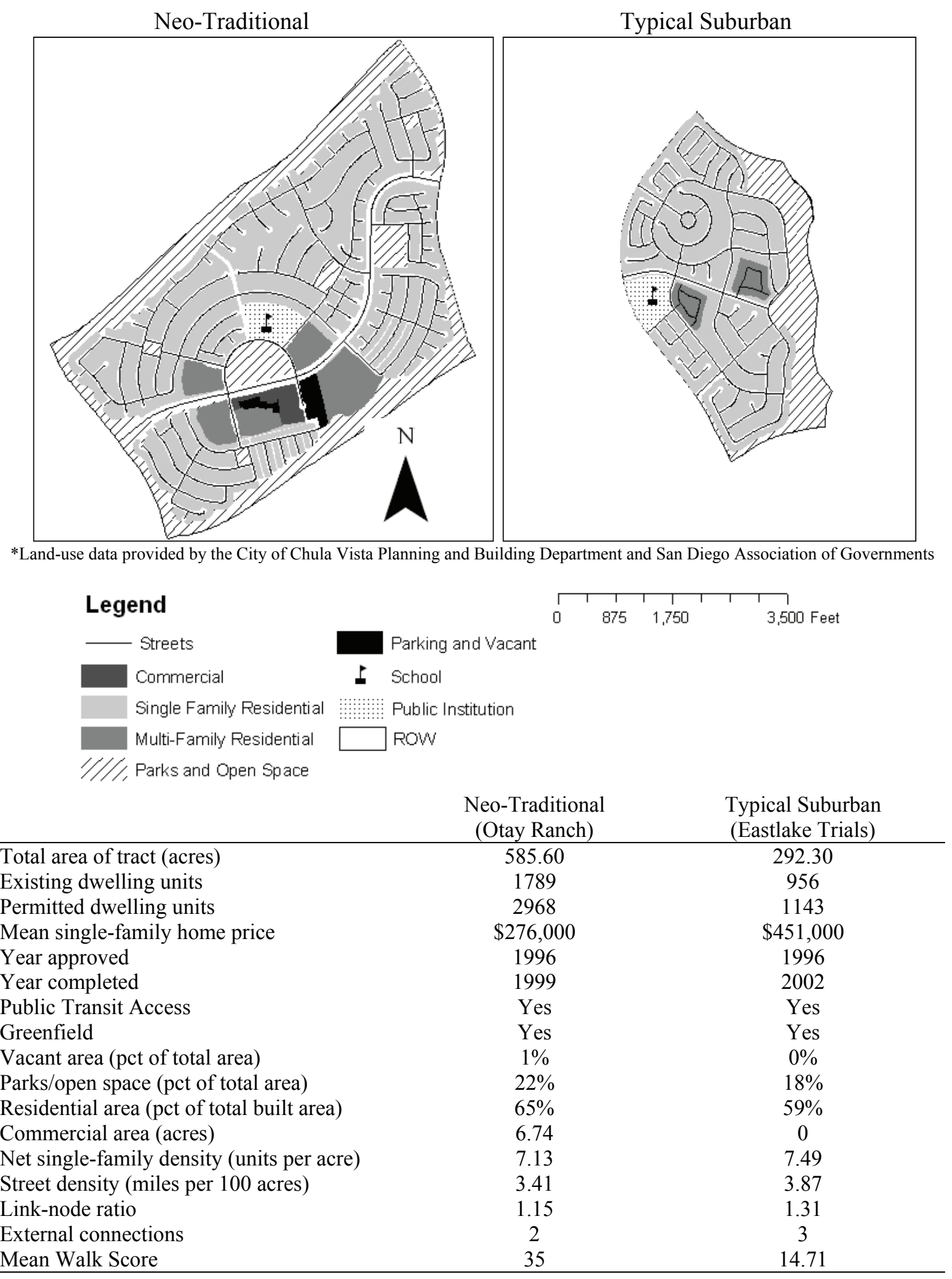




\section{Clackamas, OR}
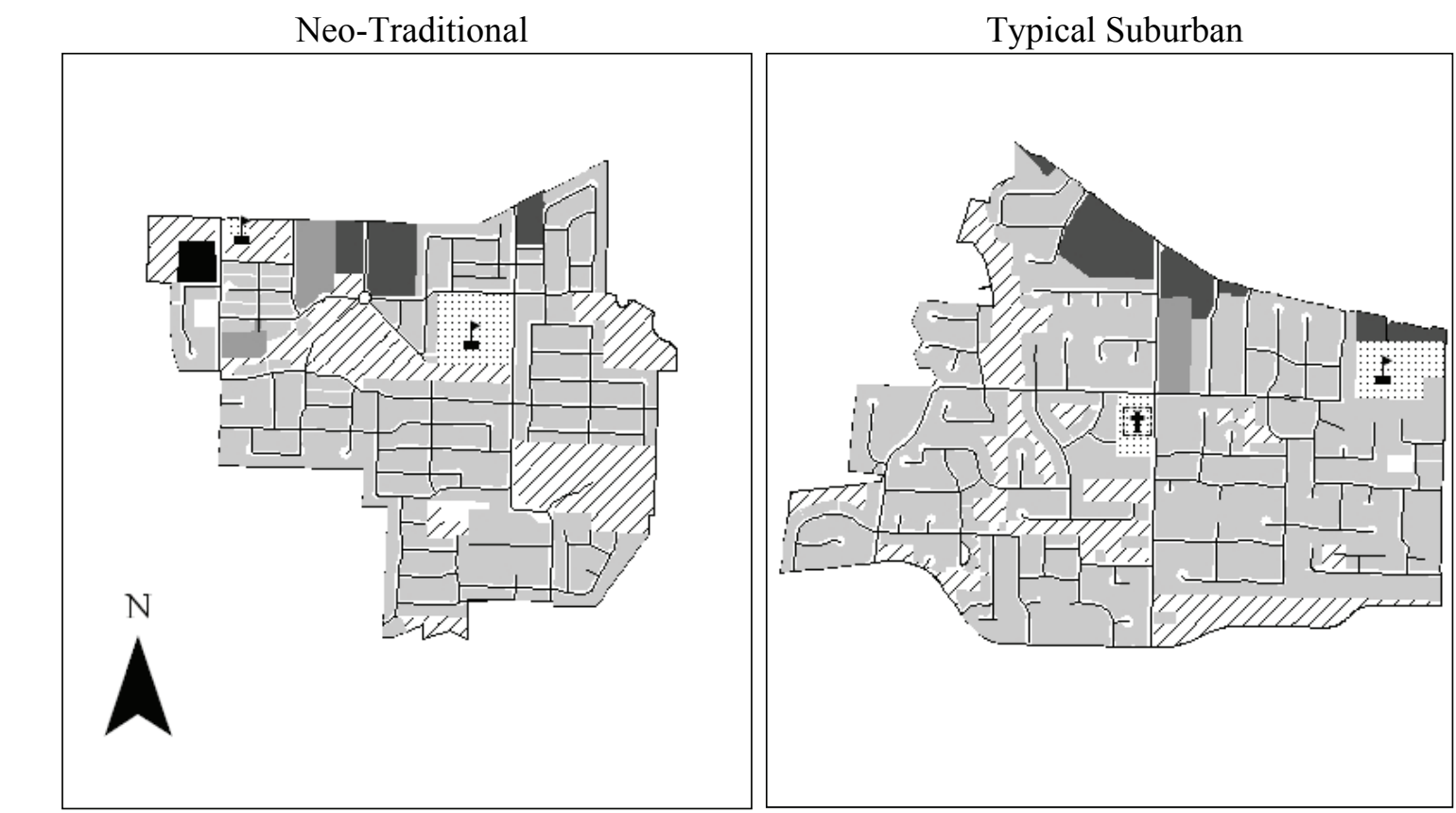

*Land-use data provided by Clackamas County Planning Department and Clackamas County Department of Transportation and Development.

\section{Legend}

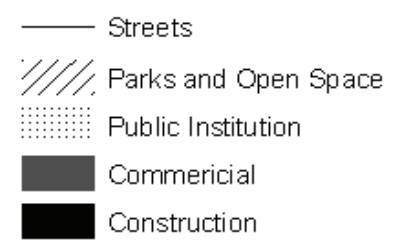

$$
\begin{aligned}
& \begin{array}{l}
\text { Single Family Residential } \\
\text { Multi-Family Residential } \\
\pm \text { School } \\
\pm \text { Church } \\
\square \text { ROW }
\end{array} \\
& \begin{array}{l|ccc|c|c|}
\hline & 1 & 1 & 1 & 1 \\
0 & 700 & 1.400 & & 2800
\end{array}
\end{aligned}
$$

Neo-Traditional (Sunnyside Village)

Total area of tract (acres)

Existing dwelling units

Permitted dwelling units

Mean single-family home price

Year approved

Year completed

Public Transit Access

Greenfield

Vacant area (pct of total area)

Parks/open space (pct of total area)

Residential area (pct of total built area)

Commercial area (acres)

Net single-family density (units per acre)

Street density (miles per 100 acres)

Link-node ratio

External connections

Mean Walk Score
290.40

1016

$\sim$

$\sim$

$\sim$

$\sim$

Yes

Yes

$0 \%$

$21 \%$

$64 \%$

9.29

6.69

4.00

1.35

11

37.9
Typical Suburban (122 ${ }^{\text {nd }}$ Ave area) 394.70

1109

$\sim$

1993

Yes

Yes

$0 \%$

$13 \%$

$72 \%$

18.56

4.56

2.92

1.09

14

39.92 


\section{Colorado Springs, CO}

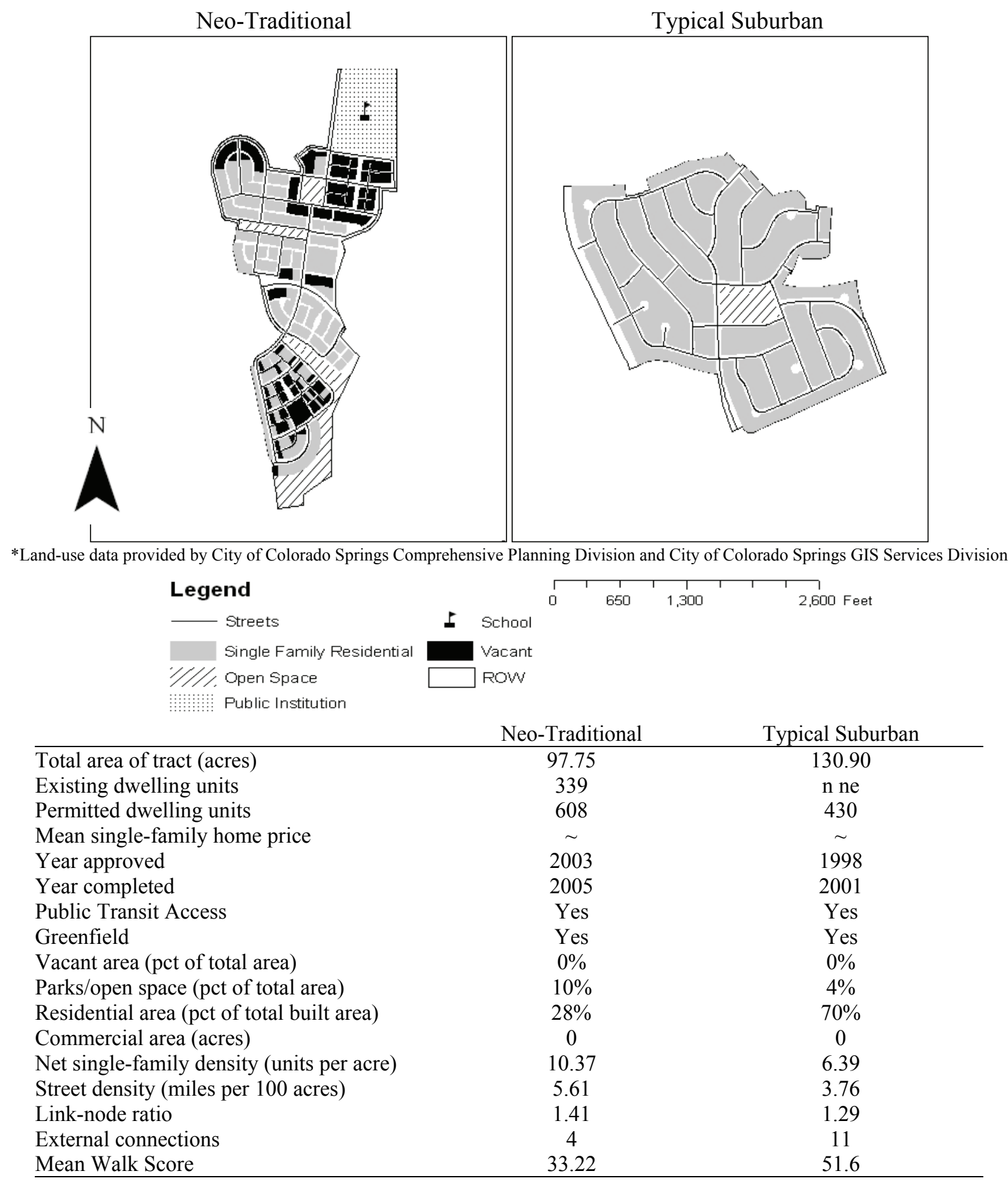




\section{Cumming, GA}

Neo-Traditional

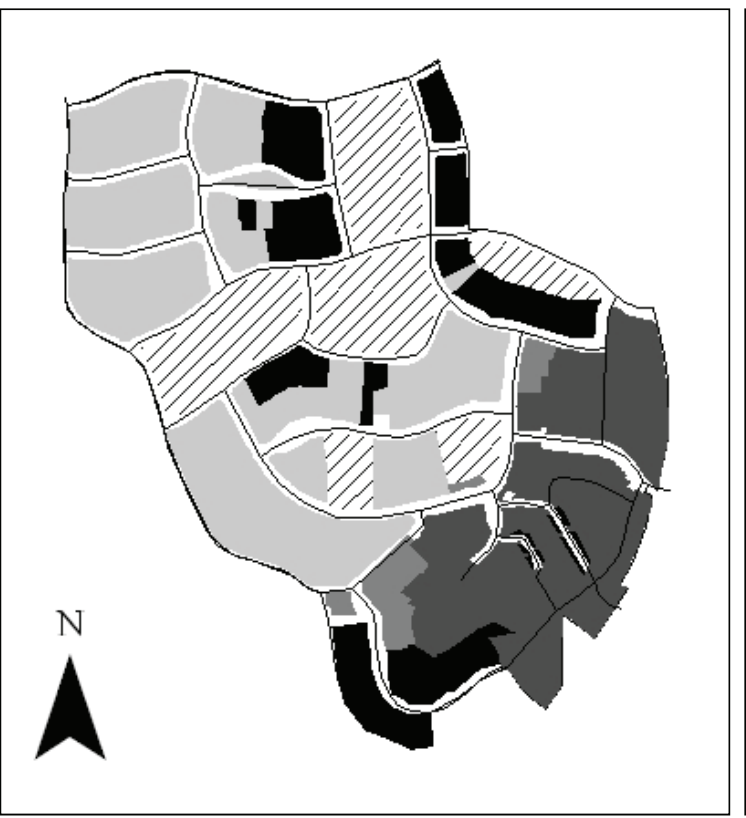

Typical Suburban

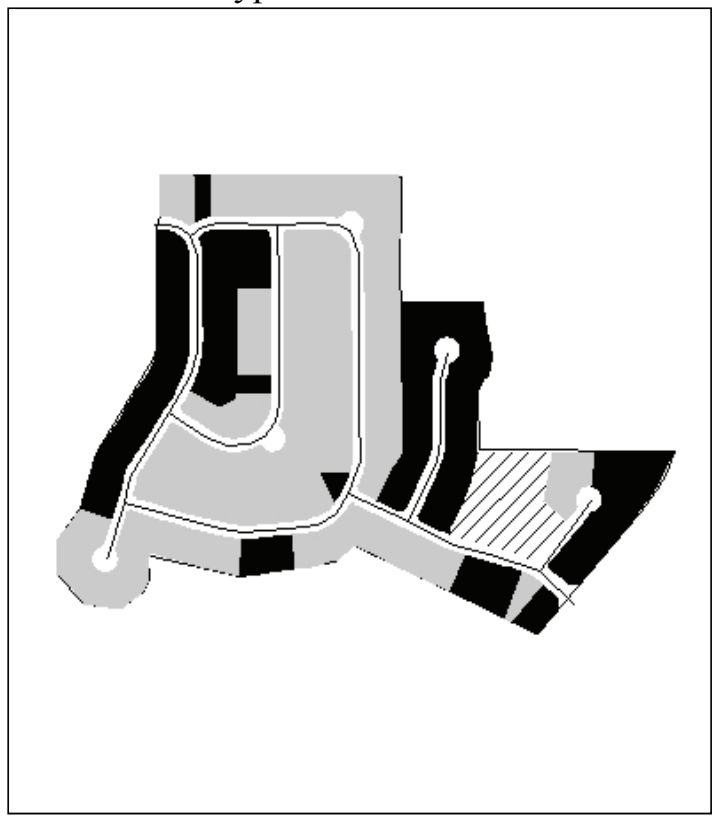

*Land-use data provided by Forsyth County Department of Planning and Development and Forsyth County Geographic Information Services Department.

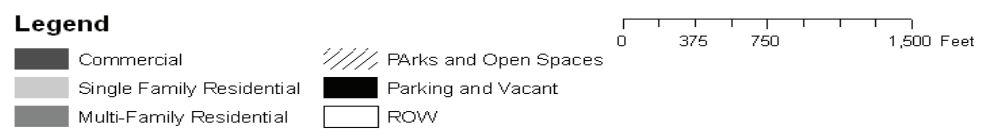

\begin{tabular}{lcc} 
& $\begin{array}{c}\text { Neo-Traditional } \\
\text { (Vickery Village) }\end{array}$ & $\begin{array}{c}\text { Typical Suburban } \\
\text { (Wild Meadows) }\end{array}$ \\
\hline Total area of tract (acres) & 88.90 & 54.10 \\
Existing dwelling units & 149 & 108 \\
Permitted dwelling units & 431 & 400 \\
Mean single-family home price & $\sim$ & $\sim$ \\
Year approved & 2000 & 1996 \\
Year completed & $\sim$ & $\sim$ \\
Public Transit Access & No & No \\
Greenfield & Yes & Yes \\
Vacant area (pct of total area) & $11 \%$ & $31 \%$ \\
Parks/open space (pct of total area) & $17 \%$ & $5 \%$ \\
Residential area (pct of total built area) & $43 \%$ & $74 \%$ \\
Commercial area (acres) & 10.83 & 0 \\
Net single-family density (units per acre) & 5.88 & 4.22 \\
Street density (miles per 100 acres) & 5.41 & 2.62 \\
Link-node ratio & 1.44 & 1 \\
External connections & 3 & 1 \\
Mean Walk Score & 29.77 & 3 \\
\hline
\end{tabular}




\section{Davidson, NC}
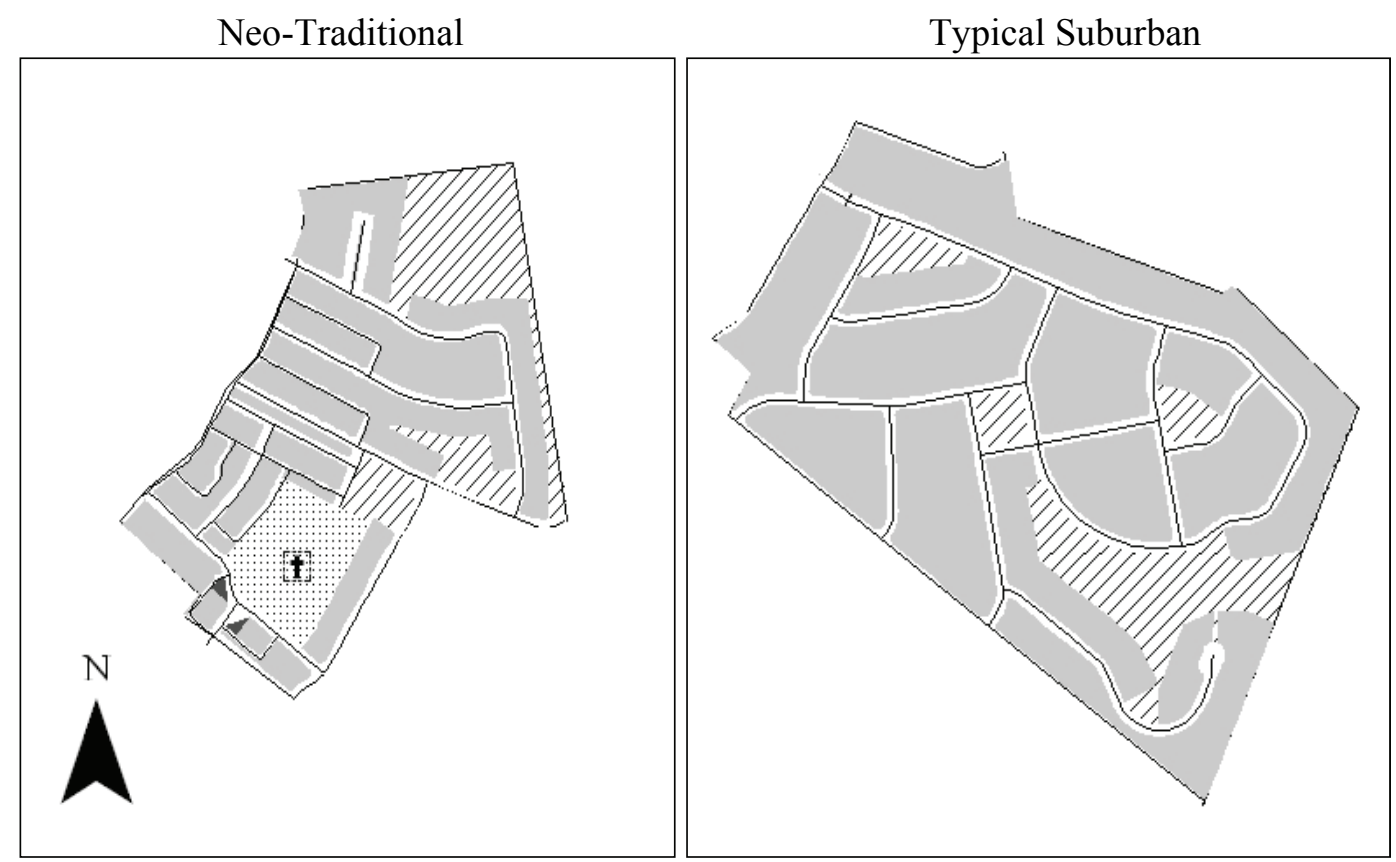

*Land-use data provided by the Town of Davidson Planning Department
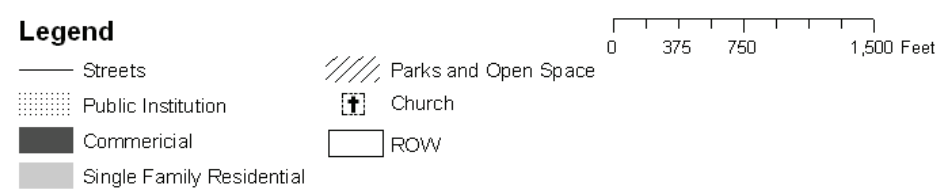

Neo-Traditional

(A New Neighborhood in

Old Davidson)

Total area of tract (acres)

$\begin{array}{cc}66.40 & 94.50 \\ 257 & 202 \\ 253 & 201 \\ \$ 241,000 & \$ 230,00 \\ 2000 & 1998 \\ 2005 & 2000 \\ \text { No } & \text { No } \\ \text { Yes } & \text { Yes } \\ 0 \% & 0 \% \\ 19 \% & 14 \% \\ 71 \% & 70 \% \\ <1 & 0 \\ 5.52 & 3.10 \\ 5.15 & 3.10 \\ 1.37 & 1.40 \\ 3 & 2 \\ 2 & 2 \\ \end{array}$

Typical Suburban

(McConnell)

Existing dwelling units

Permitted dwelling units

Mean single-family home price

Year approved

Year completed

Public Transit Access

Greenfield

Vacant area (pct of total area)

Parks/open space (pct of total area)

Residential area (pct of total built area)

Commercial area (acres)

Net single-family density (units per acre)

Street density (miles per 100 acres)

Link-node ratio

202

201

1998

2000

External connections

Mean Walk Score

2 


\section{Fort Collins, CO}

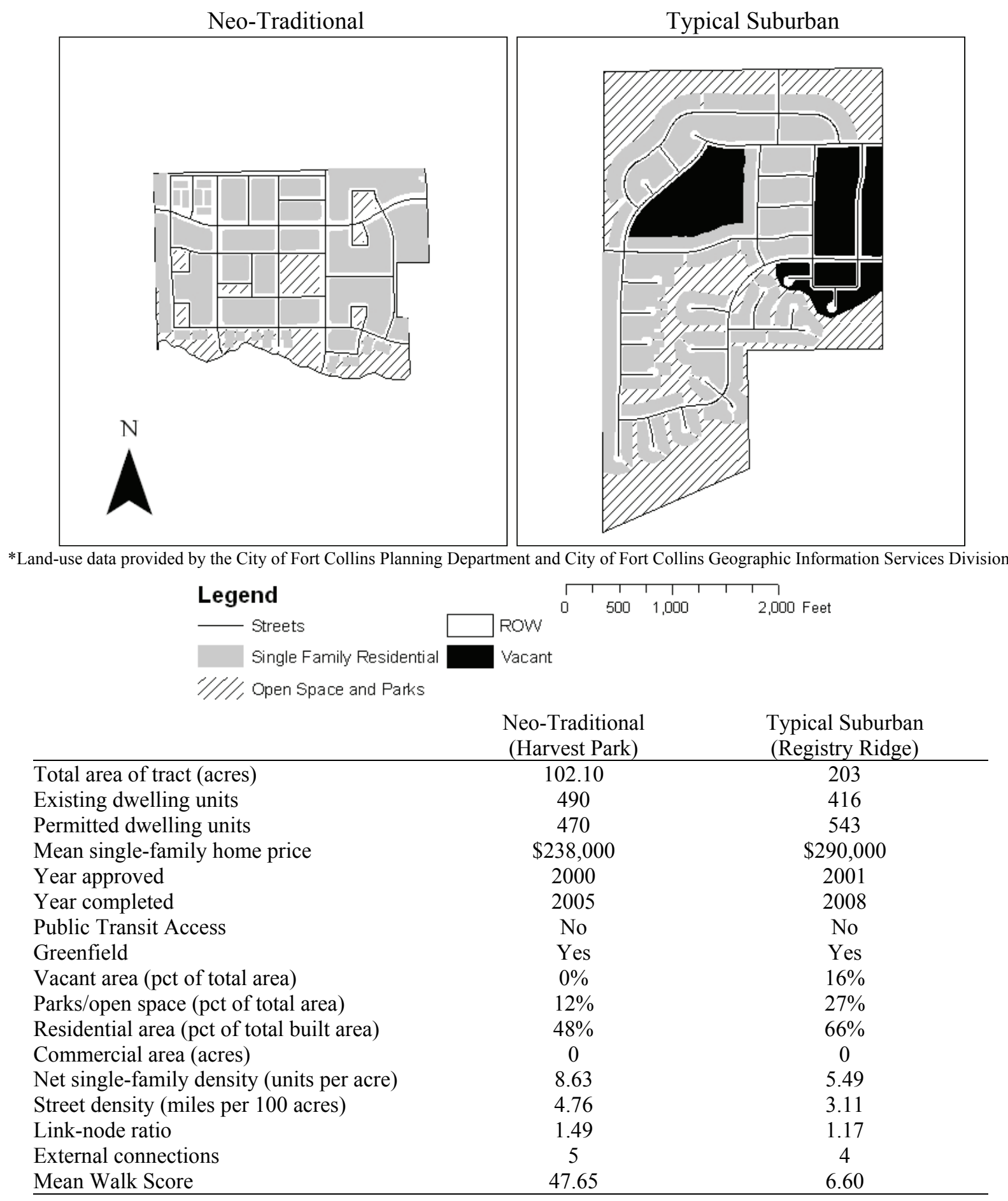




\section{Franklin, TN}

Neo-Traditional

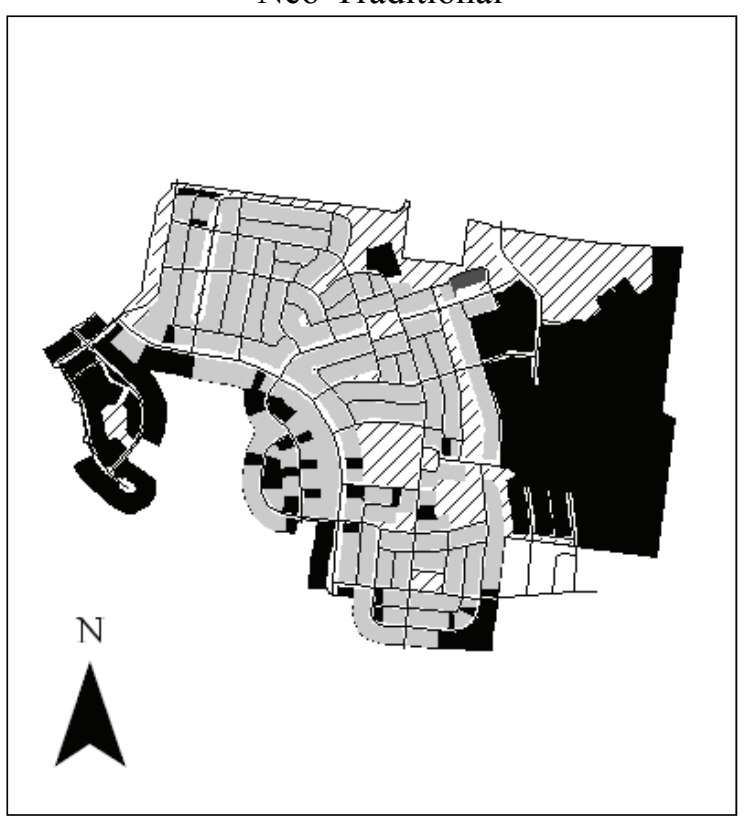

*Land-use data provided by the City of Franklin Planning Department

\section{Legend}

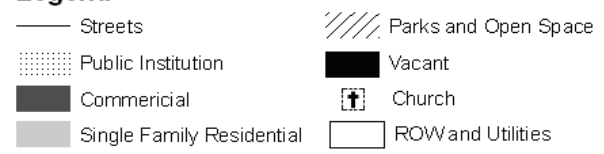

Typical Suburban

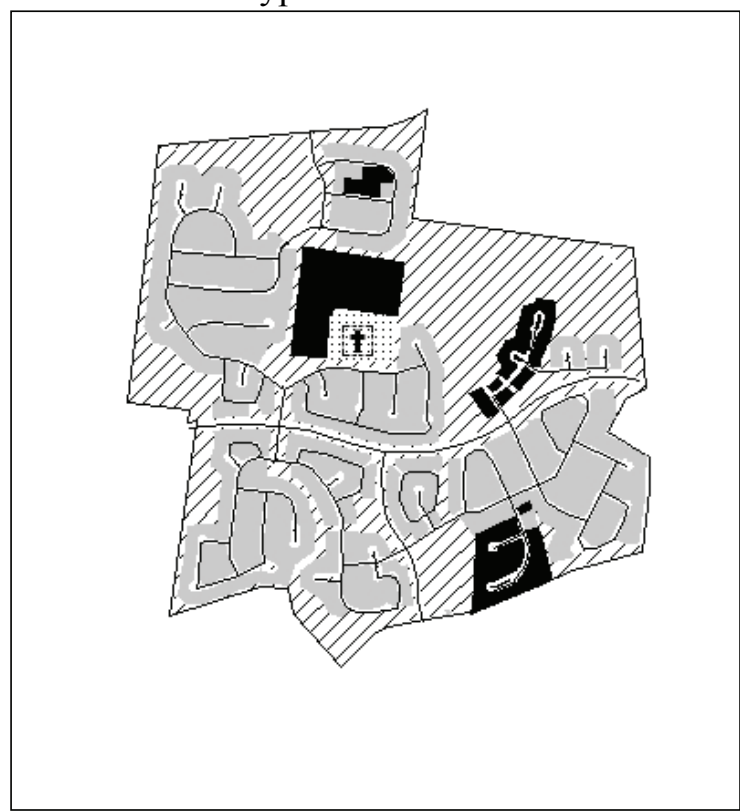

$$
\begin{array}{l|c|c|c|c|c|}
\hline & \mid & \mid & \mid & \\
0 & 750 & 1,500 & & 3,000 & \text { Feet }
\end{array}
$$

Neo-Traditional

Typical Suburban

(Westhaven)

Total area of tract (acres)

342.1

631

2750

$\$ 301,000$

Mean single-family home price

2001

Year approved

Year completed

Public Transit Access

Greenfield

Vacant area (pct of total area)

Parks/open space (pct of total area)

Residential area (pct of total built area)

Commercial area (acres)

Net single-family density (units per acre)

Street density (miles per 100 acres)

$\sim$

No

Yes

$34 \%$

$10 \%$

$60 \%$

1.01

5.24

3.46

1.53

External connections

2

Mean Walk Score

12.23 (McKay's Mill)

380.60

621

1378

$\$ 217,000$

1997

No

Yes

$8 \%$

$30 \%$

$65 \%$

0.00

4.05

3.26

1.22

3

8.61 


\section{Frederick, MD}

Neo-Traditional

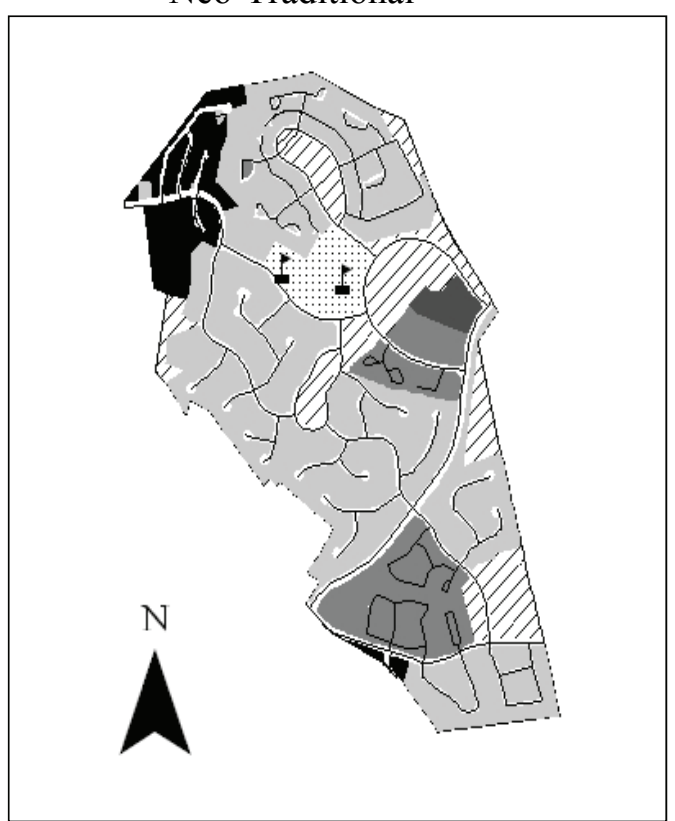

Typical Suburban

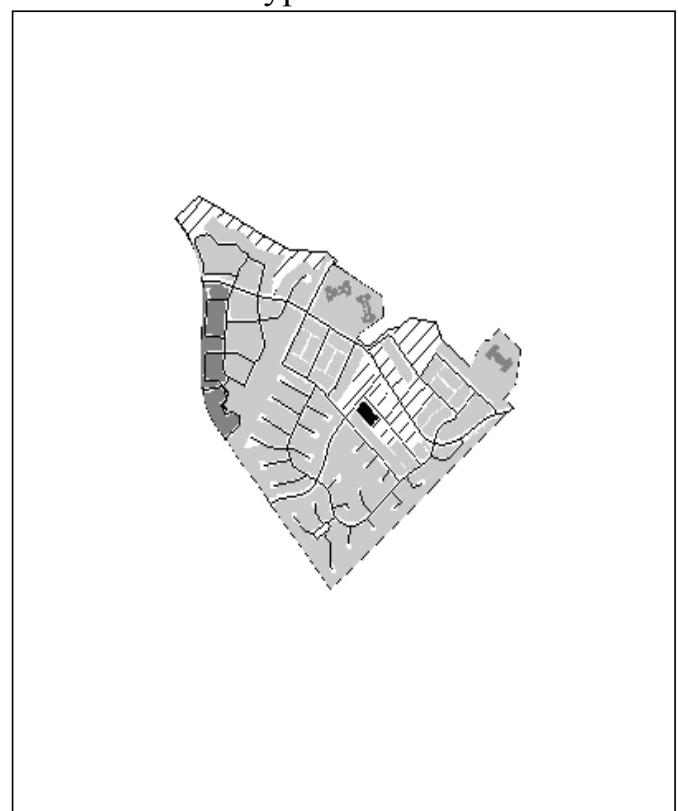

*Land-use data provided by the City of Frederick Department of Planning and City of Frederick GIS.

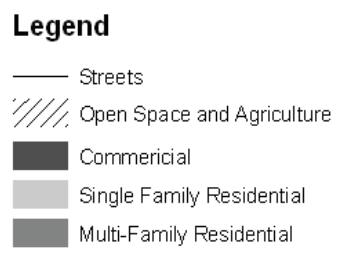

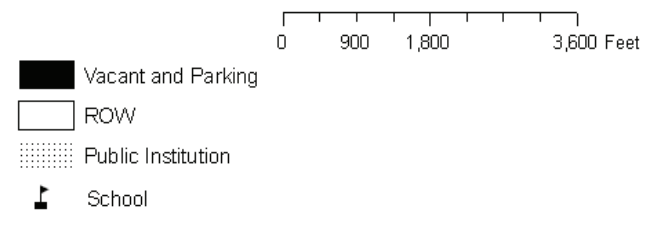

\begin{tabular}{lcc} 
& $\begin{array}{c}\text { Neo-Traditional } \\
\text { (Worman's Mill) }\end{array}$ & $\begin{array}{c}\text { Typical Suburban } \\
\text { (Whittier) }\end{array}$ \\
\hline Total area of tract (acres) & 144.60 & 349.50 \\
Existing dwelling units & 731 & 875 \\
Permitted dwelling units & 1397 & 1590 \\
Mean single-family home price & $\sim$ & $\sim$ \\
Year approved & 1992 & 1988 \\
Year completed & 2010 & 2008 \\
Public Transit Access & Yes & Yes \\
Greenfield & Yes & Yes \\
Vacant area (pct of total area) & $0 \%$ & $3 \%$ \\
Parks/open space (pct of total area) & $9 \%$ & $11 \%$ \\
Residential area (pct of total built area) & $46 \%$ & $59 \%$ \\
Commercial area (acres) & 0.00 & 5.14 \\
Net single-family density (units per acre) & 9.77 & 3.25 \\
Street density (miles per 100 acres) & 4.49 & 3.34 \\
Link-node ratio & 1.25 & 1.29 \\
External connections & 6 & 3 \\
Mean Walk Score & 43.2 & 33.42 \\
\hline
\end{tabular}




\section{Gaithersburg, MD}

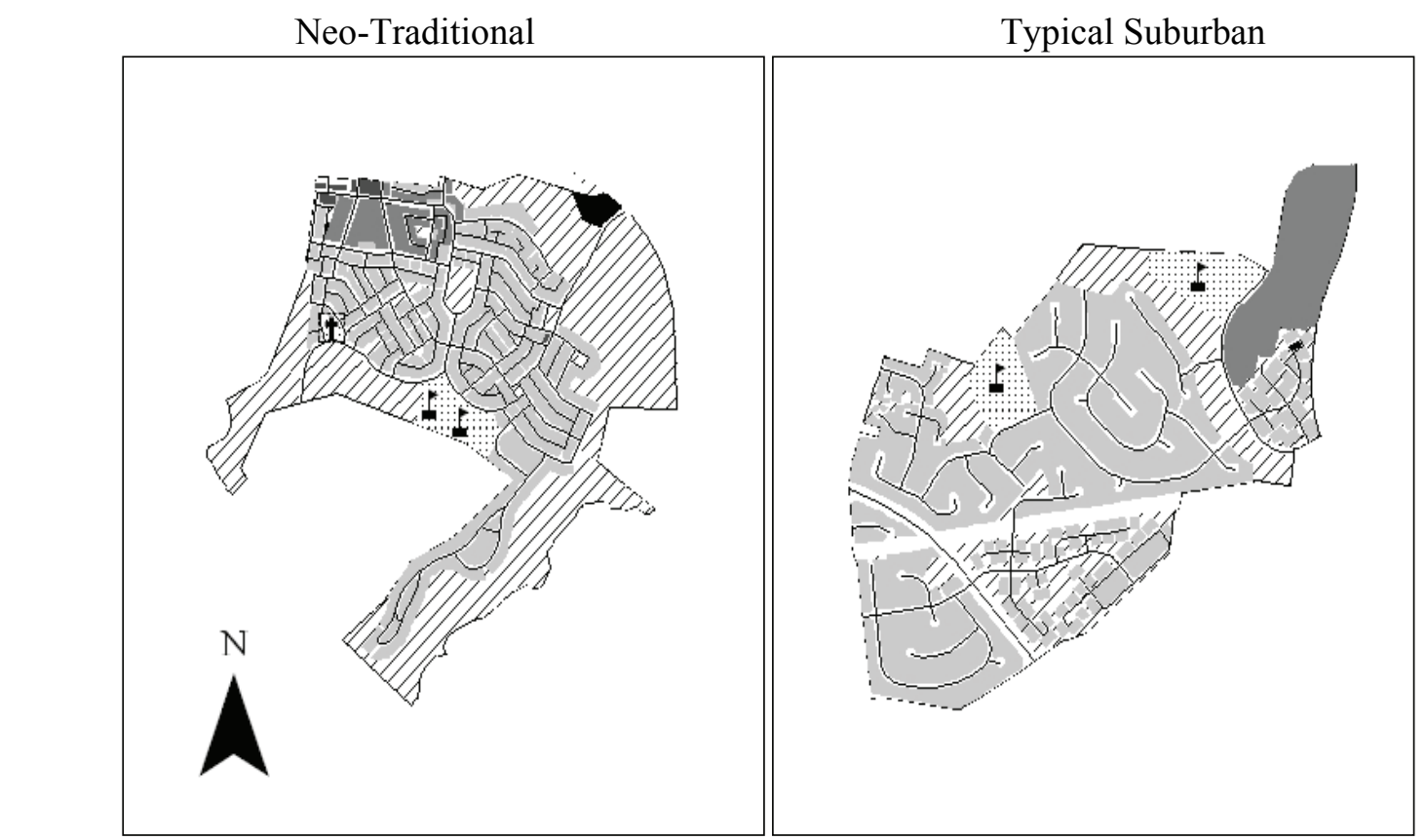

*Land-use data provided by City of Gaithersburg Department of Planning and Code Administration and Montgomery County Department of Technology Services.

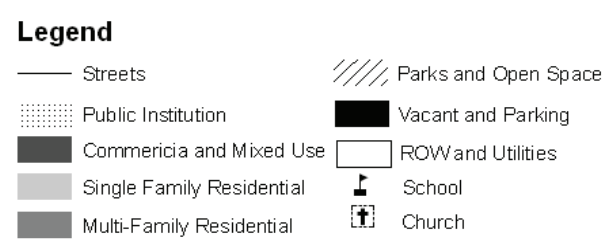

Neo-Traditional (Lakelands)

Total area of tract (acres)

Existing dwelling units

Permitted dwelling units

Mean single-family home price

Year approved

Year completed

Public Transit Access

Greenfield

Vacant area (pct of total area)

Parks/open space (pct of total area)

Residential area (pct of total built area)

Commercial area (acres)

Net single-family density (units per acre)

Street density (miles per 100 acres)

Link-node ratio

External connections

Mean Walk Score

$$
\left.\overbrace{0}^{1,000} \frac{1}{2,000}{ }_{1,1}^{1}\right|_{4,000} \text { Feet }
$$

332.10

941

1624

$\sim$

2000

2004

Yes

Yes

$1 \%$

$36 \%$

$53 \%$

0

8.26

5.45

1.55

10

65.62
Typical Suburban (Fernshire)

\subsection{0}

1083

1601

1980

1990

Yes

Yes

$0 \%$

$16 \%$

$67 \%$

0

4.22

2.78

1.14

6 


\section{Grayslake, IL}
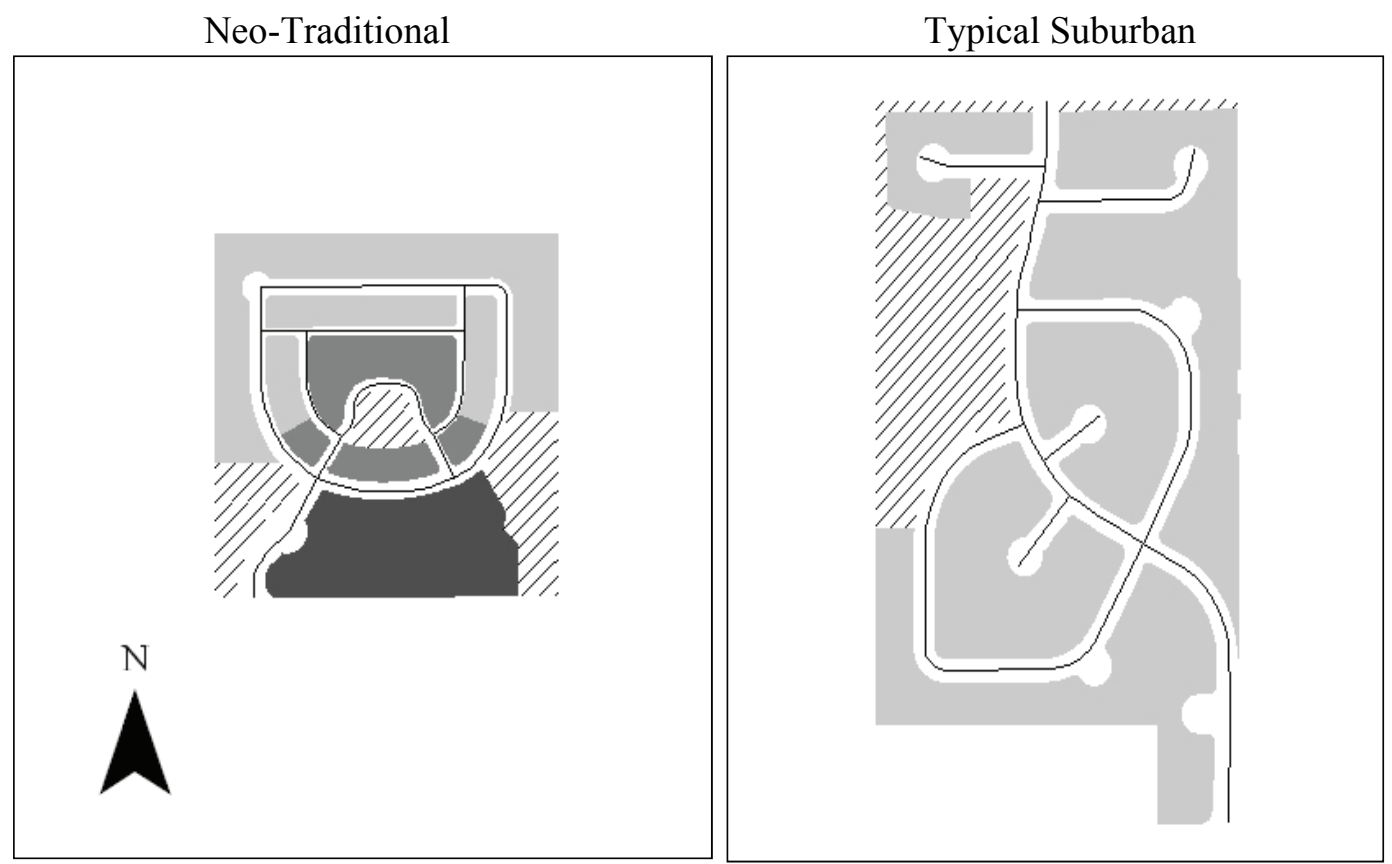

*Land-use data provided by Village of Grayslake Building Department and Lake County Department of Information Technology, GIS/Mapping Division.
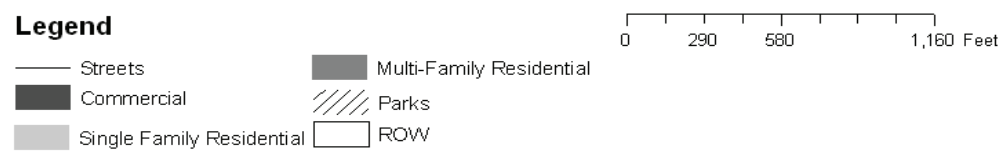

Legend
Total area of tract (acres)
Existing dwelling units
Permitted dwelling units
Mean single-family home price
Year approved
Year completed
Public Transit Access
Greenfield
Vacant area (pct of total area)
Parks/open space (pct of total area)
Residential area (pct of total built area)
Commercial area (acres)
Net single-family density (units per acre)
Street density (miles per 100 acres)
Link-node ratio
External connections
Mean Walk Score

Neo-Traditional (Washington Village)

Typical Suburban

24.40

42

(Hunter's Ridge)

Existing dwelling units

100

$\$ 95,483$

1993

48.90

126

125

$\$ 93,665$

$\sim$

1992

Yes

Yes

$0 \%$

Yes

$16 \%$

$55 \%$

4.52

5.17

4.53

Yes

$0 \%$

$18 \%$

$73 \%$

0.00

1.63

4.33

3.15

1.27

1

30

61.13 


\section{Irvine, $\mathbf{C A}$}
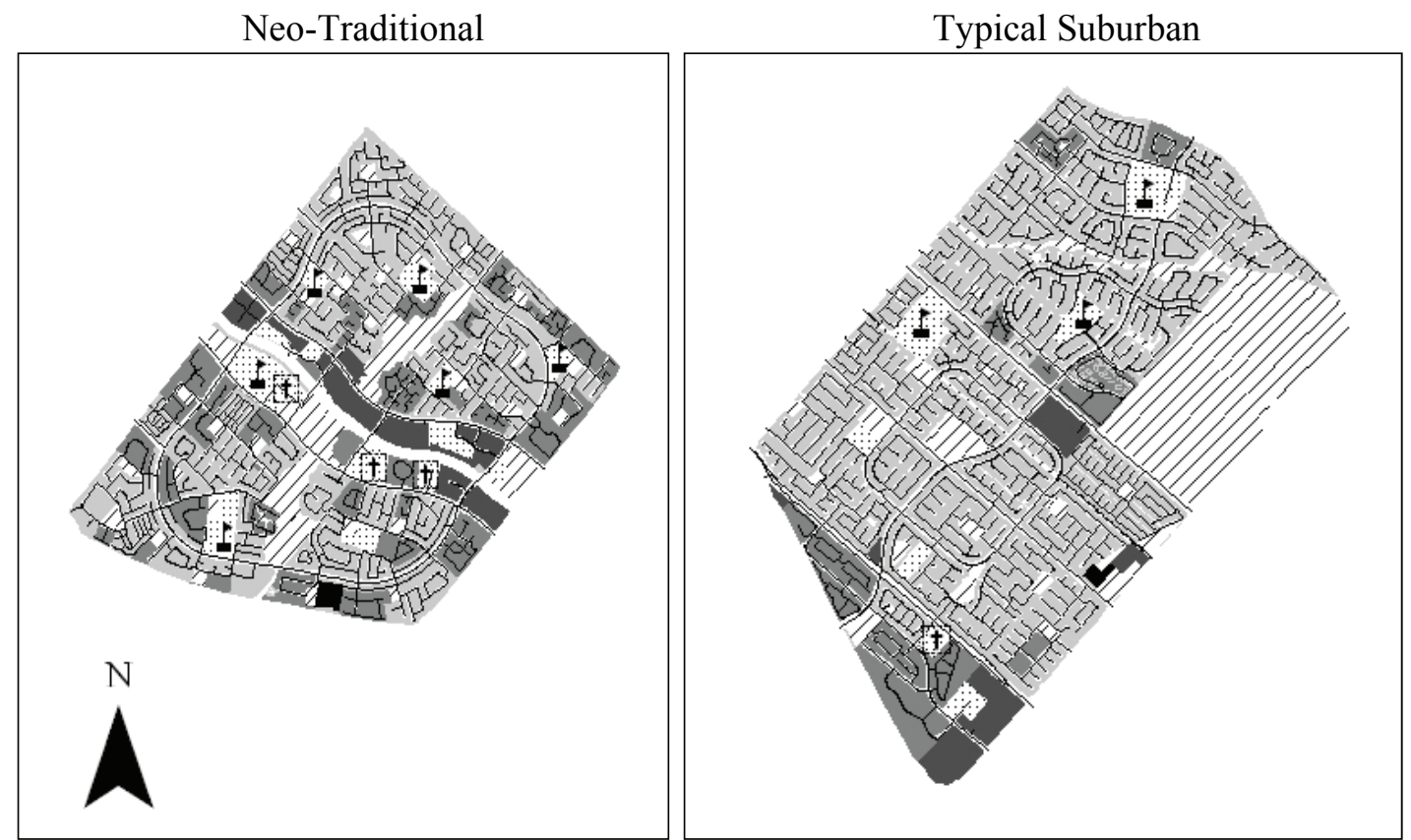

*Sources provided by City of Irvine Community Development Department.

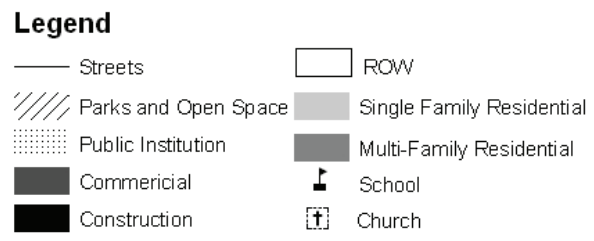

\begin{tabular}{lcc} 
& $\begin{array}{c}\text { Neo-Traditional } \\
\text { (Woodbridge) }\end{array}$ & $\begin{array}{c}\text { Typical Suburban } \\
\text { (Northwood) }\end{array}$ \\
\hline Total area of tract (acres) & 1823.60 & 2334.00 \\
Existing dwelling units & 2861 & 7188 \\
Permitted dwelling units & $\sim$ & $\sim$ \\
Mean single-family home price & $\sim$ & $\sim$ \\
Year approved & $\sim$ & $\sim$ \\
Year completed & $\sim$ & Yes \\
Public Transit Access & Yes & No \\
Greenfield & No & $0 \%$ \\
Vacant area (pct of total area) & $0 \%$ & $2 \%$ \\
Parks/open space (pct of total area) & $6 \%$ & $55 \%$ \\
Residential area (pct of total built area) & $75 \%$ & 77.88 \\
Commercial area (acres) & 90.97 & 7.84 \\
Net single-family density (units per acre) & 4.82 & 3.64 \\
Street density (miles per 100 acres) & 3.60 & 1.20 \\
Link-node ratio & 1.18 & 13 \\
External connections & 8 & 64.43 \\
Mean Walk Score & 49.05 &
\end{tabular}




\section{Jupiter, FL}

Neo-Traditional

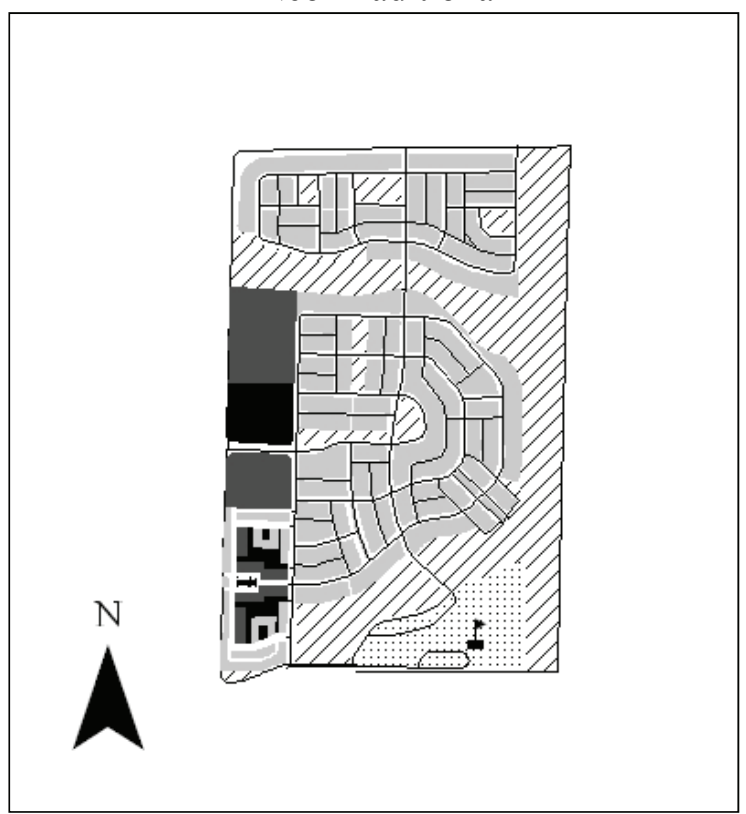

Typical Suburban

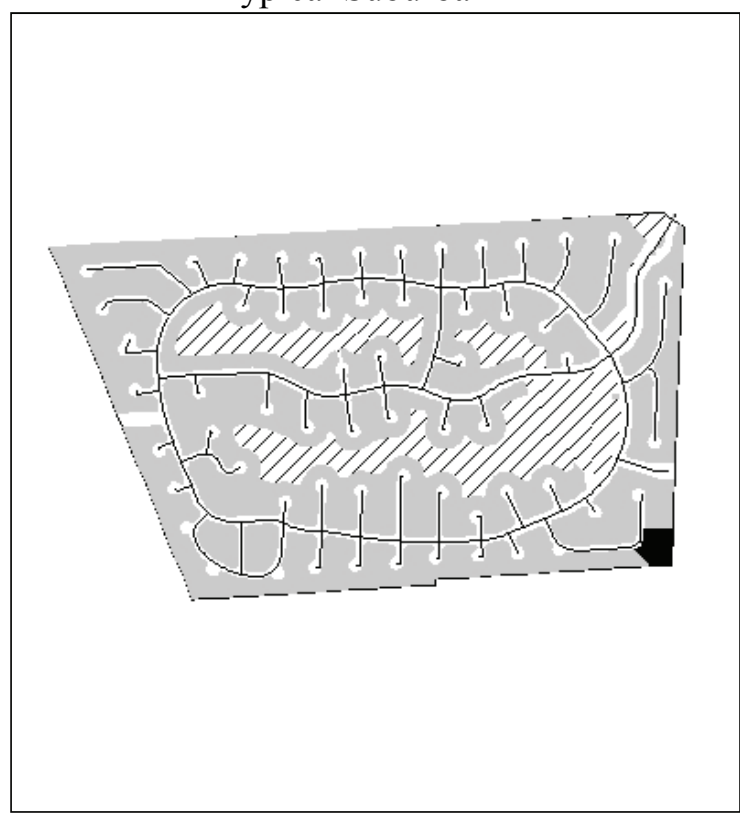

*Land-use data provided by the Town of Jupiter Department of Planning and Zoning.

Legend

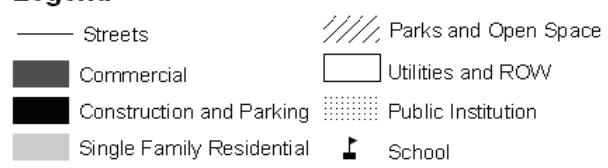

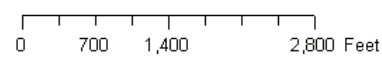

\begin{tabular}{cc}
$\begin{array}{c}\text { Neo-Traditional } \\
\text { (New Haven) }\end{array}$ & $\begin{array}{c}\text { Typical Suburban } \\
\text { (Egret Landing) }\end{array}$ \\
\hline 219.60 & 247.80 \\
605 & 669 \\
505 & 648 \\
$\$ 305,000$ & $\$ 231,000$ \\
1997 & 1989 \\
1999 & 1997 \\
No & No \\
No & No \\
$0 \%$ & $0 \%$ \\
$29 \%$ & $12 \%$ \\
$42 \%$ & $71 \%$ \\
14.70 & 0.00 \\
7.17 & 4.35 \\
5.52 & 2.91 \\
1.49 & 1.04 \\
5 & 3 \\
39.80 & 19.47 \\
\hline
\end{tabular}




\section{Longmont, $\mathrm{CO}$}

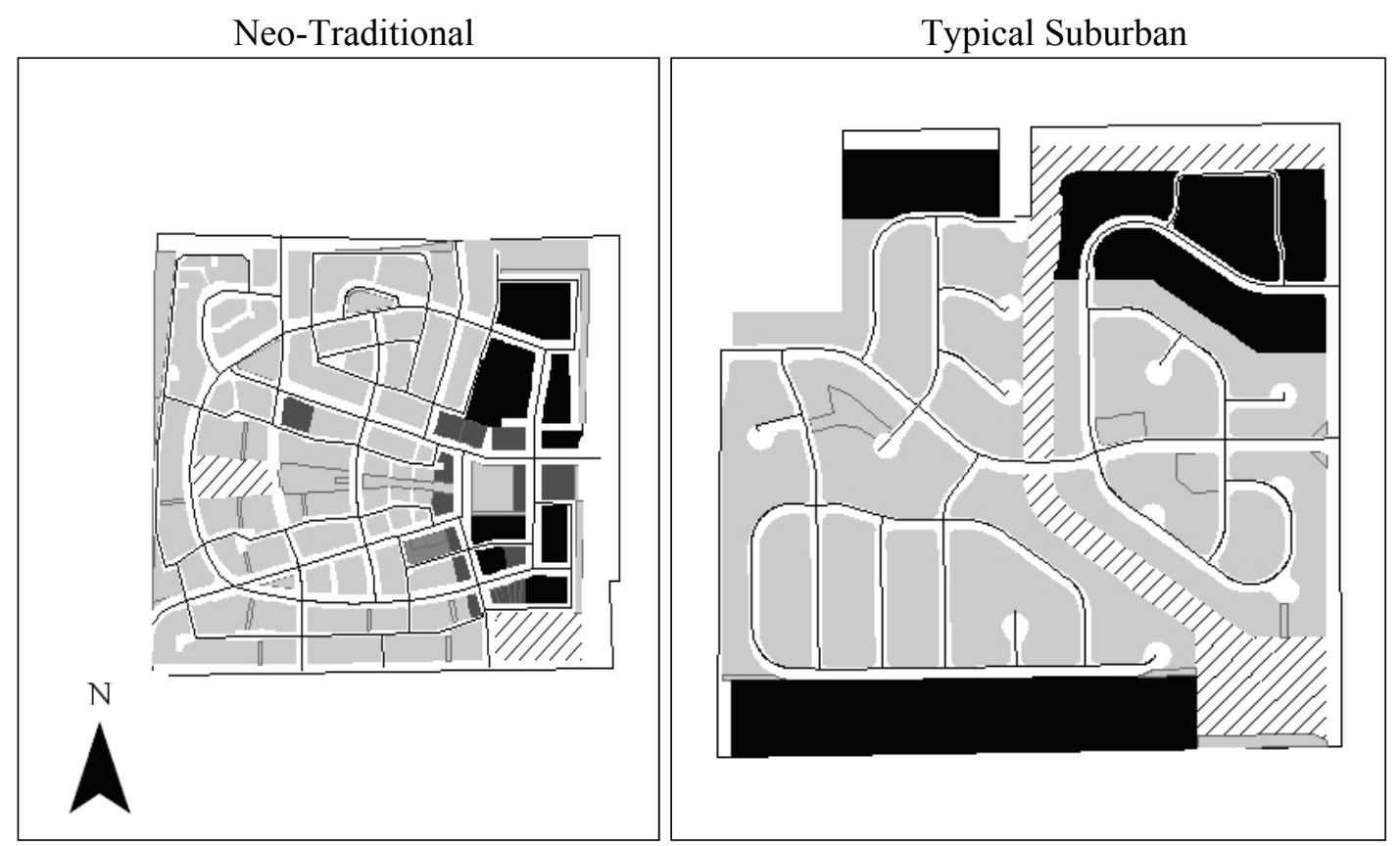

*Land-use data provided by the City of Longmont Department of Community Development.

\begin{tabular}{|c|c|c|c|c|c|}
\hline Legend & & 「 & 1 & 1 & 1,400 Feet \\
\hline - Streets & Single Family Residential & & & & \\
\hline Commercial and Mixed Use & Multi-Family Residential & & & & \\
\hline Construction and Vacant & J ROW & & & & \\
\hline
\end{tabular}

\begin{tabular}{lcc} 
& $\begin{array}{c}\text { Neo-Traditional } \\
\text { (Prospect) }\end{array}$ & $\begin{array}{c}\text { Typical Suburban } \\
\text { (Pleasant View) }\end{array}$ \\
\hline Total area of tract (acres) & 73.50 & 143.00 \\
Existing dwelling units & 268 & 320 \\
Permitted dwelling units & 656 & 472 \\
Mean single-family home price & $\$ 292,000$ & $\$ 191,000$ \\
Year approved & 1996 & 1995 \\
Year completed & $\sim$ & $\sim$ \\
Public Transit Access & Yes & Yes \\
Greenfield & Yes & Yes \\
Vacant area (pct of total area) & $6 \%$ & $23 \%$ \\
Parks/open space (pct of total area) & $4 \%$ & $3 \%$ \\
Residential area (pct of total built area) & $47 \%$ & $63 \%$ \\
Commercial area (acres) & 3 & 0.00 \\
Net single-family density (units per acre) & 8.65 & 4.73 \\
Street density (miles per 100 acres) & 5.90 & 2.72 \\
Link-node ratio & 1.74 & 1.41 \\
External connections & 5 & 3 \\
Mean Walk Score & 52.67 & 19.75 \\
\hline
\end{tabular}




\section{Mount Pleasant, SC}
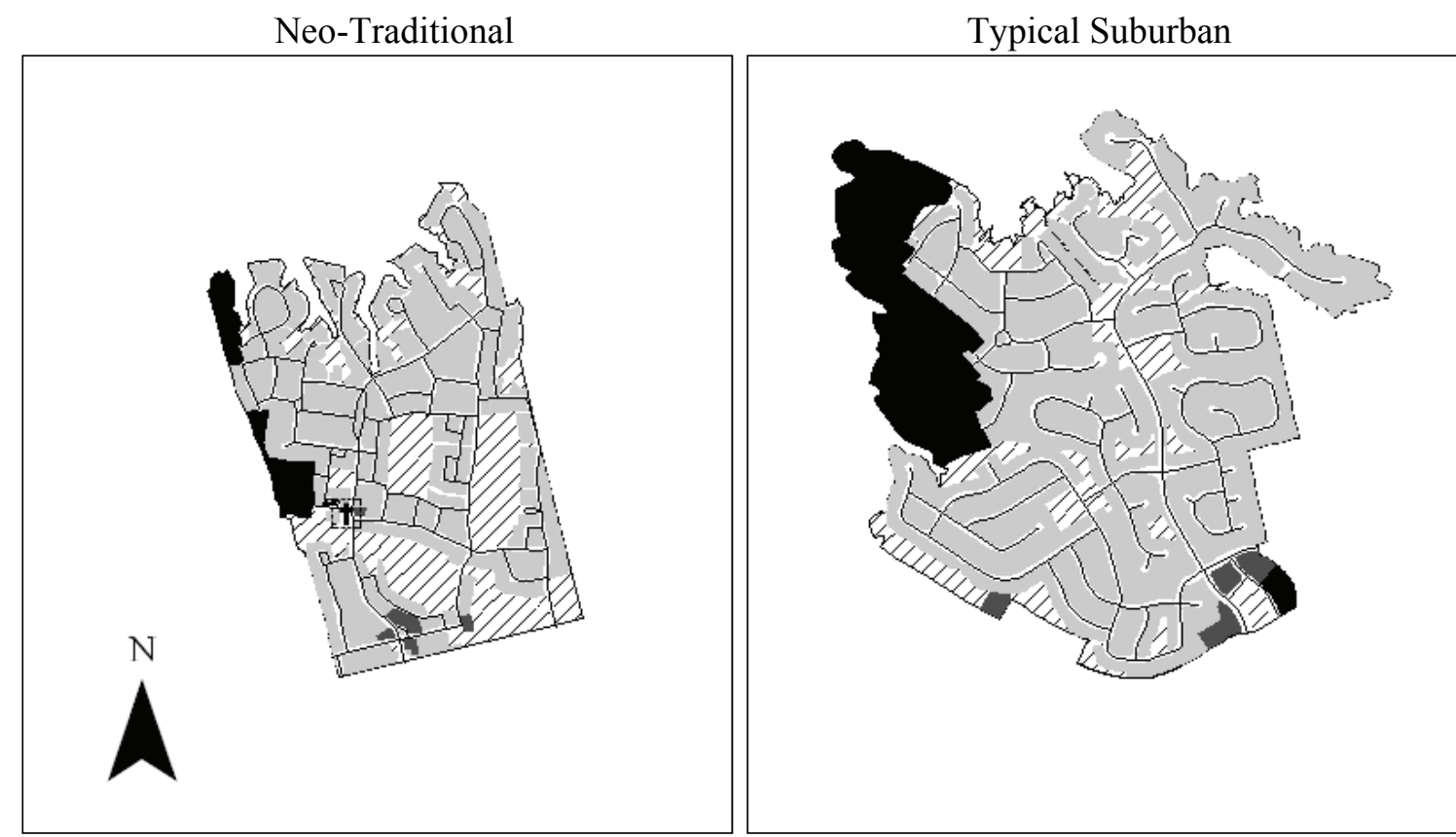

*Land-use data provided by the Town of Mount Pleasant Planning Department.

\section{Legend}

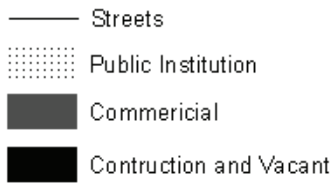

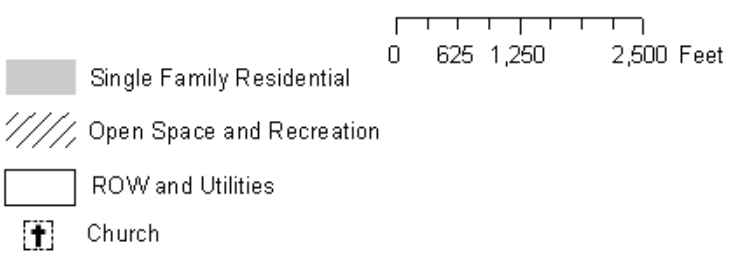

Neo-Traditional

Total area of tract (acres)

Existing dwelling units

Permitted dwelling units

Mean single-family home price

Year approved

Year completed

Typical Suburban

Public Transit Access

Greenfield

Vacant area (pct of total area)

Parks/open space (pct of total area)

Residential area (pct of total built area)

Commercial area (acres)

Net single-family density (units per acre)

Street density (miles per 100 acres)

Link-node ratio

External connections

Mean Walk Score (I'On)

243.10

729

759

(Belle Hall)

422.90

984

11.26

1997

2010

1998

No

2015

Yes

$0 \%$

$24 \%$

$62 \%$

2.62

6.28

4.21

No

Yes

$15 \%$

$10 \%$

$71 \%$

5.25

4.39

2.57

1.38

1.17

3

62.84
26.96 


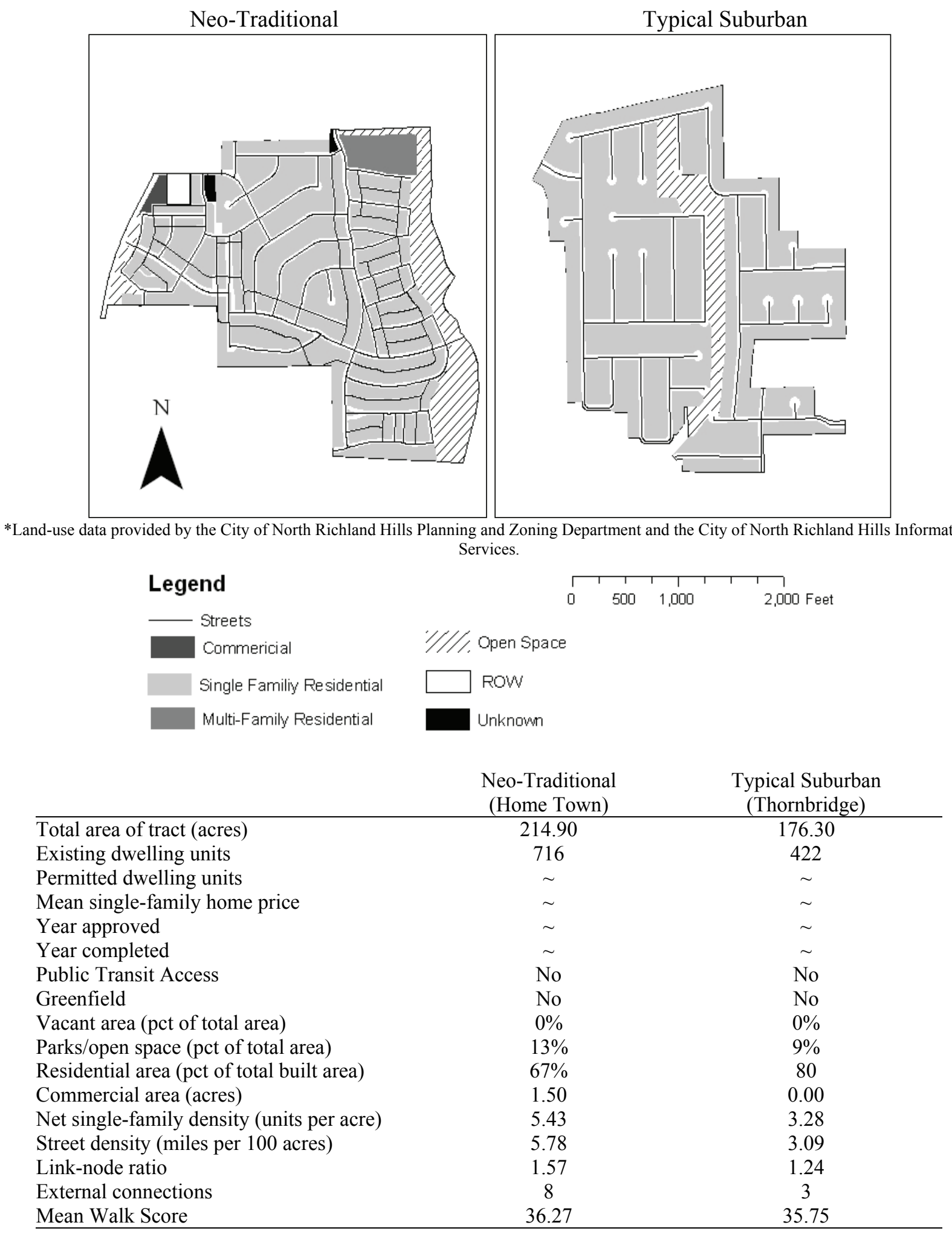




\section{Pensacola, FL}
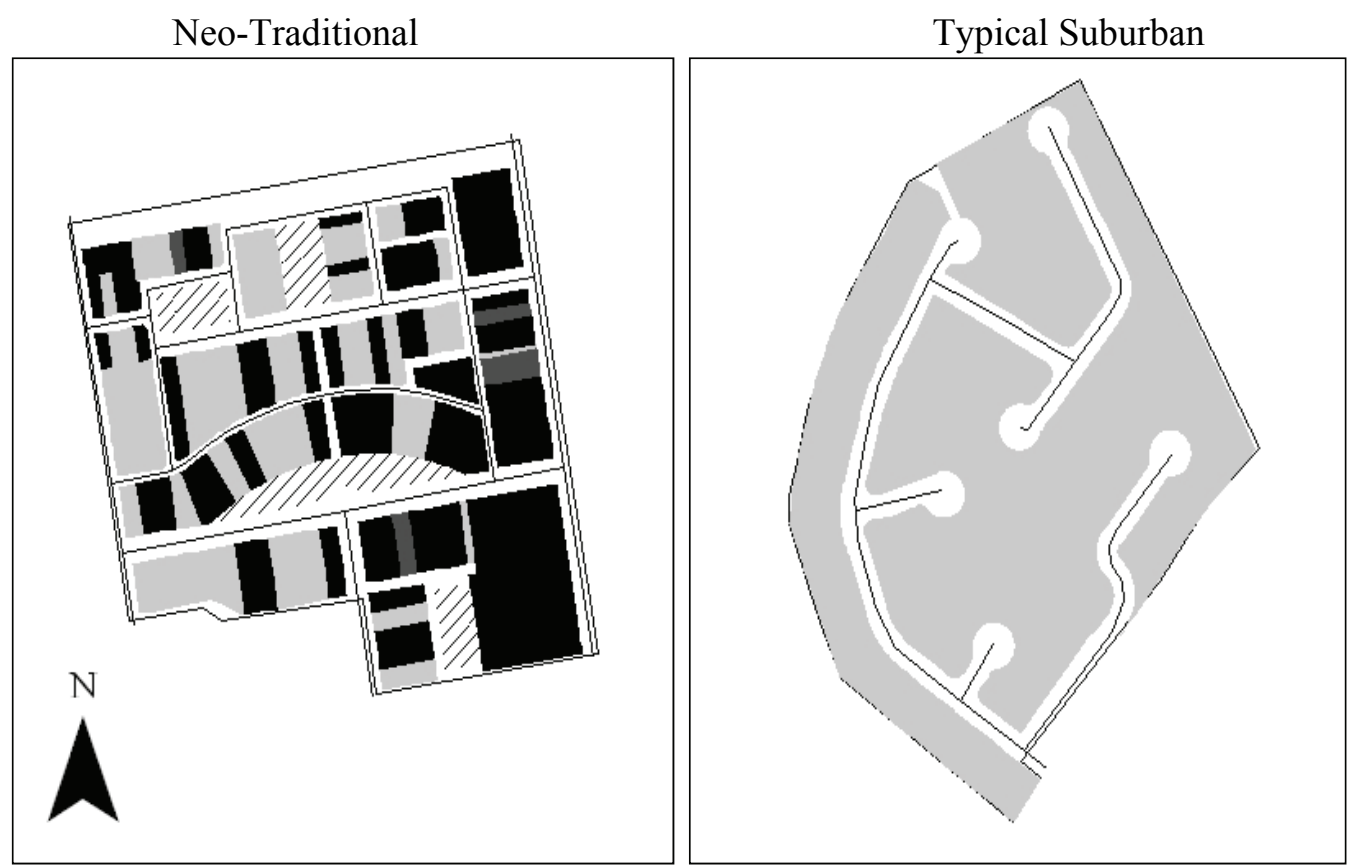

*Land-use data provided by the City of Pensacola Community Redevelopment Agency.

\section{Legend}

- Streets

Commericial and Mixed Use

Single Family Re sidential

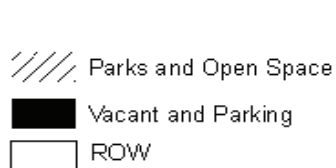

Y/./. Parks and Open Space ROW

\begin{tabular}{lcc} 
& $\begin{array}{c}\text { Neo-Traditional } \\
\text { (Aragon) }\end{array}$ & $\begin{array}{c}\text { Typical Suburban } \\
\text { (The Whispers) }\end{array}$ \\
\hline Total area of tract (acres) & 23.8 & 24.4 \\
Existing dwelling units & 62 & 109 \\
Permitted dwelling units & 143 & 100 \\
Mean single-family home price & $\$ 136,000$ & $\$ 141,000$ \\
Year approved & 2000 & 2000 \\
Year completed & $\sim$ & $\sim$ \\
Public Transit Access & Yes & Yes \\
Greenfield & No & No \\
Vacant area (pct of total area) & $34 \%$ & $0 \%$ \\
Parks/open space (pct of total area) & $8 \%$ & $0 \%$ \\
Residential area (pct of total built area) & $73 \%$ & $79 \%$ \\
Commercial area (acres) & 0.45 & 0.00 \\
Net single-family density (units per acre) & 10.71 & 5.64 \\
Street density (miles per 100 acres) & 6.47 & 2.91 \\
Link-node ratio & 1.19 & 0.92 \\
External connections & 6 & 1 \\
Mean Walk Score & 76.53 & 63 \\
\hline
\end{tabular}





\section{Appendix II. Survey instruments}

Initial survey

\section{ALL RESPONSES WILL BE KEPT STRICTLY CONFIDENTIAL.}

If you get to a question you cannot or choose not to answer, please skip to the next one.

1. Can you walk unassisted for $\mathbf{2 0}$ minutes or more?

No _ _ [please Stop and send in empty survey] Yes

2. What best describes your race/ethnicity? [check all that apply]

a $\square$ African American
b $\square$ Asian/Pacific Islander
c $\square$ Latino/a
d $\square$ Native American
e $\square$ White
f $\square$ Other
g $\square$ Don't know

3. What is your gender?

a $\square$ Female
b $\square$ Male

4. What type of home do you currently live in? $\square$ Detached single house

b Duplex, townhouse, or rowhouse

c $\square$ Apartment or condominium

d $\square$ Other [Specify]

e $\square$ Don't know

5. Do you rent or own your current home?

a $\square$ Own
b $\square$ Rent
c $\square$ Other [Specify]
d $\square$ Don't know

6. What year and month did you move into your current neighborhood?

a_Year Month

7. How many people live in your household? [Please do not include anyone who usually lives somewhere else or is just visiting]

a

8. Including yourself, please list the age in years of each member of your household.

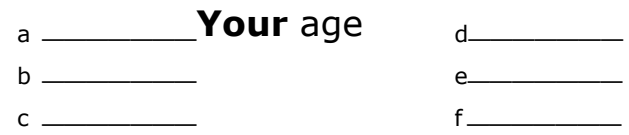

9. How many, if any, cars are available in your household? [Include leased, vanpool, or company-owned motorized vehicles if they are used by household members on a regular basis] Number
10. For the two most used cars in your household, please list the make, model, year, miles driven last year, and number of years your household has owned or leased them.

Primary Vehicle

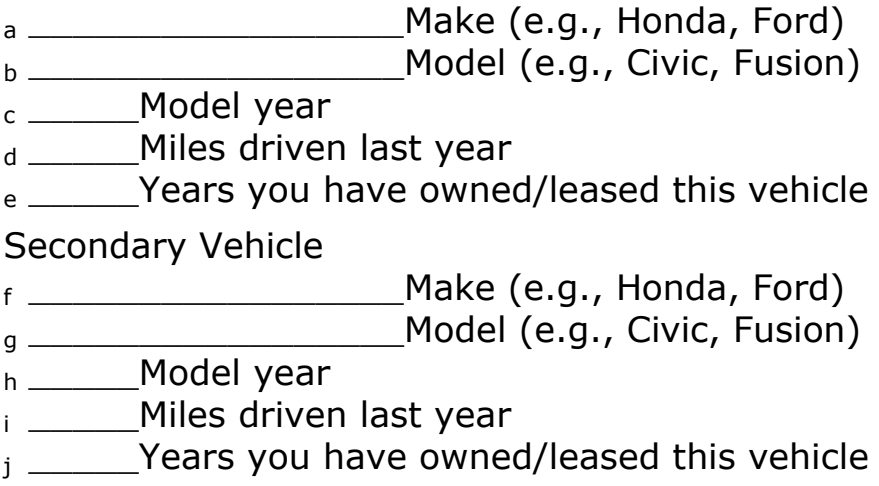

11. What is the highest level of education you have completed?
a $\square$ Less than High School
b $\square$ High School or GED
c $\square$ Vocational/Technical Degree/ Some College
d $\square$ Bachelor's Degree (BA,BS)
e $\square$ Some graduate school, no degree
$\mathrm{g} \square$ Graduate or Professional School

12. If you work, what is your approximate household income before taxes? [information is strictly confidential]

$$
\begin{array}{ll}
\text { a } \square \text { Under } \$ 20,000 & \mathrm{f} \square \$ 60,001-\$ 80,000 \\
\text { b } \square \$ 20,000-\$ 30,000 & \mathrm{~g} \square \$ 80,001-\$ 100,000 \\
\text { c } \square \$ 30,001-\$ 40,000 & \mathrm{~h} \square \$ 100,001-\$ 150,000 \\
\text { d } \square \$ 40,001-\$ 50,000 \text { i } \square \$ 150,001-\$ 200,000 \\
\text { e } \square \$ 50,001-\$ 60,000 & \text { j } \square \text { Over } \$ 200,000
\end{array}
$$

13. My ideal commuting time to work or school is:

a Less than 5 minutes
b_Between 5 and 15 minutes
c Between 15 and 30 minutes
d_B More than 30 minutes

14. If the cost of gasoline increased $50 \%$ in the next year, I would [check all that apply]

$\mathrm{a} \_$Drive less
$\mathrm{b} \_$Move to a different location
$\mathrm{c} \_$Purchase an alternative fuel vehicle
[hybrid, electric, E-85, etc. ]
$\mathrm{d} \_$Do nothing
$\mathrm{e} \_$Other [Specify]


1. What best describes your employment status? [Please check only one and answer the following questions accordingly] $\left.\begin{array}{l}\text { a } \square \text { Work full-time outside the home } \\ \text { b } \square \text { Work part-time outside the home }\end{array}\right\} \rightarrow \begin{aligned} & \text { Please continue } \\ & \text { to que stion } 2\end{aligned}$

с $\square$ Student $\rightarrow$ Please skip to que stion 3

d $\square$ Work full-time at home

e $\square$ Work part-time at home

f $\square$ Unemployed (non-student)

g $\square$ Retired

$\mathrm{h} \square$ Other [Specify]
2. Do you ever telecommute/telework to work? If so, how many times per week?

${ }_{a} \square$ No $\quad b \square$ Yes, times per week

3. How long does it typically take to get to your main place of work or school from your home?

a__ hours b_ minutes

4. How much do you typically spend on traveling to work or to school per week? [Include all gas, parking, or transit fares] a $\$$

5. About how many miles per week do you travel by car?

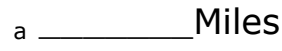

\section{In a typical week, Monday through Friday, how often do you travel to the following places?}

$$
\text { never 1-2 times 3-5 times 6+ times }
$$

To your work or school as the driver

Outside your neighborhood

Within your neighborhood

To your work or school driven by someone else

Outside your neighborhood

Within your neighborhood

To your work or school using public transportation

Outside your neighborhood

Within your neighborhood

To your work or school by walking or bicycle

Outside your neighborhood

Within your neighborhood

Transporting someone (for example pickup someone, take and wait for someone, drop off someone)

Outside your neighborhood

Within your neighborhood

To go shopping or run an errand as a driver or driven by someone else

Outside your neighborhood

Within your neighborhood

To go shopping or run an errand by walking or bicycle

Outside your neighborhood

Within your neighborhood

To go out for recreation, entertainment, or meals (watch/play sports, movie, museum, restaurant/bar, visit friends/relatives) as a driver or driven by someone else

Outside your neighborhood

Within your neighborhood 
Please consider moderate and vigorous physical activities. Moderate activities cause small increases in breathing or heart rate, while vigorous activities cause large increases in breathing or heart rate.

1. In a usual week, do you do MODERATE physical activities for at least 10 minutes at a time, such as brisk walks, bicycling, vacuuming, gardening, or anything else that causes SMALL INCREASES in breathing or heart rate?

No a _ \{skip to Question 5\} Yes b

2. How many days per week do you do these MODERATE activities for at least 10 minutes at a time?

Now consider vigorous activities that cause large increases in breathing or heart rate such as jogging, swimming, or aerobics

5. In a usual week, do you do VIGOROUS physical activities for at least 10 minutes at a time, such as running, aerobics, heavy yard work, or anything else that causes LARGE INCREASES in breathing or heart rate?

No _ _ skip to Question 9\} Yes

6. How many days per week do you do these VIGOROUS activities for at least 10 minutes at a time? a

7. On days when you do VIGOROUS activities for at least 10 minutes at a time, how much total time per day do you spend doing these activities?
3. On days when you do MODERATE activities for at least 10 minutes at a time, how much total time per day do you spend doing these activities?

a_hours b_ minutes

4. What percentage of the total time that you spend on MODERATE activities do you spend:

a__ $\%$ At home

b__ \% Outside my home but in my neighborhood c_ \% Outside of my neighborhood a_hours b_ minutes
8. What percentage of the total time that you spend on VIGOROUS activities do you spend:

a__ \% At home

b__ \% Outside my home but in my neighborhood c_ \% Outside of my neighborhood

9. What is your weight? a pounds

10. What is your height feet inches

11. How often have you used the Internet in the past 6 months at home?
a $\square$ Everyday
b $\square$ Almost everyday
c $\square$ Once a week
d $\square$ Once a month
e $\square$ Never

On a scale of 1 to 5, please rate how important each of the following reasons was in your decision to move to your neighborhood. $1=$ not at all important... 5= very important [Circle a number for each statement]

Affordability/value of my home

$\begin{array}{ccc}1 & 2 & 3 \\ \text { not at all important } & & \text { somewhat import } \\ \text { important } & & \\ \text { Closeness to open space, such as parks }\end{array}$

Closeness to open space, such as parks

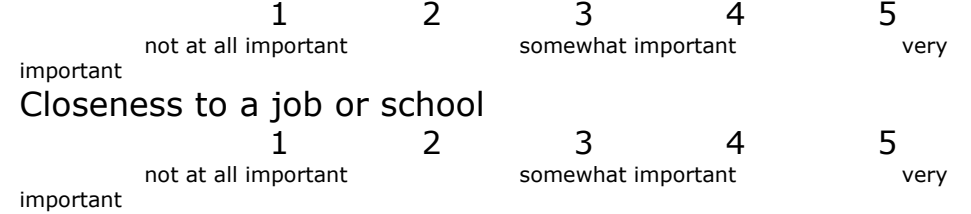

Closeness to public transportation

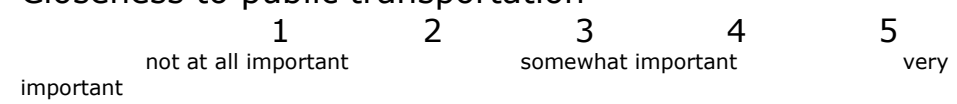

Desire for nearby shops and services

\begin{tabular}{|c|c|c|c|}
\hline$\stackrel{1}{\text { not at all important }}$ & 2 & $\begin{array}{cc}3 & 4 \\
\text { somewhat important }\end{array}$ & 5 \\
\hline Ease of walking & & & \\
\hline $\begin{array}{l}1 \\
\text { important } \\
\text { Sense of at all important } \\
\end{array}$ & 2 & $\begin{array}{cc}3 & 4 \\
\text { somewhat important }\end{array}$ & 5 \\
\hline important $\quad 1$ & 2 & $\begin{array}{cr}3 & 4 \\
\text { somewhat important }\end{array}$ & 5 very \\
\hline
\end{tabular}

5 very very very very

(1)


On a scale of 1 to 5, express your level of agreement with the following statements. $1=$ strongly disagree.... $\mathbf{5}=$ strongly agree [Circle a number for each statement]

I enjoy walking or bicycling

$\begin{array}{ccccc}1 & 2 & 3 & 4 & 5 \\ \text { strongly disagree } & & \text { neutral } & & \text { strongly agree }\end{array}$

I am comfortable riding a bus

$$
\begin{array}{ccrrr}
1 & 2 & 3 & 4 & 5 \\
\text { strongly disagree } & & \text { neutral } & & \text { strongly agree }
\end{array}
$$

It's important for children to have a large backyard for playing

$\begin{array}{ccrcc}1 & 2 & 3 & 4 & 5 \\ \text { strongly disagree } & & \text { neutral } & & \text { strongly agree }\end{array}$

Environmental protection is an important issue

$$
\begin{array}{ccrcc}
1 & 2 & 3 & 4 & 5 \\
\text { strongly disagree } & & \text { neutral } & & \text { strongly agree }
\end{array}
$$

I enjoy a house close to the sidewalk so that I can see and interact with passersby

$\begin{array}{ccrcc}1 & 2 & 3 & 4 & 5 \\ \text { strongly disagree } & & \text { neutral } & & \text { strongly agree }\end{array}$

Too much land is consumed for new housing, stores, and offices

$$
\begin{array}{ccrcc}
1 & 2 & 3 & 4 & 5 \\
\text { strongly disagree } & & \text { neutral } & & \text { strongly agree }
\end{array}
$$

I can be comfortable living in close proximity to my

neighbors

$$
\begin{array}{ccrcc}
1 & 2 & 3 & 4 & 5 \\
\text { strongly disagree } & & \text { neutral } & & \text { strongly agree }
\end{array}
$$

I prefer lots of space between my home and the street

$\begin{array}{ccrcc}1 & 2 & 3 & 4 & 5 \\ \text { strongly disagree } & & \text { neutral } & & \text { strongly agree }\end{array}$

Children should have a large public play space within safe walking distance of their home

$\begin{array}{ccrcc}1 & 2 & 3 & 4 & 5 \\ \text { strongly disagree } & & \text { neutral } & & \text { strongly agree }\end{array}$

Having shops and services close by is important to me

$\begin{array}{ccccc}1 & 2 & 3 & 4 & 5 \\ \text { strongly disagree } & & \text { neutral } & & \text { strongly agree }\end{array}$

Household energy consumption in the US is a major contributor to global climate change

$\begin{array}{ccccc}1 & 2 & 3 & 4 & 5 \\ \text { strongly disagree } & & \text { neutral } & & \text { strongly agree }\end{array}$

The government should put more emphasis on

encouraging places that makes people less dependent on automobiles

$$
\begin{array}{ccrcc}
1 & 2 & 3 & 4 & 5 \\
\text { strongly disagree } & & \text { neutral } & & \text { strongly agree }
\end{array}
$$

As an individual, I can make a difference when it comes to conserving energy and protecting the environment

$\begin{array}{ccccc}1 & 2 & 3 & 4 & 5 \\ \text { strongly disagree } & & \text { neutral } & & \text { strongly agree }\end{array}$

This is a close-knit neighborhood

$\begin{array}{ccrcc}1 & 2 & 3 & 4 & 5 \\ \text { strongly disagree } & & \text { neutral } & & \text { strongly agree }\end{array}$

People in my neighborhood can be trusted

$\begin{array}{ccrrr}1 & 2 & 3 & 4 & 5 \\ \text { strongly disagree } & & \text { neutral } & & \text { strongly agree }\end{array}$

There are sidewalks on most of the streets in my neighborhood

$\begin{array}{ccccc}1 & 2 & 3 & 4 & 5 \\ \text { strongly disagree } & & \text { neutral } & & \text { strongly agree }\end{array}$

People in my neighborhood are willing to help their neighbors

$$
\begin{array}{crrrr}
1 & 2 & 3 & 4 & 5 \\
\text { strongly disagree } & & \text { neutral } & & \text { strongly agree }
\end{array}
$$

Considering road and traffic conditions, it is safe to ride a bicycle in or near my neighborhood

$$
\begin{array}{ccccc}
1 & 2 & 3 & 4 & 5 \\
\text { strongly disagree } & & \text { neutral } & & \text { strongly agree }
\end{array}
$$

My neighborhood is safe enough for a 10 year old child to walk around the block alone during daytime

$\begin{array}{ccccc}1 & 2 & 3 & 4 & 5 \\ \text { strongly disagree } & & \text { neutral } & & \text { strongly agree }\end{array}$

There are many places to go within easy walking

distance of my home

$\begin{array}{ccrcc}1 & 2 & 3 & 4 & 5 \\ \text { strongly disagree } & & \text { neutral } & & \text { strongly agree }\end{array}$

People in my neighborhood generally do not get along with each other

$\begin{array}{ccrcc}1 & 2 & 3 & 4 & 5 \\ \text { strongly disagree } & & \text { neutral } & & \text { strongly agree }\end{array}$

People in this neighborhood do not share similar values

$$
\begin{array}{ccrcc}
1 & 2 & 3 & 4 & 5 \\
\text { strongly disagree } & & \text { neutral } & & \text { strongly agree }
\end{array}
$$

Parents in this neighborhood know their children's

friends

$\begin{array}{ccrcc}1 & 2 & 3 & 4 & 5 \\ \text { strongly disagree } & & \text { neutral } & & \text { strongly agree }\end{array}$

Most of my kids' friends live in this neighborhood

$\begin{array}{ccccc}1 & 2 & 3 & 4 & 5 \\ \text { strongly disagree } & & \text { neutral } & & \text { strongly agree }\end{array}$

You can count on adults in this neighborhood to watch out for kids and keep them safe

$$
\begin{array}{ccrcc}
1 & 2 & 3 & 4 & 5 \\
\text { strongly disagree } & & \text { neutral } & & \text { strongly agree }
\end{array}
$$

Adults in this neighborhood do not know who the local children are

$\begin{array}{ccrcc}1 & 2 & 3 & 4 & 5 \\ \text { strongly disagree } & & \text { neutral } & & \text { strongly agree }\end{array}$

There are adults in this neighborhood that children can look up to

$\begin{array}{ccrcc}1 & 2 & 3 & 4 & 5 \\ \text { strongly disagree } & & \text { neutral } & & \text { strongly agree }\end{array}$

Parents in this neighborhood generally do not know each other

$\begin{array}{ccrcc}1 & 2 & 3 & 4 & 5 \\ \text { strongly disagree } & & \text { neutral } & & \text { strongly agree }\end{array}$

It is easy to find good housing in this area in places where I do not need to rely on a car for everything

$\begin{array}{ccccc}1 & 2 & 3 & 4 & 5 \\ \text { strongly disagree } & & \text { neutral } & & \text { strongly agree }\end{array}$


How many, if any, cars are available in your household? [Include leased, vanpool, or company-owned motorized vehicles if they are used by household members on a regular basis]

\section{a} Number

For the two most used cars in your household, please list the make, model, year, miles driven last year, and number of years your household has owned or leased them.

Primary Vehicle

a Make (e.g., Honda, Ford)

b Fusion)

c Model year

d__ Miles driven last year

e Years you have owned/leased this

vehicle

Model (e.g., Civic,
Secondary Vehicle

$f$

Honda, Ford)

g Fusion)

c Model year

d__ Miles driven last year

e Y Years you have owned/leased this Make (e.g., Model (e.g., Civic, vehicle

never 1-2 times 3-5 times 6+ times

To your work or school as the driver

Outside your neighborhood

Within your neighborhood

To your work or school driven by someone else

Outside your neighborhood

Within your neighborhood

To your work or school using public transportation

Outside your neighborhood

Within your neighborhood

To your work or school by walking or bicycle

Outside your neighborhood

Within your neighborhood

Transporting someone (for example pickup someone, take and wait for someone, drop off someone)

Outside your neighborhood

Within your neighborhood

To go shopping or run an errand as a driver or driven by someone else

Outside your neighborhood

Within your neighborhood

To go shopping or run an errand by walking or bicycle

Outside your neighborhood

Within your neighborhood

To go out for recreation, entertainment, or meals (watch/play sports, movie, museum, restaurant/bar, visit friends/relatives) as a driver or driven by someone else

Outside your neighborhood

Within your neighborhood 
QUESTIONS ABOUT YOUR ACTIVITIES

Please consider moderate and vigorous physical activities. Moderate activities cause small Increases in breathing or heart rate, while vigorous activities cause large increases in breathing or heart rate.

In a usual week, do you do MODERATE physical activities for at least 10 minutes at a time, such as brisk walks, bicycling, vacuuming, gardening, or anything else that causes SMALL INCREASES in breathing or heart rate?

No a _ _ skip to Question 5\} Yes b

How many days per week do you do these

MODERATE activities for at least 10 minutes at a time? a

Now consider vigorous activities that cause large increases in breathing or heart rate such as jogging, swimming, or aerobics.

In a usual week, do you do VIGOROUS physical activities for at least 10 minutes at a time, such as running, aerobics, heavy yard work, or anything else that causes LARGE INCREASES in breathing or heart rate?

No __ _skip to the next section\} Yes

How many days per week do you do these

VIGOROUS activities for at least 10 minutes at a

time? a
On days when you do MODERATE activities for at least 10 minutes at a time, how much total time per day do you spend doing these activities?

a_hours b_minutes

What percentage of the total time that you spend on MODERATE activities do you spend: $\%$ At home

b___ $\%$ Outside my home but in my neighborhood $\%$ Outside of my neighborhood
On days when you do VIGOROUS activities for at least 10 minutes at a time, how much total time per day do you spend doing these activities?

a_hours b_ minutes

What percentage of the total time that you spend on VIGOROUS activities do you spend: $\%$ At home

b___ $\%$ Outside my home but in my neighborhood c_ Outside of my neighborhood

On a scale of 1 to 5 , please rate how important each of the following reasons was in your decision to move to your neighborhood. $1=$ not at all important.... 5= very important [Circle a number for each statement]

Affordability/value of my home

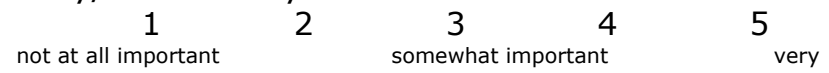

important

Closeness to open space, such as parks

important

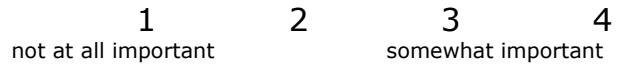

5

Closeness to a job or school

$$
\begin{array}{cccc}
1 & 2 & 3 & 4 \\
\text { not at all important } & & \text { somewhat important }
\end{array}
$$

Closeness to public transportation

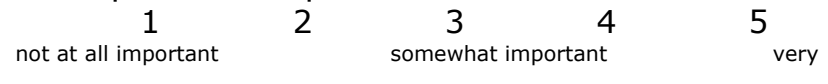

important

Desire for nearby shops and services

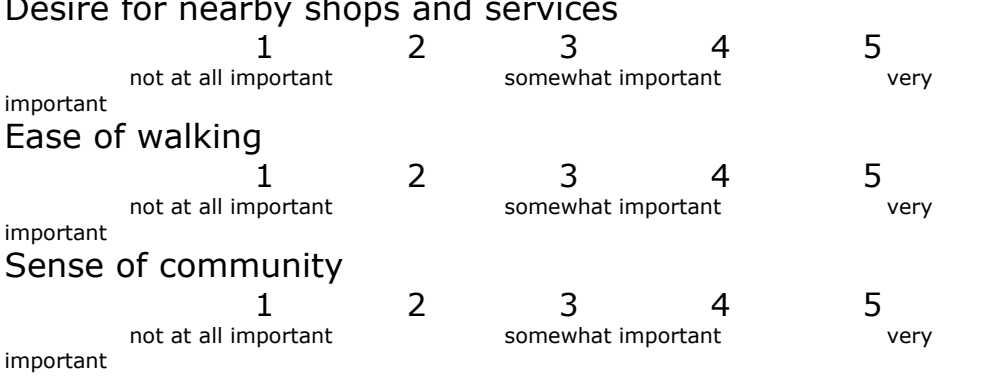


On a scale of 1 to 5 , express your level of agreement with the following statements. $1=$ strongly disagree.... $\mathbf{5}=$ strongly agree [Circle a number for each statement]

I enjoy walking or bicycling

$\begin{array}{ccrcc}1 & 2 & 3 & 4 & 5 \\ \text { strongly disagree } & & \text { neutral } & & \text { strongly agree }\end{array}$

I am comfortable riding a bus

$\begin{array}{ccrrc}1 & 2 & 3 & 4 & 5 \\ \text { strongly disagree } & & \text { neutral } & & \text { strongly agree }\end{array}$

It's important for children to have a large backyard for playing

$\begin{array}{ccrcc}1 & 2 & 3 & 4 & 5 \\ \text { strongly disagree } & & \text { neutral } & & \text { strongly agree }\end{array}$

Environmental protection is an important issue

$\begin{array}{ccccc}1 & 2 & 3 & 4 & 5 \\ \text { strongly disagree } & & \text { neutral } & & \text { strongly agree }\end{array}$

I enjoy a house close to the sidewalk so that I can see and interact with passersby

$\begin{array}{ccrcc}1 & 2 & 3 & 4 & 5 \\ \text { strongly disagree } & & \text { neutral } & & \text { strongly agree }\end{array}$

Too much land is consumed for new housing, stores, and offices

$\begin{array}{ccrcc}1 & 2 & 3 & 4 & 5 \\ \text { strongly disagree } & & \text { neutral } & & \text { strongly agree }\end{array}$

I can be comfortable living in close proximity to my neighbors

$$
\begin{array}{ccrcc}
1 & 2 & 3 & 4 & 5 \\
\text { strongly disagree } & & \text { neutral } & & \text { strongly agree }
\end{array}
$$

I prefer lots of space between my home and the street

$\begin{array}{ccccc}1 & 2 & 3 & 4 & 5 \\ \text { strongly disagree } & & \text { neutral } & & \text { strongly agree }\end{array}$

Children should have a large public play space within safe walking distance of their home

$\begin{array}{ccccc}1 & 2 & 3 & 4 & 5 \\ \text { strongly disagree } & & \text { neutral } & & \text { strongly agree }\end{array}$

Having shops and services close by is important to me

$\begin{array}{ccccc}1 & 2 & 3 & 4 & 5 \\ \text { strongly disagree } & & \text { neutral } & & \text { strongly agree }\end{array}$

Household energy consumption in the US is a major contributor to global climate change

$\begin{array}{ccccc}1 & 2 & 3 & 4 & 5 \\ \text { strongly disagree } & & \text { neutral } & & \text { strongly agree }\end{array}$

The government should put more emphasis on

encouraging places that makes people less dependent on automobiles

$\begin{array}{ccrcc}1 & 2 & 3 & 4 & 5 \\ \text { strongly disagree } & & \text { neutral } & & \text { strongly agree }\end{array}$

As an individual, I can make a difference when it comes to conserving energy and protecting the environment

$\begin{array}{ccccc}1 & 2 & 3 & 4 & 5 \\ \text { strongly disagree } & & \text { neutral } & & \text { strongly agree }\end{array}$

This is a close-knit neighborhood

$\begin{array}{ccrcc}1 & 2 & 3 & 4 & 5 \\ \text { strongly disagree } & & \text { neutral } & & \text { strongly agree }\end{array}$

People in my neighborhood can be trusted

$\begin{array}{ccrcc}1 & 2 & 3 & 4 & 5 \\ \text { strongly disagree } & & \text { neutral } & & \text { strongly agree }\end{array}$

There are sidewalks on most of the streets in my neighborhood

$$
\begin{array}{ccrcc}
1 & 2 & 3 & 4 & 5 \\
\text { strongly disagree } & & \text { neutral } & & \text { strongly agree }
\end{array}
$$

People in my neighborhood are willing to help their neighbors

$\begin{array}{ccrcc}1 & 2 & 3 & 4 & 5 \\ \text { strongly disagree } & & \text { neutral } & & \text { strongly agree }\end{array}$

Considering road and traffic conditions, it is safe to ride a bicycle in or near my neighborhood

$$
\begin{array}{ccccc}
1 & 2 & 3 & 4 & 5 \\
\text { strongly disagree } & & \text { neutral } & & \text { strongly agree }
\end{array}
$$

My neighborhood is safe enough for a 10 year old child to walk around the block alone during daytime

$$
\begin{array}{ccrcc}
1 & 2 & 3 & 4 & 5 \\
\text { strongly disagree } & & \text { neutral } & & \text { strongly agree }
\end{array}
$$

There are many places to go within easy walking distance of my home

$\begin{array}{ccrcc}1 & 2 & 3 & 4 & 5 \\ \text { strongly disagree } & & \text { neutral } & & \text { strongly agree }\end{array}$

People in my neighborhood generally do not get along with each other

$\begin{array}{ccrcc}1 & 2 & 3 & 4 & 5 \\ \text { strongly disagree } & & \text { neutral } & & \text { strongly agree }\end{array}$

People in this neighborhood do not share similar values

$\begin{array}{ccrcc}1 & 2 & 3 & 4 & 5 \\ \text { strongly disagree } & & \text { neutral } & & \text { strongly agree }\end{array}$

Parents in this neighborhood know their children's

friends

$\begin{array}{ccrcc}1 & 2 & 3 & 4 & 5 \\ \text { strongly disagree } & & \text { neutral } & & \text { strongly agree }\end{array}$

Most of my kids' friends live in this neighborhood

$\begin{array}{ccccc}1 & 2 & 3 & 4 & 5 \\ \text { strongly disagree } & & \text { neutral } & & \text { strongly agree }\end{array}$

You can count on adults in this neighborhood to watch out for kids and keep them safe

$\begin{array}{ccrcc}1 & 2 & 3 & 4 & 5 \\ \text { strongly disagree } & & \text { neutral } & & \text { strongly agree }\end{array}$

Adults in this neighborhood do not know who the local children are

$\begin{array}{ccccc}1 & 2 & 3 & 4 & 5 \\ \text { strongly disagree } & & \text { neutral } & & \text { strongly agree }\end{array}$

There are adults in this neighborhood that children can look up to

$\begin{array}{ccrcc}1 & 2 & 3 & 4 & 5 \\ \text { strongly disagree } & & \text { neutral } & & \text { strongly agree }\end{array}$

Parents in this neighborhood generally do not know each other

$\begin{array}{ccrcc}1 & 2 & 3 & 4 & 5 \\ \text { strongly disagree } & & \text { neutral } & & \text { strongly agree }\end{array}$

It is easy to find good housing in this area in places where I do not need to rely on a car for everything

$\begin{array}{ccccc}1 & 2 & 3 & 4 & 5 \\ \text { strongly disagree } & & \text { neutral } & & \text { strongly agree }\end{array}$





\section{Appendix III. Mean social capital responses}

\begin{tabular}{|c|c|c|c|c|}
\hline & & Mean & Std. dev. & $\begin{array}{c}\text { Alpha - } \\
\text { within index }\end{array}$ \\
\hline \multicolumn{4}{|c|}{ "Social cohesion and trust" questions } & 0.80 \\
\hline att14 & This is a close-knit neighborhood & 3.75 & 1.04 & 0.75 \\
\hline att15 & People in my neighborhood can be trusted & 3.93 & 0.85 & 0.73 \\
\hline att17 & $\begin{array}{l}\text { People in my neighborhood are willing to help their } \\
\text { neighbors }\end{array}$ & 4.21 & 0.84 & 0.74 \\
\hline r_att21 & $\begin{array}{l}\text { People in your neighborhood generally DO get along } \\
\text { with each other (reverse coded) }\end{array}$ & 4.51 & 0.77 & 0.80 \\
\hline r_att22 & $\begin{array}{l}\text { People in your neighborhood DO share similar } \\
\text { values (reverse coded) }\end{array}$ & 4.29 & 0.91 & 0.78 \\
\hline \multicolumn{4}{|c|}{$\begin{array}{l}\text { "Intergenerational closure" questions } \\
\text { Parents in my neighborhood know their children's }\end{array}$} & 0.81 \\
\hline att23 & & 3.80 & 0.86 & 0.77 \\
\hline att25 & $\begin{array}{l}\text { You can count on adults in the neighborhood to } \\
\text { watch out for kids and keep them safe }\end{array}$ & 3.85 & 0.89 & 0.75 \\
\hline att26 & $\begin{array}{l}\text { Adults in the neighborhood DO know who the local } \\
\text { children are (reverse coded) }\end{array}$ & 3.97 & 1.07 & 0.77 \\
\hline att27 & $\begin{array}{l}\text { There are adults in the neighborhood that children } \\
\text { can look up to }\end{array}$ & 3.93 & 0.85 & 0.77 \\
\hline att28 & $\begin{array}{l}\text { Parents in the neighborhood generally DO know } \\
\text { each other (reverse coded) }\end{array}$ & 3.89 & 1.15 & 0.78 \\
\hline
\end{tabular}





\section{Appendix IV. Reliability}

Table 24. Reliability

\begin{tabular}{|c|c|c|c|c|c|}
\hline Question & $\mathrm{N}$ & $\begin{array}{c}\text { Kappa/ } \\
\text { Concordance } \\
\text { Statistic } \\
\end{array}$ & $\begin{array}{c}\% . \\
\text { Agreement }\end{array}$ & $\begin{array}{c}\mathrm{Cl} \\
\text { lower } \\
\text { bound }\end{array}$ & $\begin{array}{c}\mathrm{Cl} \\
\text { upper } \\
\text { bound }\end{array}$ \\
\hline \multicolumn{6}{|l|}{ VEHICLES } \\
\hline \multicolumn{6}{|l|}{ Kappa/Concordance mean $=.74 ;$ range $=.40-.95$} \\
\hline How many cars are available in your household & 50 & 0.949 & 98.667 & 0.905 & 0.992 \\
\hline What is the model year of your primary vehicle & 51 & $0.828^{*}$ & $\mathrm{n} / \mathrm{a}$ & 0.739 & 0.917 \\
\hline $\begin{array}{l}\text { How many miles was your primary vehicle driven } \\
\text { last year }\end{array}$ & 47 & $0.569^{*}$ & $\mathrm{n} / \mathrm{a}$ & 0.416 & 0.721 \\
\hline $\begin{array}{l}\text { How many years have you owned/leased your } \\
\text { primary vehicle }\end{array}$ & 49 & $0.796^{*}$ & $\mathrm{n} / \mathrm{a}$ & 0.692 & 0.899 \\
\hline What is the model year of your secondary vehicle & 37 & $0.865^{*}$ & $\mathrm{n} / \mathrm{a}$ & 0.78 & 0.949 \\
\hline $\begin{array}{l}\text { How many miles was your secondary vehicle driven } \\
\text { last year }\end{array}$ & 31 & $0.403^{*}$ & $\mathrm{n} / \mathrm{a}$ & 0.114 & 0.693 \\
\hline $\begin{array}{l}\text { How many years have you owned/leased your } \\
\text { secondary vehicle }\end{array}$ & 35 & $0.742^{*}$ & $\mathrm{n} / \mathrm{a}$ & 0.589 & 0.895 \\
\hline \multicolumn{6}{|l|}{ TRAVEL BEHAVIOR: "How often do you..." } \\
\hline $\begin{array}{l}\text { Kappa/Concordance mean }=.51 \text {; range }=-.02-1.0 \\
\text { travel to work or school outside your neighborhood } \\
\text { as driver }\end{array}$ & 45 & 0.789 & 91.852 & 0.635 & 0.943 \\
\hline $\begin{array}{l}\text { travel to work or school inside your neighborhood as } \\
\text { driver }\end{array}$ & 34 & 0.495 & 86.275 & $0 . \overline{164}$ & 1.154 \\
\hline $\begin{array}{l}\text { travel to work or school outside your neighborhood } \\
\text { as passenger }\end{array}$ & 45 & 0.549 & 94.074 & 0.141 & 0.956 \\
\hline $\begin{array}{l}\text { travel to work or school inside your neighborhood as } \\
\text { passenger }\end{array}$ & 35 & -0.019 & 94.286 & $\underset{\wedge}{0.250}$ & $0.211^{\wedge}$ \\
\hline $\begin{array}{l}\text { travel to work or school outside your neighborhood } \\
\text { on public transit }\end{array}$ & 45 & 1 & 100 & $\stackrel{1.000}{\wedge}$ & $1.000^{\wedge}$ \\
\hline $\begin{array}{l}\text { travel to work or school inside your neighborhood on } \\
\text { public transit }\end{array}$ & \multicolumn{5}{|c|}{ no variation in responses } \\
\hline $\begin{array}{l}\text { travel to work or school outside your neighborhood } \\
\text { on bike or foot }\end{array}$ & 45 & 0.534 & 95.556 & $0 . \overline{0} 2$ & 1.121 \\
\hline $\begin{array}{l}\text { travel to work or school inside your neighborhood on } \\
\text { bike or fo }\end{array}$ & 37 & 0.582 & 95.496 & $0 . \overline{0}$ & 1.24 \\
\hline transport someone outside your neighborhood & 46 & 0.435 & 84.058 & 0.141 & 0.728 \\
\hline transport someone inside your neighborhood & 37 & 0.499 & 90.09 & 0.193 & 0.806 \\
\hline $\begin{array}{l}\text { go shopping as driver or passenger outside your } \\
\text { neighborhood }\end{array}$ & 46 & 0.501 & 84.058 & 0.233 & 0.77 \\
\hline $\begin{array}{l}\text { go shopping as driver or passenger inside your } \\
\text { neighborhood }\end{array}$ & 41 & 0.522 & 82.927 & 0.118 & 0.927 \\
\hline $\begin{array}{l}\text { go shopping on bike or foot outside your } \\
\text { neighborhood }\end{array}$ & 43 & 0.493 & 90.698 & 0.296 & 0.691 \\
\hline $\begin{array}{l}\text { go shopping on bike or foot inside your } \\
\text { neighborhood }\end{array}$ & 45 & 0.468 & 88.148 & 0.091 & 0.845 \\
\hline $\begin{array}{l}\text { go out for recreation, entertainment or meals outside } \\
\text { your neighborhood }\end{array}$ & 47 & 0.398 & 83.688 & 0.274 & 0.521 \\
\hline $\begin{array}{l}\text { go out for recreation, entertainment or meals inside } \\
\text { your neighborhood }\end{array}$ & 41 & 0.458 & 83.74 & 0.253 & 0.662 \\
\hline \multicolumn{6}{|l|}{ PHYSICAL ACTIVITY } \\
\hline \multicolumn{6}{|l|}{ Kappa/Concordance mean $=.60 ;$ range $=.26-.84$} \\
\hline In a usual week, do you do moderate exercise & 52 & 0.297 & 92.308 & 0.199 & $0.794^{\wedge}$ \\
\hline
\end{tabular}




\begin{tabular}{|c|c|c|c|c|c|}
\hline $\begin{array}{l}\text { How many days per week do you do moderate } \\
\text { exercise }\end{array}$ & 43 & 0.537 & 86.047 & 0.32 & 0.754 \\
\hline How many minutes do you do moderate exercise & 40 & $0.490^{*}$ & $\mathrm{n} / \mathrm{a}$ & 0.257 & 0.723 \\
\hline What $\%$ of moderate exercise is at home & 39 & $0.682^{*}$ & $\mathrm{n} / \mathrm{a}$ & 0.511 & 0.854 \\
\hline $\begin{array}{l}\text { What } \% \text { of moderate exercise is outside of home but } \\
\text { in the neighborhood }\end{array}$ & 39 & $0.835^{*}$ & $\mathrm{n} / \mathrm{a}$ & 0.737 & 0.932 \\
\hline $\begin{array}{l}\text { What \% of moderate exercise is outside the } \\
\text { neighborhood }\end{array}$ & 39 & $0.738^{*}$ & $\mathrm{n} / \mathrm{a}$ & 0.591 & 0.884 \\
\hline In a usual week, do you do vigorous exercise & 51 & 0.749 & 88.235 & $\underset{\wedge}{0.561}$ & $0.937^{\wedge}$ \\
\hline $\begin{array}{l}\text { How many days per week do you do vigorous } \\
\text { exercise }\end{array}$ & 27 & 0.488 & 83.796 & $0 . \overline{-} 135$ & 1.11 \\
\hline How many minutes do you do vigorous exercise & 27 & $0.255^{*}$ & $\mathrm{n} / \mathrm{a}$ & $0 . \overline{-} 12$ & 0.522 \\
\hline What $\%$ of vigorous exercise is at home & 25 & $0.685^{*}$ & $\mathrm{n} / \mathrm{a}$ & 0.472 & 0.898 \\
\hline $\begin{array}{l}\text { What \% of vigorous exercise is outside, but within } \\
\text { the neighborhood }\end{array}$ & 25 & $0.711^{*}$ & $\mathrm{n} / \mathrm{a}$ & 0.513 & 0.91 \\
\hline $\begin{array}{l}\text { What \% of vigorous exercise is outside of the } \\
\text { neighborhood }\end{array}$ & 25 & $0.702^{*}$ & $\mathrm{n} / \mathrm{a}$ & 0.5 & 0.904 \\
\hline \multicolumn{6}{|l|}{$\begin{array}{l}\text { PREFERENCES: "On a scale of one to five, how } \\
\text { important is..." }\end{array}$} \\
\hline \multicolumn{6}{|l|}{ Kappa/Concordance mean $=.52 ;$ range $=.36-.76$} \\
\hline affordability/value of your home & 52 & 0.474 & 87.5 & 0.055 & 1.003 \\
\hline closeness to open space, such as parks & 52 & 0.557 & 86.058 & 0.349 & 0.765 \\
\hline is closeness to a job or school & 51 & 0.478 & 78.431 & 0.355 & 0.601 \\
\hline closness to public transportation & 52 & 0.409 & 85.577 & 0.069 & 0.749 \\
\hline desire for nearby shops and services & 52 & 0.365 & 81.25 & 0.073 & 0.657 \\
\hline ease of walking & 52 & 0.441 & 83.173 & 0.175 & 0.707 \\
\hline sense of community & 52 & 0.687 & 90.865 & 0.598 & 0.776 \\
\hline safety from crime & 52 & 0.582 & 90.865 & 0.25 & 0.913 \\
\hline quality of schools & 51 & 0.761 & 89.216 & 0.624 & 0.898 \\
\hline closeness to recreational facilities & 52 & 0.365 & 77.885 & 0.153 & 0.576 \\
\hline access to freeways & 52 & 0.549 & 85.096 & 0.392 & 0.706 \\
\hline design and atmosphere of the neighborhood & 52 & 0.555 & 89.744 & 0.283 & 0.827 \\
\hline the quality of your home & 52 & 0.644 & 93.59 & 0.264 & 1.024 \\
\hline the size of the lot or the house & 52 & 0.447 & 83.173 & 0.09 & 0.805 \\
\hline \multicolumn{6}{|l|}{ ATTITUDES } \\
\hline \multicolumn{6}{|l|}{ Kappa/Concordance mean $=.60 ;$ range $=.41-.85$} \\
\hline I enjoy walking or bicycling & 52 & 0.591 & 91.827 & 0.315 & 0.868 \\
\hline I am comfortable riding a bus & 52 & 0.672 & 87.5 & 0.458 & 0.887 \\
\hline $\begin{array}{l}\text { It is important for children to have a large backyard } \\
\text { for playing }\end{array}$ & 52 & 0.583 & 86.538 & 0.38 & 0.786 \\
\hline Environmental protection is an important issue & 52 & 0.61 & 90.865 & 0.31 & 0.91 \\
\hline $\begin{array}{l}\text { I enjoy a house close to the sidewalk so that you can } \\
\text { see and interact with passersby }\end{array}$ & 52 & 0.703 & 91.346 & 0.488 & 0.919 \\
\hline $\begin{array}{l}\text { Too much land is consumed for new housing, stores, } \\
\text { and offices }\end{array}$ & 52 & 0.431 & 81.41 & 0.124 & 0.737 \\
\hline $\begin{array}{l}\text { I can be comfortable living in close proximity to your } \\
\text { neighbors }\end{array}$ & 52 & 0.7 & 91.827 & 0.358 & 1.042 \\
\hline
\end{tabular}


I prefer lots of space between your home and the street

Children should have a large public play space within safe walking distance of their home

Having shops and services close by is important to me

Household energy consumption in the US is a major contributor to global climate change

The government should put more emphasis on encouraging places that make people less dependent driving

As an individual, you can make a difference when it comes to conserving energy and protecting the environment

This is a close-knit neighborhood

People in my neighborhood can be trusted

There are sidewalks on most of the streets in your neighborhood

People in my neighborhood are willing to help their neighbors

Considering road and traffic conditions, it is safe to ride a bicycle in or near my neighborhood

My neighborhood is safe enough for a ten-year-old child to walk around the block alone

How strongly do you agree that there are many places to go within easy walking distance

People in your neighborhood generally do not get along with each other

People in your neighborhood do not share similar values

Parents in my neighborhood know their children's friends

Most of my kids' friends live in the neighborhood

You can count on adults in the neighborhood to watch out for kids and keep them safe

Adults in the neighborhood do not know who the local children are

There are adults in the neighborhood that children can look up to

Parents in the neighborhood generally do not know each other

It is easy to find good housing in your area in places where one does not need to own a car

\begin{tabular}{|c|c|c|c|c|}
\hline 52 & 0.575 & 87.981 & 0.422 & 0.727 \\
\hline 52 & 0.528 & 88.942 & 0.343 & 0.712 \\
\hline 52 & 0.556 & 87.821 & 0.428 & 0.683 \\
\hline 52 & 0.62 & 87.019 & 0.442 & 0.799 \\
\hline 52 & 0.505 & 87.019 & 0.19 & 0.821 \\
\hline 52 & 0.626 & 91.026 & 0.173 & 1.078 \\
\hline 52 & 0.715 & 91.827 & 0.571 & 0.859 \\
\hline 52 & 0.716 & 91.667 & 0.424 & 1.008 \\
\hline 52 & 0.853 & 97.596 & 0.632 & 1.074 \\
\hline 52 & 0.584 & 90.385 & 0.52 & 0.648 \\
\hline 52 & 0.557 & 88.462 & 0.484 & 0.63 \\
\hline 52 & 0.539 & 89.904 & 0.376 & 0.701 \\
\hline 52 & 0.773 & 92.308 & 0.641 & 0.905 \\
\hline 52 & 0.582 & 90.385 & 0.317 & 0.846 \\
\hline 52 & 0.538 & 85.897 & 0.389 & 0.687 \\
\hline 51 & 0.562 & 85.621 & 0.392 & 0.731 \\
\hline 46 & 0.496 & 83.152 & 0.172 & 0.82 \\
\hline 50 & 0.411 & 85 & 0.083 & 0.739 \\
\hline 52 & 0.507 & 83.333 & 0.228 & 0.786 \\
\hline 52 & 0.611 & 87.821 & 0.408 & 0.814 \\
\hline 51 & 0.674 & 90.686 & 0.569 & 0.778 \\
\hline 52 & 0.561 & 83.173 & 0.268 & 0.855 \\
\hline
\end{tabular}

${ }^{*}=$ concordance presented instead of kappa

$\wedge=$ analytical confidence intervals. Cl's are normal for continuous variables, asymptotic for categorical except where noted.

kappa scores weighted as follows: $1-|i-j| /(k-1)$, where $i$ and $j$ index the rows and columns of the responses for the original \& follow-up questions, and $\mathrm{k}$ is the maximum number of possible responses 




\section{AOTREC \\ OREGON TRANSPORTATION RESEARCH \\ AND EDUCATION CONSORTIUM}

P.O. Box 751

Portland, OR 97207

OTREC is dedicated to stimulating and conducting collaborative multi-disciplinary research on multi-modal surface transportation issues, educating a diverse array of current practitioners and future leaders in the transportation field, and encouraging implementation of relevant research results. 